University of Rhode Island

DigitalCommons@URI

Open Access Master's Theses

1994

\title{
A Study of Compression Failure in Unidirectional Composites
}

Viswanath Akella

University of Rhode Island

Follow this and additional works at: https://digitalcommons.uri.edu/theses

\section{Recommended Citation}

Akella, Viswanath, "A Study of Compression Failure in Unidirectional Composites" (1994). Open Access Master's Theses. Paper 1003.

https://digitalcommons.uri.edu/theses/1003

This Thesis is brought to you for free and open access by DigitalCommons@URI. It has been accepted for inclusion in Open Access Master's Theses by an authorized administrator of DigitalCommons@URI. For more information, please contact digitalcommons-group@uri.edu. 
A STUDY OF COMPRESSION FAILURE

IN

UNIDIRECTIONAL COMPOSITES

BY

VISWANATH AKELLA

A THESIS SUBMITTED IN PARTIAL FULFILLMENT OF THE

REQUIREMENTS FOR THE DEGREE OF

MASTER OF SCIENCE

IN

MECHANICAL ENGINEERING

UNIVERSITY OF RHODE ISLAND

1994 


\title{
MASTER OF SCIENCE THESIS
}

\author{
OF
}

VISWANATH AKELLA

\section{APPROVED}

Thesis Commitee

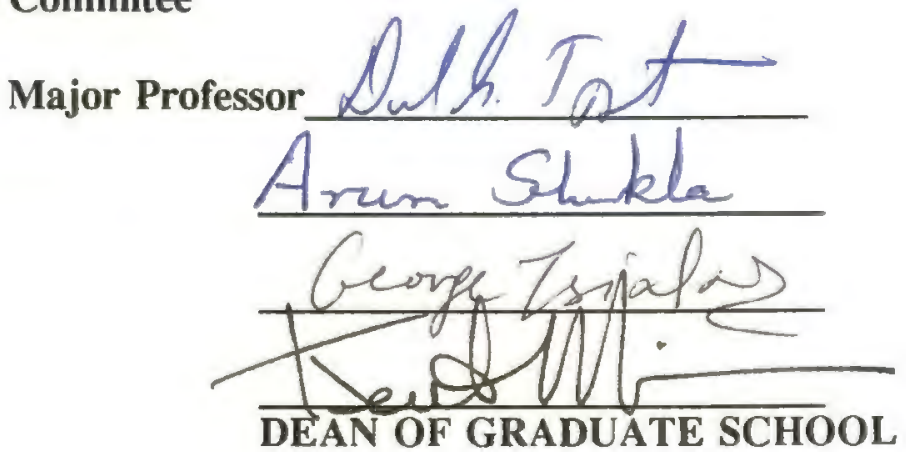

UNIVERSITY OF RHODE ISLAND 


\begin{abstract}
Interaction between the reinforcement and the matrix of a unidirectional composite while subjected to a compressive loading is studied. The effect of fiber position relative to another fiber and relative to the surface is characterized using finite element analysis. Experimental models are developed and utilized in an effort to verify the accuracy of the finite element analyses. To conduct the finite element analysis, two dimensional models are developed and compared to experimental work. The same method is used to determine results in both fiber- fiber interaction and surface- fiber interaction. An experimental method is developed from existing methods using standards followed in the 1

composites industry. Experimental specimens are developed following requirements set forth by the experimental procedure.
\end{abstract}




\section{Acknowledgement}

All of my achievements in graduate study are due to the inspiration given to me by Sundari. She encouraged me to attend graduate school. To her I dedicate all this work. Bangaram Pandu.

Dad, I wish you could have seen this day. You set a standard of excellence that few here have achieved. Mom, without your support through good and bad times this would not have happened.

Further recognition is due my Carnegie Mellon friends. J.B., Paul, Mark, Char, Tim, Sue J. Ravi, Bill A., Jim, Matt, Jason, Larry, Bill U., Dave, John Mo., M.P., Ken, 1 Mike, Cindy, Sue A. They help set the standards of excellence that I personally require in all I do. They are friends for life. Ken, Brent, Mark, Madhu, Vanchi, Yen, Karen and Janine are new friends that I am fortunate to have acquired here. They provided an alternative to the insanity. The following people I am grateful to; Matt S., for help with the waterjet; Yin W., for help with Abaqus; Govind, for resins, Cindy for help with Ideas and Torrey for the fixture. Thank you to Sunil, Linda, Frank, Debbie, Holly, Tai, Kevin, Tara, John, Mohammed, and Jay.

Thank you to the University Foundation for naming me a 1993-1994 Fellow. Thank you to Dr. Shukla for providing his laboratory equipment for my experiments and serving on my committee. Thank you to Dr. Tsiatas and Dr. Sodhi for serving on my committee. Finally, thank you to Dr. Taggart for guiding me through a challenging yet educationally beneficial experience. 
Table of Contents

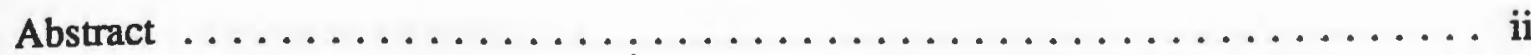

Acknowledgement $\ldots \ldots \ldots \ldots \ldots \ldots \ldots \ldots \ldots \ldots \ldots \ldots \ldots \ldots$ ii

Table of Contents $\ldots \ldots \ldots \ldots \ldots \ldots \ldots \ldots \ldots \ldots \ldots$ iv

1.0 Introduction $\ldots \ldots \ldots \ldots \ldots \ldots \ldots \ldots \ldots \ldots \ldots \ldots \ldots \ldots \ldots \ldots \ldots$

1.1 Background $\ldots \ldots \ldots \ldots \ldots \ldots \ldots \ldots \ldots \ldots \ldots \ldots$

1.2 Failure Mechanisms $\ldots \ldots \ldots \ldots \ldots \ldots \ldots \ldots \ldots$

1.3 Hypothesis $\ldots \ldots \ldots \ldots \ldots \ldots \ldots \ldots \ldots \ldots \ldots$

References $\ldots \ldots \ldots \ldots \ldots \ldots \ldots \ldots \ldots \ldots \ldots \ldots \ldots$

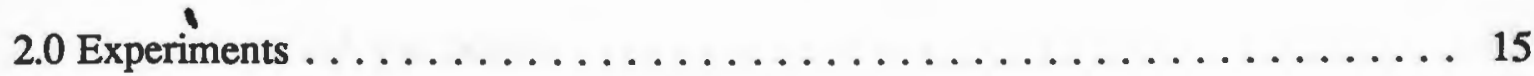

2.1 Experimental Objectives $\ldots \ldots \ldots \ldots \ldots \ldots \ldots \ldots \ldots \ldots$

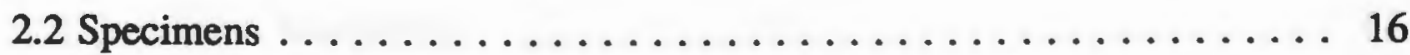

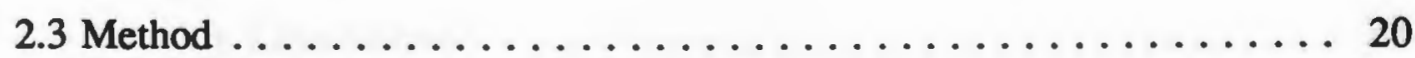

2.4 Experimental Results $\ldots \ldots \ldots \ldots \ldots \ldots \ldots \ldots \ldots \ldots \ldots \ldots$

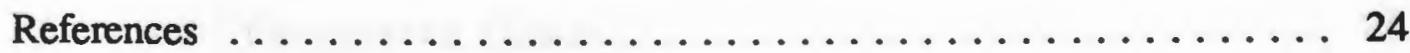

3.0 Finite Element Analysis $\ldots \ldots \ldots \ldots \ldots \ldots \ldots \ldots \ldots \ldots \ldots$

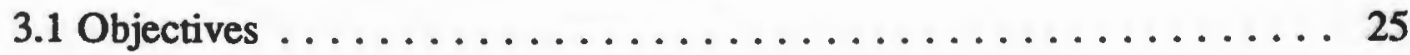

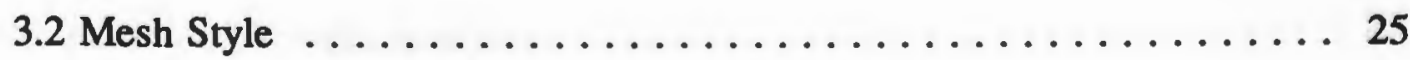

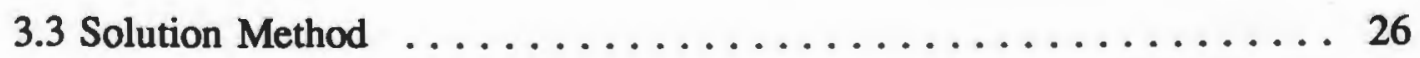

3.4 Results $\ldots \ldots \ldots \ldots \ldots \ldots \ldots \ldots \ldots \ldots \ldots \ldots \ldots \ldots \ldots$

References ............................ 29

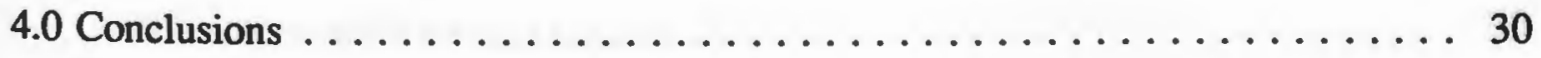

4.1 Experimental and Finite Element Results $\ldots \ldots \ldots \ldots \ldots \ldots$ 
4.3 Recommendations $\ldots \ldots \ldots \ldots \ldots \ldots \ldots \ldots \ldots \ldots \ldots \ldots$

Appendix A. Experimental Proceedure $\ldots \ldots \ldots \ldots \ldots \ldots \ldots \ldots \ldots \ldots$

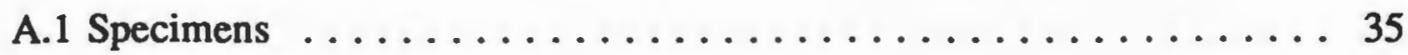

A.1.1 Single Fiber Specimen Geometry ........... 35

A.1.2 Two Fiber Geometry . . . . . . . . . . . 35

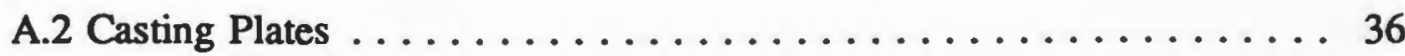

A.2.1. Casting Jig $\ldots \ldots \ldots \ldots \ldots \ldots \ldots \ldots \ldots \ldots \ldots \ldots \ldots \ldots \ldots$

A.2.2. Jig Assembly $\ldots \ldots \ldots \ldots \ldots \ldots \ldots \ldots \ldots$

1

A.2.3 The Matrix $\ldots \ldots \ldots \ldots \ldots \ldots \ldots \ldots \ldots$

A.2.4 Pouring The Matrix $\ldots \ldots \ldots \ldots \ldots \ldots \ldots \ldots$

A.3. Specimen Machining $\ldots \ldots \ldots \ldots \ldots \ldots \ldots \ldots \ldots \ldots$

A.4 Running Experiments $\ldots \ldots \ldots \ldots \ldots \ldots \ldots \ldots \ldots \ldots$

A.4.1 Strain Gages $\ldots \ldots \ldots \ldots \ldots \ldots \ldots \ldots \ldots$

A.4.2 Compression Fixture $\ldots \ldots \ldots \ldots \ldots \ldots \ldots$

A.4.3 Experimental Set-up . ............... 46

References $\ldots \ldots \ldots \ldots \ldots \ldots \ldots \ldots \ldots \ldots \ldots \ldots \ldots \ldots . \ldots . \ldots 4$

Appendix B. Finite Element Analysis . . . . . . . . . . . . . . 48

B.1 Mesh Generation . . . . . . . . . . . . . . . 48

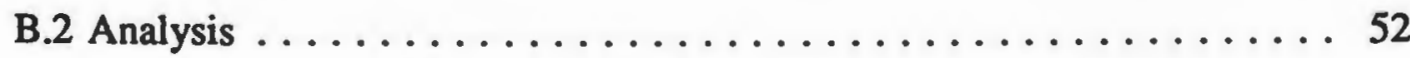

B.3 Post Processing $\ldots \ldots \ldots \ldots \ldots \ldots \ldots \ldots \ldots \ldots \ldots$

B.4 Corrected Abaqus Input Deck $\ldots \ldots \ldots \ldots \ldots \ldots \ldots \ldots$

Figures $\ldots \ldots \ldots \ldots \ldots \ldots \ldots \ldots \ldots \ldots \ldots \ldots \ldots \ldots \ldots . \ldots . \ldots . \ldots$ 


\section{Chapter 1}

\section{Introduction}

\subsection{Background}

Fiber reinforced composites have become an increasingly important class of materials in the last few decades as the need for specialized materials increases. Composites have seen increased use in aerospace, sporting goods, automobiles and even medical applications. Composite materials are defined to have at least two separate and distinct homogeneous constituent materials which when used together provide improved properties (Agarwal (1)). Typically, a significant change in properties must occur for a material to be classified as composite.

In most composite materials, The constituents include a matrix phase and reinforcing material. Typical reinforcement geometries are fibers or particles. For example concrete can be considered a composite, since the aggregate is a large particle in a matrix of cement. Commercially important fiber reinforced composites include carbon, glass and $\mathrm{Kevlar}^{1}$ fibers embedded in a polymer matrix such as polyester or epoxy. Composites with polymer matrices are often referred to as polymer composites. Another class of composites are metal matrix composites where ceramic fiber, particles or whiskers reinforce a metal matrix. High temperature applications have also been met with ceramic matrix composites.

Fiber reinforced polymer composites are available in several styles. Chopped fiber, continuous fiber and fabric are three common styles of reinforcement. Polymer

${ }^{1}$ Kevlar is a Trademark of DuPont. 
matricies are classified as either thermosetting or thermoplastic resins.

Chopped fiber is usually used in low cost applications. Chopped fiber is typically added to an uncured matrix and molded into final form. Fiber becomes oriented in random directions allowing for the composite to be considered homogeneous in nature.

Fabric consists of woven continuous fibers. It is woven much like textiles are woven, but with a looser weave. Fabric is available with various matrices, and various percentages of matrix.

Thermoplastics can be heated and attached to other layers of thermoplastics. After cooling they reach final form, but can be reheated to be reworked. Thermosets act as an adhesive at room temperature. The matrix is active until a cure cycle is complete and then the form is permanent. Uncured thermoset resins impregnated in fabric or collumated fiber are called prepregs. The type of polymer composite studied in this work consisted of continuous fibers oriented in one direction. The term for this is unidirectional tape. Since unidirectional tape has all fiber aligned in one direction, this allows for significant strength in that direction, but limited strength in the others. This is because the fiber carries the load in the direction the fibers are oriented. In the other direction, the matrix carries the load (Agarwal (1)) and is actually weakened by the discontinuity.

Recently, fiber reinforced composite technology has become more important in structural applications. As fuel economy becomes more critical, weight reduction in order to save fuel becomes an important consideration in airplanes. Previously, as the technology was first developed, materials were only applied to secondary structures such 
as interior flooring and surfaces. As these applications become saturated the emphasis is turning to primary structures.

One of the areas of concern currently is compression failure in composite parts. No reliable predictive models of compression failure exist now. The main reason for developing a more accurate model of compression failure is it is the critical failure mechanism in many applications. Since composites are typically weaker in compression relative to tension, an added factor of safety is necessary in order to insure compression failure does not occur. This leads to increased usage of material, which adds to cost and weight. In aerospace applications the increase in weight is not desired. In many cases, the addition is so significant that the use of composites becomes uneconomical. Making composites economical through factor of safety reduction will lead to weight reductions which in turn leads to fuel economy.

\subsection{Failure Mechanisms}

One of the compressive failure mechanisms is a fiber microbuckle. Others include matrix flaws, matrix plasticity, voids which create stress concentrations and fiber defects such as misalignment. The mechanism studied in this work is failure due to fiber microbuckling.

Single fiber microbuckling can be analytically modelled for fibers as column buckling on an elastic foundation which follows Timoshenko (2). Timoshenko's approach was to estimate the axial load level, $P_{c r}$ required for buckling a column of length, l, elastic modulus, E, and inertia, I, supported by another elastic material measured 
by the foundation modulus, $\beta$ and minimized by an integer, $\mathrm{m}$.

$$
P_{c r}=\frac{\pi^{2} E_{f} I}{\ell^{2}}\left(m^{2}+\frac{\beta \ell^{4}}{m^{2} \pi^{4} E_{f} I}\right)
$$

This relationships eventually leads to the following relationships for the microbuckling strain and the microbuckling wavelength.

$$
L=\left[\frac{\pi^{4}}{6} \delta\left(\frac{E_{f}}{E_{m}}\right)\right]^{1 / 3}
$$

$$
\varepsilon_{c r}=\left[\frac{4}{3} \pi \delta\left(\frac{E_{f}}{E_{m}}\right)\right]^{-2 \beta}
$$

as discussed by Taggart (3). In both the wavelength and critical strain formulas, $\delta$ represents the effective depth based on the amount of matrix support. According to Taggart, the values should be taken as $\delta=0.25$ for interior fibers, and $\delta=0.50$ for surface fibers. The interior fiber region is considered a region of infinite matrix support, because the value for critical strain versus position has reached steady state. The region between the surface and the infinite zone, which will be called the transition zone is not accounted for.

Work by Rosen (4) showed that two micro-mechanical failure modes exist, extensional mode and shear mode. The parallel fibers have buckled in phase in shear mode, resulting in a shearing action upon the matrix. In extensional mode the fibers have 
buckled out of phase. This results in transverse tension on the matrix. According to Rosen, extensional mode occurs when the percentage of fiber is less than twenty percent while shear mode typically occurs at a percentage above twenty percent. Rosen's work treated fibers as thin plates and analyzed the behavior in a two dimensional approach. Lager and June (5) conducted experiments on boron fibers in an epoxy matrix and concluded shear buckling was the failure of interest. They developed analytical models and conducted experiments to verify validity.

Chung (6) and Schuerch (7) also took the two dimensional plane approach. Schuerch's work adjusted the analytical approach for metal matrix composites since the majority of the work at the time was done with polymers. Since this work deals with polymer matrices that will not be discussed.

Sadowsky, et al (8), built upon this previous work to model the column with a given radius. They argued that the fiber radius was not properly taken into consideration in Rosen's and Schuerch's models since critical load was only proportional to column length. Sadowsky's model consists of a column of a given radius and infinite length surrounded by a matrix of infinite dimension. Sadowsky treats the fiber column as a micro- fiber column which allows for linear analysis because the radius is very small compared to the length. Sadowsky claims that two patterns of micro-buckling can occur in linear micro- fibers, torsional buckling and buckling by bending. Helical buckling is eliminated because no moments are applied. Lanir and Fung (9) developed theoretical models based on the assumption the fiber buckles inside the matrix. Greszczuk (10) conducted experimental studies and theoretical studies derived from the energy method. 
Lagoudas et al. (11) improved the Rosen model with Fourier transforms in a new analytical approach. Steif (12) distinguished between mechanical loading and thermal loading through numerical studies. Spicola et al. (13) also conducted experimental and numerical studies of fiber microbuckling.

Greszczuk (14) built upon the two microbuckling failure modes presented by Rosen and observed that three other modes of failure existed, fiber-matrix debonding which leads to microbuckling, interaction failure and strength failure. Greszczuk found that microbuckling was valid for composites, but only for matrices with a modulus lower than $55 \mathrm{ksi}(0.35 \mathrm{GPa})$. For matrices higher than $550 \mathrm{ksi}(3.50 \mathrm{GPa})$, the microbuckle was not dóminant because other failures would typically occur first. Greszczuk also noted that interfacial effects played a role in lowering compression strength. Surface treatments applied to the steel fibers affected the strength. Greszczuk also noted that the difference in Poisson's ratio affected the interaction under loading. This induced transverse stress is thought to aid in fiber matrix debonding, or what is termed interaction failure.

Jelf and Fleck (15) also discuss multiple failure mechanisms. They examined fiber failure, elastic microbuckling, matrix failure and plastic microbuckling. The observed response for global failure was brittle failure. Jelf and Fleck also discussed microbuckling in both the extensional and shear modes. They conducted experiments to reproduce fiber crushing by shear failure or fiber splitting. Matrix failure was observed on the forty five degree plane. Finally, fiber kinking was discussed, which they termed plastic microbuckling. However, Jelf and Fleck agree no consensus has been reached as to 
which mode is the dominant factor in the compression failure mechanism.

Waas (16) commented about the type of fiber failure referred to as fiber kinking. He cites work by Orowan (17) as the first published account of this. type of failure. Evans and Adler (18) discussed the kinking in relation to bundle dimensions and separations. Lagoudas and Saleh (19) discussed the effects of microbuckling on fiber kinking. They developed a model to determine the compressive strength due to this mechanism and in subsequent work, Lagoudas and Saleh (20). Camponeschi (21) concluded that fiber kinking failure was the final result of microbuckles in strong fibers residing in a higher than thirty percent volume fraction and was typically initiated by local stress concentrations. Yeh and Teply (22) discuss kinking in Kevlar/ epoxy composites andconclude that this failure mechanism is dominant over fiber microbuckling.

Waas (23) also continued the work into interface and interphase effects. Waas cited work by Pigot (24) stating that the interface region has a finite thickness with separate mechanical properties from the matrix and the fiber. The term interphase was used for this region. Wass states that shear occurs across the interphase when compression failure occurs. This was not modelled at the time and the aim was to produce a model. Hui and Lagoudas (25) developed a method of computing stress fields due to interface dislocations. Minahen and Knauss (26) also addressed the effect of adhesion on the fiber and matrix interface. Interfiber stresses were also theoretically and experimentally investigated by Greszczuk (27). Treadway and Prewo (28) discuss applying the interface in a beneficial way through the use of fiber coatings. 
Fiber compression fracture was discussed by Hawthorne and Teghtsoonian (29). They suggest that the shear failure in the fiber changes to microbuckling or fiber kinking due to anisotropy. Bascom et al. (30) embedded single carbon filaments into an_epoxy matrix and used optical birefringence to show stress concentrations developing and eventually becoming fiber fractures. Budiansky and Carrier (31) developed analytical models for this phenomena.

Some of the global effects caused by micro-failure in composites are discussed in Argon (32). Open hole compression is thought to be greatly affected by microbuckle failure. Edge effects are noted and studied by Soutis and Fleck (33). Wung and Chatterjee (34) study global laminate effects, while Weaver and Williams (35) study the hydrostatic effects. Sohi, Hahn and Williams (36) and Williams and Rhodes (37) study the matrix properties and the influence of matrix toughening on micro-failure and how this correlates to global failure. Hahn (38) studies the fiber bundle and the effects on the fibers in an epoxy matrix.

\subsection{Hypothesis}

The first theory in micro-buckle compression failure in unidirectional composites which forms the basis of this work is the effect of surface proximity to fibers causing destabilization due to the resulting loss of lateral support. An interior fiber is supported in all radial directions by the matrix. The surface fiber does not have this support. Since compression loading is similar to buckling in long columns, the interior fibers and surface fibers can be shown to buckle. This microbuckling is dependent on the matrix and the 
geometry depending on the fiber location. The critical load required to buckle the fiber will increase as the fiber receives more support from the presence of more matrix. Eventually, this reaches a steady state value. The addition of matrix no longer affects the critical load. This interior fiber is termed to have infinite support. Specimens modelled this with a single fiber in various locations.

The second study was the effect of two fibers on one another. As the distance from the first fiber increases, the critical load to initiate buckling is expected to increase. This critical load is expected to reach a constant value at a certain separation distance. This is called the infinite support distance. As the separation increases, the values Rosen (4) demonstrated for the phase will also become apparent. According to Rosen, when the volume fraction increases over twenty percent buckling in phase should occur.

Both sets of experimental data were compared to two dimensional finite element models. 


\section{References}

1. Agarwal, B. D. and Broutman, L. J., Analysis and Performance of Fiber Composites, Society of Plastics Engineers, 1980 pp. 1-14.

2. Timoshenko, S.P. and Gere, J.M., Theory of Elastic Stability, 2nd edition, McGraw- Hill, New York, 1961, pp. 94-98.

3. Taggart, D. G. "Free Edge Effects in Microbuckling Failure of Unidirectional Composites", Proceedings of International Conference of Composite Materials, Vol. 8, July 1991.

4. Rosen, B.W., Fiber Composite Materials, American Society for Metals, pp. 37-75.

5. Lager, J.R. and June, R.R., "Compressive Strength of Boron-Epoxy Composites", Journal of Composite Materials, Vol. 3, January, 1969 pp. 48-52.

6. Chung, W.Y. and Testa, R.B., Journal of Composite Materials, Vol 3, 1969, pp. 58-80.

7. Scheurch, H., AIAA Journal, Vol.4, no. 1, January, 1966, pp. 102-106.

8. Sadowsky, M.A., and Pu, S. L., Hussain, M.A., Journal of Applied Mechanics, December, 1967, pp. 1011-1016.

9. Lanir, Y. and Fung, Y.C.B. "Fiber Composite Columns Under Compression", Journal of Composite Materials, Vol 6., July, 1972, pp. 387-401.

10. Greszczuk, L.B. "Microbuckling Failure of Circular Fiber-Reinforced Composites", AIAA Journal, Vol. 13, No. 10 October,1975, pp. 1311-1318.

11. Lagoudas, D.C., Tadjbakhsh, I. and Fares, N., "A New Approach to Microbuckling of Fibrous Composites", Journal of Applied Mechanics, June, 1991, pp. 1-7. 
12. Steif, P.S., "An exact Two Dimensional Approach to Fiber Microbuckling", International Journal of Solids Structures, Vol. 23, No. 9, September, 1987 pp. 1235-1246.

13. Spicola, F., Dubois, N., Tucker, W. and Butts, J., "Compressive Strength of Fiber Reinforced Composites as a Function of Matrix Modulus of Elasticity and Component Wall Thickness", Proceedings of the Ninth International Committee on Composite Materials, July, 93 pp. 573-579.

14. Greszczuk, L. B., "On Failure Modes of Unidirectional Composites under Compressive Loading," Proceedings of the Second USA-USSR Symposium, G.C Sih ed. March 1981. pp 231-246.

15. Jelf, P.M. and Fleck, N.A., "Compression Failure Mechanisms in Unidirectional Composites", Journal of Composite Materials, Vol. 26, No. 18, 1992 pp. 2706.

16. Wass, A.M., Babcock, C.D., and Knauss, W.G., "A Mechanical Model for elastic Fiber Microbuckling," Journal of Applied Mechanics, March 1990, pp.138-149.

17. Orowan, E., " A Type of Plastic Deformation New in Metals," Nature, Vol. 149, 1949, pp. 643-644.

18. Evans, A.G. and Adler, W.F., "Kinking as a mode of Structural Degradation in Carbon Fiber Composites", Acta Metallurgica, Vol. 26, 1978, pp. 725-738.

19. Lagoudas, D.C. and Saleh, A.M., "Comparison Between Compressive Strength Due to Microbuckling and Kinking in Fibrous Composites", Proceedings of the International Conference of Composite Materials, July 1991, pp. 35e1-35e9.

20. Lagoudas, D.C. and Saleh, A.M.,"Compressive Failure due to Kinking of Fibrous 
Composites", Journal of Composite Materials, Vol. 27, No.1, 1993, pp. 83-106.

21. Camponeschi, E.T., "Compression of Composite Materials: A Review", David Taylor Research Center, November 1987.

22. Yeh, J.R. and Teply, J.L., "Compressive Response of Kevlar/Epoxy Composites", Journal of Composite Materials, Vol. 22, March 1988, PP.245-257.

23. Wass, A.M., "Effect of Interface on Compressive Strength of Unidirectional Composites," Journal of Applied Mechanics, 1992, pp. 1-6.

24. Piggot, M.R., Sandai, A., Chua, P.S. and Andison, D., Mechanical Interactions in the Interphasial Region of Fibre Reinforced Thermosets," Composite Interfaces, H. Ishida and J.L. Koenig eds., Amsterdam.

25. Hui, C.Y. and Lagoudas, D.C., "Stress Fields of Interface Dislocations", Journal of Applied Mechanics, Vol. 57, March 1990, pp. 247-249.

26. Minahen, T.M. and Knauss, W.G., "A Note on Microbuckling in Unidirectional Fibrous Composites", Journal of Applied Mechanics, Vol. 56, December, 1989, pp. 983-985.

27. Hawthorne, H.M., Teghtsoonian, E., "Axial Compression in Carbon Fibers", Journal of Materials Science, Vol. 10, 1975, pp 41-51.

28. Greszczuk, L.B., "Interfiber Stress in Filamentary Composites", AIAA Journal, Vol. 9, July, 1971, pp. 1274-1280.

29. Treadway, W.K. and Prewo, K.M., "Improved Performance in Monofilament Fiber Reinforced Glass Matrix Composites Through the Use of Fiber Coatings", Materials Research Society Symposium Proceedings, Vol. 170, 1990, pp. 215-274. 
30. Bascom, W.D., Boll, D.J., Jensen, R.M., Cordner, L., "Compression Behavior of Single Carbon Filaments Embedded in an Epoxy Polymer", Journal of Composite Materials, Vol. 24, February, 1990, pp. 204-219.

31. Budiansky, B. and Carrier, G.F., "High Shear Stresses in Stiff-Fiber Composites", Journal of Applied Mechanics, Vol. 51, December 1984, pp. 733-735.

32. Argon, A.S., "Fracture of Composites", Treatsie on Materials Science and Technology, Vol. 1, Herman ed, Academic Press, New York, 1972.

33. Soutis, C., and Fleck, N.A., "Failure Prediction Technique for Compression Loaded Carbon Fiber-Epoxy Laminate with Open Holes", Journal of Composite Materials, Vol. 25, November, 1991, pp. 1476-1498.

34. Wung, E.C.J., and Chatterjee, S. N., "On the Failure Mechanisms in Laminate Compression Specimens and the Measurement of Strengths", Journal of Composite Materials, Vol. 26, No. 13, 1992, pp. 1885-1914.

35. Weaver, C.W. and Williams, J.G., "Deformation of a Carbon-Epoxy Composite Under Hydrostatic Pressure", Journal of Materials Science, Vol. 10, 1975, pp. 1323-1333.

36. Sohi, M.M., Hahn,H.T., Williams, J.G., "The Effect of Resin Toughness and Modulus on Compressive Failure Modes of Quasi-Isotropic Graphite/Epoxy Laminates", NASA Technical Memorandum 87604, March, 1986.

37. Williams, J.G. and Rhodes, M.D., "The Effect of Resin on the Impact Damage Tolerance of Graphite-Epoxy Laminates", NASA Technical Memorandum 83213, October, 1981. 
38. Hahn, H.T., Williams, J.G., "Compression Failure Mechanisms in Unidirectional Composites", Composite Materials: Testing and Design (Seventh Conference), ASTM STP 893, J.M. Whitney, Ed., American Society for Testing Materials, Philadelphia, 1986. pp. 115-139. 


\section{Chapter 2}

\section{Experiments}

\subsection{Experimental Objectives.}

Unidirectional composites loaded in compression demonstrate many failure mechanisms. The emphasis of this work was fiber microbuckling. The goals of the experimental portion of this work were to: first, develop a method for mechanically producing microbuckles in specimens; second, record the load and strain levels when microbuckles occur, third, measure the wavelength of the microbuckle; and finally, observe any unexpected behavior. Two types of interactions were to be studied, fiberfiber interaction and fiber- surface interaction.

In the single fiber experiments, the goal was to observe the critical microbuckle load, the critical microbuckle strain level and the wavelength of a specimen, all as a function of fiber position. Specimens with a single fiber located in various positions were machined. The position of the fiber relative to the near surface was taken as the critical dimension. At least four specimens for each of the six positions were tested.

In the two fiber specimens, the goal was to observe the interaction of fibers upon one another. This set of experiments recorded the critical microbuckling strain, the critical load and wavelengths. Five experiments were conducted for each of the three positions.

Analytical results were available to predict single fiber behavior at the interior and at the surface (Taggart (1)). It was assumed that the intermediate positions would behave within this analytical range. It was further assumed that the single fiber microbuckling 
estimates could be applied to the double fiber model to estimate strain and load levels (see equations 1-2 and 1-3 in chapter 1). It should be noted that the most important material property is the ratio of fiber modulus to matrix modulus.

\subsection{Specimens.}

Two types of specimens were studied. Single fiber specimens and dual fiber specimens were cast and machined in the laboratory. Complete details of casting and machining are available in appendix A.

The fiber type chosen for final experiments was a high strength steel wire, with 1

a modulus of $30 \mathrm{Msi}(210 \mathrm{GPa})$. The matrix used was eighty-five percent by weight MR17090 and fifteen percent by weight MR9600 provided by Aristech Chemical Company. The catalyst used was 0.03 percent by weight Cobalt Octate and the hardener 0.85 percent by weight Methyl Ethyl Ketone- Peroxide, Khanna (2).

Initial work approached the experiments as a standard compression experiment in composite materials. After discussions with Pike (3), the ASTM-D695 fixture was chosen. This fixture is used in compression loading of unidirectional composites. It is also designed for testing plastics in compression (4). It was thought with some modification, this fixture would allow for composites, plastics and photoelastic analysis.

Unfortunately, some unexpected complications arose in the use of the D695 fixture. With the view-port restricted to a 0.5 inch square, microbuckle wavelengths had to be less than this dimension. The width of the specimen was also limited causing problems with the experiment. The width of the specimens was chosen to be 0.50 inches, 
based on the fixture limitations. Unfortunately, the narrow specimen width contributed to global buckling of specimens prior to microbuckling failure. Figure 2.1 is an example of a global buckle. Euler's global buckling formula for a column with fixed ends was applied to the specimen geometry which from Gere and Timoshenko (5) is,

$$
P_{\sigma}=\frac{4 \pi^{2} E I}{L^{2}}
$$

By converting this relationship to one for strain, the following relationship is found,

$$
\epsilon_{\sigma}=\frac{\pi^{2} n^{2}}{3 L^{2}}
$$

where $\mathrm{h}$ is the width and, 1 is the length. By applying the specimen geometry, a strain level when microbuckling ceases being the dominant failure and global buckling becomes dominant is determined. By overestimating the length of the specimen a factor of safety was added. Through this calculation, a strain of 6.71 percent was determined to be the global buckling strain level.

Since a global strain level of 6.71 percent was determined to be the maximum allowable strain, the fiber to matrix modulus ratio was adjusted to account for this. Upon further inspection, a maximum strain of 3.0 percent was deemed acceptable because the electrical resistance strain gage maximum strain rating. 
Applying Taggart's (1) theoretical prediction (1-3), a fiber- matrix modulus ratio should have been fifty five or higher for the interior fiber. Surface fibers are expected to microbuckle at a lower strain, making the interior case more relevant in this calculation. Taggart indicated that a normalized effective foundation, $\delta$, which was determined through comparison to numerical work to be 0.25 for interior fibers and 0.50 for surface fibers was applied in this case. Unfortunately, experiments conducted at a ratio of sixty yielded global buckling failure.

Another limitation is the matrix had to be clear and optically birefringent. Optical birefringence allows for stress patterns to be observed through the use of polarized light. The microbuckle failure would compress and tension the matrix transversely. This would cause a sinusoidal pattern to be shown in the matrix. The microbuckle would otherwise be barely discernable to the naked eye. The exact procedure followed is discussed in section 2.3

Initial work was done on copper, E-glass and nickel fibers embedded in a matrix of MR17090. These also proved unsatisfactory for various reasons. The copper wire modulus was low and created a low ratio for fiber to matrix modulus. This created a high microbuckle strain level and a long microbuckle wavelength. The nickel fibers exhibited a great deal of waviness which would have caused eccentricities in loading. The E- glass was unmanageable on the single fiber level and could not be seen easily. The steel wire was chosen for it's high modulus, availability, isotropic behavior and handling ease. With 0.020 inch diameter steel wire as the fiber, the desired fiber modulus to matrix modulus ratio had to be well over 60 and less than 240. A ratio below 60 would cause 
the strain level to be too high for microbuckling, and other failure modes would be observed. A minimum of 100 was deemed appropriate from the strain gage limitation. A ratio above 240 would cause the wavelength to be too long to be seen in the view-port.

With the MR17090 resin the modulus of the matrix was $55 \mathrm{ksi}(3.5 \mathrm{GPa})$. This resulted in a fiber-matrix modulus ratio of 60 . Using the limits dictated by the fiber and the fixture the modulus of the matrix had to be lowered until the fiber- matrix modulus ratio was over 100.

This was accomplished with the addition of fifteen percent by weight MR9600 plasticizer. The effect of MR9600 on modulus was not known and experiments were conducted to ascertain the correct weight ratio. The modulus of the matrix after the addition of plasticizer was $170 \mathrm{ksi}(1.19 \mathrm{GPa})$. The MR17090/MR9600 was chosen as the matrix because of it's ease in handling. Urethane and epoxy were also available but were not chosen for several reasons. The urethane was not clear, it was tinted a dark brown color. Both the epoxy and urethane were highly viscous and air bubbles remained in the mixtures. The modulus of the epoxy and the modulus of the urethane was too low causing the fiber- matrix ratio to be above 250 .

With the matrix and the fiber chosen, the final specimens were machined. All machining was done on the student milling machine. Exact details of how the single fiber and the two fiber specimens were machined is discussed in appendix A. Although the fly cutter produced the best finish on the specimen, use of a side mill superseded the use of a fly cutter, due to the age and unreliability of the student milling machine. The $\mathrm{Z}$ axis could not be reliably maintained. Since the fly cutter would only cut in the $Z$ axis, 
it was not used. Side milling of specimens was done in the X-Y plane. This allowed the auto-feed feature to be used. Dimensioning was done by setting the $\mathrm{Y}$ axis to the desired coordinates. Each step was checked with a depth micrometer. Coolant was used in all steps, because thermally induced patterns would interfere with the birefringence of the matrix. The final dimensions followed the following criteria. Thickness was dictated by the casting jig. A thickness greater than 0.400 inches would locate the specimen off center from the loading head. This was due to the thickness of the rear specimen grip. The reinforcement grip would prevent microbuckle failure in the thickness dimension. It would be analogous to a continuation of matrix, but harder. This would force the I microbuckle to occur in the plane visible to the viewer. Width was dictated by the bolts which held the grips in place and the size of the view-port. The bolts were approximately 0.700 inches apart. Since some of the single fiber specimens would have a fiber along the edge, view-port size and the need to keep the loading head centered dictated the use of the 0.500 inch dimension. Dual fiber specimens were symmetric and were limited to 0.700 inches. Finally, length of the specimen was dictated by the strained length of the specimen and the height of the grips. The loading of the grips by the loading head contacting the upper side of the grips had to be avoided. A strain level of ten percent was chosen which includes a factor of safety. Based on these factors, a minimum length of 3.15 inches was determined. The maximum length of the specimen was 3.30 inches, because global buckling was a concern. Appendix A discusses the specimen machining. 


\subsection{Method}

Electrical resistance gages were bonded to the farthest side from the fiber to avoid interference from the fiber. This is discussed in Appendix A. Leads were connected to the Omega 900 series data acquisition system. An A/D card received load voltage signals. All this data was saved using Lab-tech Notebook data acquisition software. For the initial experiments, the specimens were only loaded until the resistance strain gage failed. This was typically at three percent strain. The stress strain curve showed that the matrix was too stiff. Consequently, no microbuckles were observed at that time.

The second round of experiments was conducted with the single fiber specimens and the softened matrix. The single fiber specimens were loaded in the same manner as the first round. When the strain gage failed, data acquisition and the loading were stopped. No microbuckle was observed at strain gage failure which contradicted the analytically predicted behavior. Specimens were loaded to higher levels, with the load signal recorded. The higher level of loading and strain caused a high gradient in the photoelastic stress pattern. It was not possible to see any stress pattern in the fixture viewport with the naked eye. It was noted that after unloading a permanent deformation stress pattern existed. The experiment had to be adjusted to allow checking for microbuckles between loading levels. The experimental procedure was modified so the specimen was periodically unloaded and then checked with hand held polarizers for a microbuckle. It usually took several incremental steps in load level before a microbuckle was observed. The specimen was repositioned in the fixture and loaded again to a higher load. The specimen was unloaded and rechecked for the microbuckle. This process was 
repeated until a microbuckle was observed. All the load voltages were recorded by the Lab-Tech Notebook.

Once a microbuckle was observed, the wavelength was measured with a pair of calipers. The measurement was taken over several wavelengths averaged in order to minimize error. This was done immediately, since stress relaxation caused the fringe patterns to fade with time. The measurements were prone to error due to the specimen and two polarizers being held in one hand and the calipers in the other. Preliminary measurement was done in case of photographic film loss. Photographs were taken of each microbuckle. The microbuckle was photographed as quickly as possible, because significant stress relieving occurred soon after the specimen was unloaded. The photographs were taken with a reference length. The average microbuckle wavelengths were measured on the photograph over several wavelengths, to minimize measurement error. These results were used instead of the measurements done during the experiment, because the precision was better.

\subsection{Experimental Results}

Because the experimental method was modified for both the single and dual fiber experiments, the results did not give exact microbuckle strain measurements. Each microbuckle occurrence resulted in a range of strain and load. Since the microbuckle occurred at or before the observed microbuckle load but after the prior load observation these were taken as the high and low points of the range respectively. A typical microbuckle stress- strain curve is shown in figure 2.2. These curves were extrapolated 
from the stress- strain curves generated from the data that was recorded using the resistance strain gage and load signal. The effective modulus was also calculated for each specimen. Using the effective modulus, the fiber modulus and the cross sectional area ratios, the matrix modulus was then calculated.

The average matrix modulus was measured to be $170 \mathrm{ksi}(1.187 \mathrm{GPa})$ which yielded a fiber to matrix modulus ratio of 176.9. The infinite support case predicted a 0.358 inch wavelength occurring at a $3.0 \%$ strain. The experiments yielded an average wavelength of 0.129 inches occurring in the average of $5.10 \%$ strain. The surface case predicted a 0.225 inch wavelength occurring at a $1.94 \%$ strain. Experimental results yielded an average wavelength of 0.115 inches occurring at an average of $2.89 \%$ strain. Figure 2.3 shows a photograph of a microbuckled interior fiber. Figure 2.4 shows a photograph of a microbuckled surface fiber.

Since no analytical model exists for two fiber interaction, the infinite matrix support prediction was used as an estimate for wavelength and strain. The average measured matrix modulus was $197 \mathrm{ksi}(1.376 \mathrm{GPa})$. This yielded a fiber- matrix modulus ratio of 152.6. The predicted wavelength was 0.170 inches, at a strain of 3.39 percent. Experiments yielded an average wavelength of 0.0994 inches at a strain of 3.88 percent. Figure 2.5 shows a typical dual fiber microbuckle.

One of the single fiber specimens exhibited a global failure after microbuckles were observed. This specimen had a very faint fringe pattern, and after measurments were taken, a higher load level was applied in an effort to yield clearer fringes. Initially, the failure was thought to be a global buckle. Upon inspection, the single fiber resembled 
a kink band, albiet for only one fiber. It is interesting to note that this occured after the microbuckle was observed. 


\section{References}

1. Taggart, D.G. "Free Edge Effects in Microbuckling Failure of Unidirectional Composites," Proceedings of International Conference of Composite Materials, Vol 8. July, 1991.

2. Shukla, A. and Khanna, S.K., "Effect of Fiber Reinforcement on Dynamic Crack Growth in Brittle Matrix Composites," Journal of Engineering Materials and Technology, January 1993, pp. 140-145.

3. Pike, T. Verbal Communication, April 1992.

4. American Society for Testing Materials, D-695-80, American National Standards.

5. Gere, J.M., Timoshenko, S.P. Mechanics of Materials, 2nd ed., Brooks Cole, 1984, pp. 551-567. 


\section{Chapter 3}

\section{Finite Element Analysis}

\subsection{Objectives}

Finite element models were used to model fiber microbuckling. There were three objectives in the finite element work. The first objective was to create, analyze and compare two dimensional single fiber meshes to previous work. The second objective was to model the experiments using real material values and the meshes from the first objective. The third objective was to model the two fiber interaction with a series of meshes. A nominal fiber to matrix modulus ratio was analyzed as well as the actual , material properties determined from the experiments.

Mesh creation and finite element analysis was done using I-DEAS ${ }^{2}$. Some mesh generation and input deck creation was done for $\mathrm{ABAQUS}^{3}$.

\subsection{Mesh Style}

The two dimensional meshes used parabolic eight noded plane stress elements. The quadratic elements required three nodes per side on the element, $\operatorname{Cook}(1)$. Four nodes were placed on the corners and four were in intermediate positions on the element. In all cases an element aspect ratio less than five was maintained.

Meshes varied in density in relation to the position of the fiber. In all two dimensional analyses, the fiber and adjoining matrix was modelled with elements five

\footnotetext{
2 I-DEAS Trademark Structural Dynamics Research Corporation.

${ }^{3}$ ABAQUS Trademark Hibbitt, Karlsson and Sorensen.
} 
millimeters wide and ten millimeters tall. This height was chosen for convenience of mesh extrusion, which was used extensively in the model method.

A restraint set was created in the bottom row of nodes. The restraints prevented deflection in the vertical (Y) axis. A comer node of the row was restrained in the horizontal (X) axis to prevent rotation of the mesh. A constraint set was created in the top row of nodes which forced all the nodes to deflect an equal amount in the $\mathrm{Y}$ axis. An in-plane edge pressure was applied to the constrained edge. The value of the edge pressure was set at unity. A buckling analysis was performed to determine the critical buckling load. Details of the mesh creation are given in Appendix B. Figure 3.1 shows an undeformed single fiber mesh. Figure 3.2 shows a deformed single fiber mesh.

\subsection{Solution Method}

The method for determining the critical strain for a position involved three to six analyses. The first analysis wavelength was estimated using Eq 1-3. A mesh base which had been created for each fiber position was then extruded to a mesh height of one and a half wavelengths. In most cases this was thirty elements high or $300 \mathrm{~mm}$. After this analysis was complete, a single wavelength mesh height was estimated from the solution. Subsequent analyses were conducted with mesh heights above and below the estimated single wavelength mesh height. This yielded a second order function of strain as a function of mesh height. The derivative of this quadratic yielded the actual wavelength, which in turn yielded the critical strain. See figure 3.3. Adjustment procedure is discussed in Appendix B. 
In a few of the intermediate fiber positions, where neither infinite support nor surface support were the case, the microbuckle wavelength value increased at the critical strain value. The critical strain values and the microbuckle wavelenghts were plotted versus position.

When two dimensional analysis of the two fiber models was done, the same curve fitting procedure was applied. Fewer data points were generated because, the larger meshes required more time to process.

The final analyses done utilized the real material values generated in the experiments. The real values were easily substituted into the meshes. An isotropic $\checkmark$ material was created with the fiber modulus and another was created with the matrix modulus.

\subsection{Results}

Since the equations provide only for response at infinite support and at surface support, one would have intuitively expected that values would fall into this range. From the results, it is clear that the finite element analysis shows a deviation from this expected result for wavelength. Figure 3.4 and figure 3.5 are the wavelength versus position in fiber diameters and strain versus position in fiber diameters, respectively. Both curves were generated for a single fiber analysis using the fiber-modulus ratio of 100 to 1 .

Another two sets of data were generated for critical buckling strain versus fiber matrix modulus ratios in the infinite support case and surface support case. These compare favorably to previous work done by Taggart (2). Figure 3.6 demonstrates this. 
Two fiber meshes were also generated and analyzed. The initial case was a 100 to 1 ratio. The separation of fibers was fifteen, eleven, five and two fiber diameters. Matrix on either side extended well into the infinite zone based on results from the single fiber analysis. A typical deformed two fiber mesh is shown in figure 3.7. Figure 3.8 shows the microbuckle strain for the two fibers versus separation in fiber diameters. Figure 3.9 shows the wavelength versus position in fiber diameters.

The dual fiber analyses done with a fiber- matrix modulus ratio of 100 were compared to the single fiber analyses previously done with this ratio. At a separation of fifteen diameters in the dual fiber specimen, the microbuckle strain was the same as the single fiber microbuckle strain in the infinite support case. This would indicate no adverse effects occurred from fiber- fiber interaction. As exhibited in figure 3.8, a downward trend existed in the microbuckle strain as the fiber spacing decreased. This indicated an interaction between fibers did exist. However, this did not appear to approach the single fiber surface value.

The dual fiber and single fiber meshes were analyzed with real material values. These results will be discussed in chapter four.

Three dimensional meshes, were created on the I-DEAS preprocessor but could not be analyzed on I-DEAS because of disk space limitations. These meshes were converted into input decks for ABAQUS, following the correction procedure discussed in Appendix B. Due to hardware limitations, these cases were not run and are provided here for informational purposes. 


\section{References}

1. Cook, R.D., Malkus, D.S., Plesha, M.E., Concepts and Applications of Finite Element Analysis, Third Ed., Wiley, 1989, New York.

2 Taggart, D.G., "Free Edge Effects in Microbuckling Failure of Unidirectional

Composites," Proceedings of International Conference of Composite Materials, Vol. 8, July, 1991. 


\section{Chapter Four}

\section{Conclusions}

\subsection{Experimental and Finite Element Results}

Single fiber experimental results and finite element results for critical strain versus fiber position are shown in figure 4.1. The average wavelength measured from the photographs and the wavelength determined through finite element analysis, versus fiber position are compared in figure 4.2. The finite element analyses was done with an average matrix modulus taken from the experimental results.

The single fiber strain predictions and experimental results followed the same trend. Critical microbuckle strain increased both experimentally and in finite element analysis as the fiber position varied from surface to infinite support. While the experimentally observed wavelengths seemed consistent, with no increase or decrease; the finite element results indicated a sharp increase would occur followed by a drop to the surface wavelength. Figure 4.1 shows critical strain for both finite element and experiments versus each position. Figure 4.2 shows the microbuckle wavelength observed experimentally and through finite element analysis versus position.

Dual fiber experimental results and finite element results for critical strain versus fiber separation are shown in figure 4.3. The average wavelengths measured from photographs and finite element wavelengths versus fiber separation are shown in figure 4.4.

Dual fiber finite element analysis showed a microbuckle wavelength roughly four times what was observed in the infinite support region. The finite element analysis 
indicated an increase in wavelength would occur as fiber separation increased. Experimental data recorded a decrease in the wavelength as separation increased. Instability in strain levels was found to begin at roughly 12.5 diameters separation in the finite element analysis. Critical strain did not seem affected by position in the experimental results. There is a slight downward trend, but it can be argued that this is due to experimental scatter. Figure 4.3 shows critical strain from both experimental and finite element analysis results versus position. Figure 4.4 shows the microbuckle wavelength observed experimentally and observed through finite element analysis.

\subsection{Discussion}

In the single fiber comparison, the strain followed the same general trend in the experiment and the finite element analysis. The wavelength versus position curve shows a peak in the transitional region. It is possible the difference in positions in the experimental data was too coarse to allow for these results to be observed. Additionally, the error in the experiments was so great that this trend was not discerned from the experimental results. The standard deviation was quite high in both the surface and the infinite case indicating a large error range.

The two fiber discrepancy is much greater. Here the standard deviation was quite large due to the high scatter. Insufficient experiments were done to clearly show a trend in the experimental data. Due to machining limitations, only three data points were selected. One more data point is needed in close proximity. Another data point could be used in the infinite support region. While a third data point could be used in the 
transitional zone. Unfortunately, the test fixture limits another infinite zone experiment due to dimensions. The width of the specimen would be too great for the current configuration.

In both sets of experiments, the experimental results were significantly higher than the finite element analysis. Scatter in the experiments can be attributed to variations in the matrix modulus. The average matrix modulus was $212 \mathrm{ksi}$, with a standard deviation of $37.5 \mathrm{ksi}$. The overall discrepancy is more difficult to explain, since the Rosen model typically overestimates observed compressive strength. The interface between the fiber and the matrix can be eliminated as a factor since bond failure did not occur during machining, and the bond did not fail when the fiber of a single fiber specimen was inadvertantly machined. Localized imperfect bonds would also tend to lower microbuckle strain. Microbuckling was observed to occur in the upper and lower regions of the specimen. The central portions were typically last to microbuckle. The energy required to continue the fiber microbuckle through the entire length might then increase due to the instability created in the ends of the specimen. This assertion is supported by the observation of microbuckles in the end regions at lower strain levels. This is contradicted by the use of the lower bound in strain measurment, because the lower bound value had no observed microbuckle.

Another possible reason for the discrepancy was the experimental proceedure for detecting fiber microbuckling. Since microbuckles were not visible in the fixture viewport it was necessary to remove the specimen to observe the microbuckles. This proceedure may have prevented observation of the onset of microbuckling due to stress 
relaxation and fiber straightening. Hence, the recorded failure load is associated with permanent deformation which is likeley to be much higher than the load required for the onset of microbuckling.

\subsection{Recommendations}

Experimental work was done based on the ASTM- D695 fixture. The fixture creates limits on the fiber- matrix modulus ratio that can be used. This limitation needs to be avoided since specimen design based on the fixture makes suitable birefringent materials difficult to acquire. By designing a new fixture, a longer, wider and thicker I

specimen can be tested. Thickness and width should be adjusted to allow for global buckling concerns. Euler's formula for buckling of columns can be applied. This can be converted to strain to check if the microbuckle strain occurs before or after the global buckle.

A preliminary design would place a specimen in two parallel inward facing $U$ channels. These $\mathrm{U}$ channels should be reinforced to prevent deflection. One of the Uchannels could be notched allowing for a region where surface support does not exist. Otherwise, this would interfere with surface fiber experiments. Another symmetrically opposed notch could be made in the second U-channel, allowing for a electrical resistance strain gage. These channels could be attached to a flat base. The assembly could be placed on the Instron with the current compression load configuration. A loading head would have to be designed which would allow the specimens to be compressed by the cross head. The loading head would attach to the cross head and have a flat surface 
which would contact the specimen. See figure 4.5 .

Larger specimens could be manufactured in the lab using the current casting jig. New fiber holders would need to be manufactured. Specimens could be squared quickly in the machine shop. The critical dimension could be machined quickly. Squaring would require no rough cutting. Only final cuts would be done. Specimen width tolerances could be relaxed since the wider specimens are well in the infinite support region on the farthest side.

Use of a higher fiber- matrix modulus ratio would allow for a lower microbuckling strain. By having a larger specimen, and a larger view area the problem of insufficient space to view the microbuckle wavelength would be avoided. 


\section{Appendix A: \\ Experimental Procedure}

\section{A.1 Specimens.}

Initial work was done with specimens machined from samples provided by Khanna(1). These were plates manufactured with spaced multiple fibers embedded in them. Based on the results of these preliminary tests, final specimen geometry was developed. All experimental work was done on specimens manufactured in the laboratory.

\section{A.1.1 Single Fiber Specimen Geometry.}

The single fiber specimen design followed the geometric requirements set by the ASTM-D695 fixture. This fixture will be discussed in section A.4.2. The initial geometry for the compression specimens was 0.5 inches in width, 0.4 inches in thickness and 3.25 inches in length. The fiber chosen was a 0.020 inch diameter steel piano wire. The fiber location was varied as per experimental requirements. In all specimens the fiber direction was parallel to the specimen length. See Figure A.1

Six locations were chosen for fiber placement. The center of the fiber was positioned $12.5,10,5,3.75,1.25$ and 0.75 fiber diameters $(0.250,0.200,0.100,0.075$, $0.025,0.015$ inches) from the near edge. Tolerances in the fiber location were the most critical thus all were machined to 0.0005 inches. The 0.250 inch position was selected to model infinite matrix support, while the 0.015 inch position models a free edge. 


\section{Appendix A: \\ Experimental Procedure}

\section{A.1 Specimens.}

Initial work was done with specimens machined from samples provided by Khanna(1). These were plates manufactured with spaced multiple fibers embedded in them. Based on the results of these preliminary tests, final specimen geometry was developed. All experimental work was done on specimens manufactured in the laboratory.

\section{A.1.1 Single Fiber Specimen Geometry.}

The single fiber specimen design followed the geometric requirements set by the ASTM-D695 fixture. This fixture will be discussed in section A.4.2. The initial geometry for the compression specimens was 0.5 inches in width, 0.4 inches in thickness and 3.25 inches in length. The fiber chosen was a 0.020 inch diameter steel piano wire. The fiber location was varied as per experimental requirements. In all specimens the fiber direction was parallel to the specimen length. See Figure A.1

Six locations were chosen for fiber placement. The center of the fiber was positioned $12.5,10,5,3.75,1.25$ and 0.75 fiber diameters $(0.250,0.200,0.100,0.075$, $0.025,0.015$ inches) from the near edge. Tolerances in the fiber location were the most critical thus all were machined to 0.0005 inches. The 0.250 inch position was selected to model infinite matrix support, while the 0.015 inch position models a free edge. 


\section{A.1.2 Two Fiber Geometry.}

As in the single fiber specimens, the multiple fiber specimen design requirements also followed the geometric requirements set by the ASTM-D695 fixture. The specimen width was increased as necessary in order to keep both fibers in the infinite matrix support zone. Length and thickness were maintained at 3.25 inches and 0.4 inches respectively. The center to center distance between the two fibers was two, three and five fiber diameters $(0.040,0.080$ and 0.120 inches). Tolerances in this distance was determined by the dimensions of the fiber holder in the casting jig, which is discussed in section A.2.1. Because of difficulties in drilling 0.020 inch holes, the holes did not lie 1

in the same plane. The maximum inter-fiber deviation was estimated to be 0.007 inches. See figure A.2.

\section{A.2. Casting Plates.}

Each single fiber and dual fiber plate cast contained six specimens. One of each fiber-to-edge location was obtained from each single fiber plate. Each dual fiber plate gave three fiber-to-fiber distances, or two specimens of each distance. This avoided any inconsistency that might have existed between plates biasing a single position. The plate's dimensions were 7.5 inches in length, 3.0 inches in width, and 0.40 inches in thickness. The plates were all cast in a mold, machined in the mechanical engineering machine shop. See figure A.3.

\section{A.2.1 Casting Jig.}


The casting jig was rectangular with inner dimensions equalling the plate's. The inside of the rectangle was tapped at both ends to accept the various pairs of fiber holders. For the single fiber specimens, the fiber holders contained three 0.020 inch holes which were 0.75 inches apart. The two fiber holder contained six 0.020 inch holes for three pairs of fibers. The holes were set at $0.040,0.080$, and 0.120 inches to give interfiber spacing of two, four and six fiber diameters. Each pair of holders attached with 832 cap-screws. See figure A.4.

\section{A.2.2 Jig Assembly}

A procedure was developed in order to assure consistent plates. A two foot length of fiber was run through each pair of holes of the appropriate holders. These lengths were thoroughly inspected for kinks no matter how minor. If a kink was found the fiber was discarded. After all lengths of fiber were run through the holders, one holder was lifted out of place while leaving the other attached. Silicone caulk was dabbed on the ends of the holder. The holder was reattached by firmly screwing the cap screws. This was repeated with other holder. This procedure was found to avoid tangles in the fiber which could result in slight kinking. A piece of Mylar was placed on a plexiglas sheet. The jig and fiber assembly was placed on the Mylar. A steel anchor with three holes drilled in it was placed in the hood abutting the plexiglas. The fiber was run through the three holes and twisted together. The jig was lifted and silicone caulk was applied to the underside of the jig along all four edges. The jig was placed down again and seated against the Mylar by pressing with both hands for several seconds. Care was taken not 
to get caulk on the fibers. The fibers were covered with a rag and the inner edges of the mold were coated with mold release. After spraying the mold release, excess mold release was wiped away with the rag. The rag was then discarded. The fibers were thoroughly wiped with a rag and acetone. This was done until no contaminant was picked up. This operation was the most critical in setting up the mold because any contaminants would cause fiber matrix debonding. More weights were placed on the anchor in order to avoid slippage when tension was applied to the fibers. To apply tension, steel plates with holes drilled in them were used as weights. The fiber was connected to the steel plate and hung out of the hood. A pair of pliers was used to pull , the wire taught at the base. The wire was grasped outside of the mold, to avoid kinking the fiber inside the mold. Finally, the jig assembly was checked for level. When necessary, the plexiglas was shimmed to achieve level. After the wires were inspected for kinks again, silicone caulk was applied to the top surface at the rear of the mold. A piece of mylar cut larger than the inner dimensions of the mold was attached to the rear of the mold and held in place with the caulk. A good bond between the mylar and mold was important because of the final step described in section A.2.4.

\section{A.2.3 The Matrix.}

The base resin used was Aristech's MR-17090 polyester resin. The initial work done was done following Khanna(1). Initial plates were cured with 0.85 percent by weight Methyl Ethyl Ketone Peroxide (MEK-P) hardener and 0.03 percent by weight Cobalt Octate catalyst. This formulation gave a resin modulus that was too high for the 
fiber microbuckling experiments.

To address this problem Aristech MR-9600 plasticizer was added, Broady(2). Several experiments were performed to determine the effect of the plasticizer content on resin modulus. See figure A.2. A plasticizer content of fifteen percent by weight was found to provide a more suitable modulus. The weight of the base resin and plasticizer was taken together in determining the percentages of catalyst and hardener. These percentages did not need to be adjusted.

A waxed paper paint cup and tongue-depressor was zeroed on the scale. MR17090 was poured from the five gallon bucket into a paint cup reserved for the MR17090. MR-9600 was poured into another paint cup reserved for it. A respirator was worn during this pouring, as the vapors are harmful. The percentage of hardener and catalyst did not change based on the addition of plasticizer. The weight of the plasticizer added to the base resin was used when calculating these numbers.

The procedure to mix the resin was to pour 170 grams of MR17090 in the zeroed paper paint mixing cup. Thirty grams of MR9600 was poured into this cup. The cup was stirred gently for three to five minutes with the tongue depressor until the swirls disappeared. The tongue depressor was left in the cup so the resin weight did not change. The cup was then placed back onto the scale and 0.06 grams of Cobalt Octate was added with an eye dropper. The 1.70 grams of MEK-P was added using another eye dropper. The Cobalt Octate and the MEK-P were added to different sides of the container to avoid any reaction starting prematurely. This mixture was stirred gently for 3 to 5 minutes with the same tongue depressor until the swirls disappeared. Both times the stirring occurred, 
great care was exercised in order not to introduce air bubbles into the mixture. The sides of the cup were also scraped down in order to prevent loss of hardener and catalyst.

Inevitably, stirring added some air bubbles to the mixture. These bubbles were removed by degassing. The cup of resin was then placed in the vacuum chamber for twenty minutes at a setting of fifteen inches of mercury. The degassing was longer than Khanna(1) recommended because the additional stirring required when adding the MR9600 introduced additional air bubbles.

\section{A.2.4 Pouring The Matrix}

After removal from the vacuum chamber, the mixture was taken to the mold. With one hand holding the top sheet of Mylar up, the resin was carefully poured into the mold. More resin than required was poured forming a meniscus held in place by surface tension. The Mylar was worked along the length towards the front of the mold by dragging the index fingers of either hand along the edges of the mold. This is why the anchoring of the mylar was done. This was done slowly to avoid the addition of any air bubbles. When the front was reached, a piece of plexiglas was placed on top of the Mylar to hold it in place.

Any air-bubbles that were observed, were worked out by sticking a length of wire into the mold between the top Mylar and the top of the mold. A gentle pulling action pulled the air bubbles out. After the air bubbles were pulled out steel weights were placed on the top of the plexiglas. The resin was allowed to cure thirty-six hours at room temperature. 
After curing was completed, the plates were removed from the mold. The first step was to cut the wires two inches from the exit of the fiber holders. It was discovered that the best way to remove the plate was to unscrew the holders and press on the fiber holders while holding the sides of the mold. The plate was not touched to avoid marring the surface. After the plate was free the fiber holders were gently slid back from the plate along the fibers. A wire cutter was used to cut the wire approximately 0.25 inches from the surface. All of the flash around the edges was carefully trimmed away with a utility knife.

\section{A.3. Specimen Machining.}

The reason for freeing the plate from the mold with fiber protruding was it aided in the critical dimensioning of the specimens. This was done after the first rough cuts were done. The best method for machining was determined through trial and error because no source of information was available. Great care had to be exercised in order to prevent heating the specimens as warpage had been observed in previous batches causing quality problems.

The rough cuts were done on the band saw. A misting attachment was added to the band saw table to provide cooling. This was focused on the blade at the point of entry into the plate. The table was set so the plates were cut into three strips each containing a fiber or fiber pair. The blade speed was set to 550 inches per minute. The plates were pushed though very slowly.

The strips were then taken to a milling machine for final dimensioning. Prior to 
machining, the milling machine had to be set-up. The first step was to true the table to the milling head. A dial gage used for surfaces was inserted into a collet and the milling head. The two bolts restraining the head were loosened. By swinging the gage in the widest arc from a parallel to another parallel the true was adjusted.

After the table was set, two parallels were inserted into the slots in the table. From these other parallels were placed building up the position to the rear or the table. Next to the last pair of parallels a pair of tooling bits was placed. These had trapezoidal cross-sections coming to a less than 90 degree acute corner. The two fiber surface intersections were placed against these tooling bit corners. The strips sat on a piece of cardboard to avoid marring the surface. Another piece of cardboard was placed on top of the strip and the clamps were secured to that.

For the single fiber specimens the following procedure was followed. The cooling spray was also attached to the milling head and focused on the mill. A side mill was used at a speed of 660 RPM and a feed rated of 0.01 inch per second. For all the single fiber specimens the critical dimension of fiber location relative to the near edge was machined first. One pass was made with the side mill. This was noted as the zero cut. A depth micrometer was used to determine exact position of the fiber in relation to the surface. Using the $\mathrm{Y}$-axis indicator, the $\mathrm{y}$ axis was adjusted and the appropriate cut was made. Typically the cuts were made in increments with a depth check after each pass. This avoided as much error as possible.

On the final pass of the single fiber strips, the $\mathrm{X}$-axis motion was stopped at a half way point on the strip. The appropriate $\mathrm{Y}$-axis amount was adjusted for. This was done 
because two specimens came from each strip and each had a different fiber-to-edge distance. This was repeated for all the strips. On the edge fiber and close to edge fiber passes, great care was taken not to break the fiber though the surface.

After the critical dimension was completed on the single fiber strips, the width cuts were made. In order to save time the milling machine was set up for repetitive cutting. The pairs of parallels which were anchored into the table were adjusted so that instead of the fiber abutting them, the previously machined side was held against them. After the first piece was cut, a depth micrometer was used to measure the distance from the parallel to the newly cut surface. The Y-axis was adjusted accordingly. All of the 1 strips could be machined to the same width after this step. The minimum allowable width was 0.5 inches, and anything above that was acceptable to a maximum of 0.55 inches.

This left strips which had the proper width and fiber location for two specimens. Unfortunately, machining the ends of the specimens proved to be difficult. These difficulties were associated with machining the steel fiber which was embedded in a relatively soft matrix. In the cases where the fiber was near the edge, the mill would actually pull it out. In some other cases, the fiber would debond and be pushed through to the other side. In most cases the fiber would simply bend at the intersection of fiber and matrix and displace matrix. A diamond saw wheel was tried with similar results.

One approach would have been to cut the matrix on the band saw up to the fiber. The fiber in the partially cut strip could be cut on the fiber wheel and then the remaining matrix on the band saw. The coolant attachment would have to be used on the band saw. This was not done because the surface produced could not be guaranteed to be free from 
inconsistencies due to the three cutting steps.

A better method for machining the specimen ends was to use the abrasive water jet machining. Preliminary trials led to the following water-jet machining procedure. A squaring plate was secured to the cross bars in the water jet. The jet head was jogged back and forth along the $\mathrm{Y}$-axis in order to true the plate to the head. The plate was found to be square within 0.003 inches over the six inch span. Since the specimen width was 0.5 inches, this was acceptable. Since the plate was machined to a 90 degree angle, $\mathrm{X}$-axis was also true. The plate was secured with clamps. Three strips were placed against the $\mathrm{x}$-axis surface and secured with a clamp. This insured that the cut would be perpendicular to the previously machined surfaces.

The water jet was set at $35 \mathrm{ksi}$. The nozzle used was a 0.070 inch nozzle with an 0.018 inch orifice. The feed rate was 4.26 inches per minute. Barton number 80 grit sand was used as the abrasive.

The jet was jogged to a position approximately a quarter of an inch from the end of the three strips. This was cut in a pass. The specimens were reversed and the process repeated for the other end of the strips. With both ends square, the strips were centered over the bars, using a surface to keep them true. The jet was jogged to a position at the edge of the strips. The $\mathrm{X}$-axis was programmed to 3.25 inches. This cut was made producing three specimens. The strips still secured to the plate were then checked with a caliper. The appropriate distance was jogged in order to produce a 3.25 inch length. This fourth and final cut was made. Thus six specimens were produced. This was repeated for all the sets of strips. 


\section{A.4. Running Experiments.}

The specimens were tested using the mechanical engineering department's Instron test machine and 20,000 load cell. The specimens were instrumented with electrical resistance strain gages. The strain and load signals were recorded using an Omega 900 series data acquisition system, an analog to digital interface card and the Lab-tech Notebook software package. The load signal was also recorded by the Lab-tech notebook. The specimens were placed in a compression fixture modified from the ASTM-D695 standard.

\section{A.4.1 Strain Gages}

After machining the specimens, strain gages were bonded to them. Student strain gages from Micro-measurements were used. The strain gages were bonded on the side farthest from the fiber. This was to avoid any interference on the near-fiber side of the specimen. The entire procedure outlined by Micro-Measurements(3) was followed except for the first step, degreasing. Since excessive amounts of degreaser was found to react with the specimen chemically, degreaser was sprayed on a gauze pad and wiped on the specimen. Soldering was also done carefully, as excessive heat from the soldering iron would distort the photoelastic qualities. However, no changes in the outlined procedure were made.

\section{A.4.2 Compression Fixture}

The compression fixture used in the experiments was a modified ASTM-D695 test 
fixture. It was chosen because of its use as a compression test fixture in the composites industry. ASTM-D695 machine drawings were provided by Pike(4). The primary modification from the standard fixture was a view port to allow the polarized light to pass through, so that microbuckle induced photoelastic patterns could be seen. The port consisted of a half inch by half inch square hole through the center of the fixture. It was necessary to widen the grips to accommodate the view port. Drawings of the modified fixture are in figures A.5 through A.8.

An adapter was designed to attach to the compression fixture. As shown in figure A.9, the adapter consisted of a plunger which screwed into the crosshead and inserted into । the fixture. A centering ball between the plunger and the fixture was used to minimize eccentric loading.

When early specimens exhibited global buckling, a pair of side grips (figure A.10) was machined in order to constrain lateral motion of the specimen and thereby inhibit global buckling. The front and rear grips prevented global buckling in the thickness direction. The side grips were recessed so that they did not contact the center portion of the specimen. As a result, the strain gage and the micro-buckle region was not influenced by the side grips.

\section{A.4.3. Experimental Set-up.}

The Instron was configured with the 20,000 pound load cell on the bottom ring. A pedestal attachment was screwed into the load cell. The compression fixture was placed on this attachment. The cross-head was jogged into position manually. The load 
cell voltage signal was tapped into and leads were connected to the A/D board on the computer. The leads for the strain gages were connected to the Omega Data acquisition box. The Lab-Tech notebook was set-up for recording data every second from both sources. An ASCII file containing voltage and microstrain readings was saved. This file was imported into other software packages for analysis.

Once the cross-head was in position, and all the parts were insured to be secure, the experiment could be run. Zero load strain levels were entered into the Lab-Tech software, as null strain was usually given as some value. The cross-head speed was set at 0.02 inches per minute. Both the Instron and the Lab-tech were started simultaneously and stopped when any type of failure occurred. 


\section{References}

1. Shukla, A., Khanna, S.K., "Effect of Fiber Reinforcement on Dynamic Crack Growth in Brittle Matrix Composites," Journal of Engineering Materials and Technology, January 1993, pp.140-145.

2. Broady, B. Aristech Corporation, Verbal Communication.

3. Measurements Group, Student Manual for Strain Gage Technology, Vishay, 1991.

4. Pike, T., Hexcel Corp., Verbal Communication. 
Appendix B.

\section{Finite Element Analysis.}

All finite element work was done on computers available at the University of Rhode Island. The program used in all mesh generation was Ideas. I-deas was also used for most of the analysis. Some analysis was done on Abaqus. Abaqus, by Hibbitt, Karlsson and Sorensen was available on an IBM RISC 6000 called Grinder, through the Academic Computing Center. I-deas, by Structural Dynamics Research Corporation was available on a VAX 4000 called ECL1, a DEC-station 5000 called Vader and a MicroVAX called MCEMV, all available through the Engineering Computer Lab.

This appendix will describe how mesh generation was done then will describe how the analysis was completed and will describe how the results were displayed.

\section{B.1 Mesh Generation}

I-deas has two modules that were used. The Solid Modelling module and the Finite Element Module were both accessible from the main global menu. At first all three dimensional models were drawn in Solid Modelling.

In Solid Modelling, a cube and a cylinder were created. The cylinder represented the fiber and the cube the matrix it was embedded in. The cube had a base of $250 \mathrm{~mm}$ by $250 \mathrm{~mm}$ and the cylinder a diameter of $10 \mathrm{~mm}$. The cylinder was placed in the cube, it's position dependent on the analysis. The height was also determined by the analysis in progress. This was saved as a "universal file". The Finite Element module was then selected. 
The three dimensional elements were solid twenty noded parabolic brick elements. The two dimensional elements were eight noded parabolic plane stress elements. The reason for these element types was they both would fit curves better than linear elements.

In the Finite Element module, the mesh creation option was chosen usually through "geometry modelling". The solid model was imported. A mesh volume was created around the object. Unfortunately, Ideas had difficulty with this procedure. I-deas was unable to import the solid model properly on many occasions, losing the dimensions. Another difficulty Ideas had was it was unable to recognize the cylinder and in some cases would ignore the cylindrical boundary. The third biggest problem with Ideas was the meshing sequence would default to tetrahedrons and could not easily be set to brick elements. Even setting the default to brick element would not solve this problem.

Because of these limitations, the Solid Modelling procedure was abandoned. The approach used was to create a base in "geometry model". "Geometry model" was one of the options available in the Finite Element module. A two dimensional base with the cross-section of the model was created.

To create the base, the "geometry model- create" selection was chosen. The dimensions were entered by keying in the coordinates for each line segment. The line segments would usually be connected to form a mesh area. Next a circle was chosen. The diameter of the circle was chosen and then it's center point keyed in. Another mesh area was created using this circle. For two fiber models, the procedure was repeated with a second circle, see figure B.1.

With a base created, the number of elements per unit length could be defined, 
along the edges of the cube and the edge of the cylinder or cylinders. Using the "mesh creation- automesh" function, the elements were automatically generated to fill the cylinder, and the matrix around the cylinder. This base could then be extruded into any height desired using the "elements- create- extrude- translate" command. The entire face was chosen for this procedure. See figure B.2.

All of the nodes on the bottom face were restrained in the vertical $\mathrm{Y}$ direction. Two were restrained in all three directions. A constraint was applied to all the top face nodes with a corner node being the independent node and all others being dependent. $A$ face pressure of magnitude unity was applied to the top face elements.

\section{1}

Some of the two dimensional meshes were generated in the same manner as the three dimensional bases. The geometry was created for the fiber. This was meshed and the "element- create- extrude" command used to extend the matrix on either side. This created some problems with node sequences and caused some analyses to fail.

The approach settled on was to create the mesh manually. An eight noded single element was created. The eight nodes were created using the "nodes- create- singlekey_in" command. Each node was placed in position by typing in it's coordinates. A single element was created using the "element- create- single" command and choosing the eight nodes. The "extrusion- translate" command was used to create the bottom row of the mesh. Regions far from the fiber had a base of $50 \mathrm{~mm}$, while the fiber elements and adjoining matrix elements had a base of $5 \mathrm{~mm}$. Intermediate elements had bases of $10 \mathrm{~mm}$ and $20 \mathrm{~mm}$ for a smooth transition. The "elements- create- extrude- translate" command allowed for different widths by prompting the user for the translation amount per axis. 
It would then prompt for the number of elements in the translated amount. For the single fiber analysis, the base length was kept the same for all meshes, $300 \mathrm{~mm}$. The double fiber elements were varied as the distance between the fibers varied. Once the base was created the mesh was extruded into a mesh twenty five elements $(250 \mathrm{~mm})$ to thirty elements $(300 \mathrm{~mm})$ high.

Subsequent analyses would require shortening the mesh, by deleting elements. The "analysis data set" from the previous run would have to be deleted, the restraints deleted and then the elements could be removed. This was accomplished with the "element- delete- screen area" command. The screen area was defined by diagonal points. The nodes would be deleted by selecting "nodes- delete- all". Even though it would seem all the nodes would be deleted with this, only those not attached to elements would be deleted.

The next step was to add the boundary conditions. The commands for constraints, restraints, and structural loads were found inside the "boundary conditions" function. Restraints would be added to the bottom of the mesh. All of the bottom nodes were restrained in the vertical $(Y)$ direction using "boundary conditions- restraints- createscreen area- diagonal points." A corner node was restrained in both the $Y$ direction and the horizontal $\mathrm{X}$ direction using boundary conditions- restraints- create- single." A constraint was added to the top of the mesh, so all of the top nodes would deflect the same $\mathrm{Y}$ distance. In all cases a corner node was selected as the independent node. The constraint was done with "boundary condition- constraint- create." An edge pressure was applied to the constrained surface, with a value of unity using "boundary condition- 
structural loads- edge pressure- screen area."

The actual material properties were substituted into these meshes upon completion of the nominal ratio. This was done using the command "mesh create- material properties- create." Next the command "mesh create-elements- modify- all" was selected giving all the elements the matrix value. The command "elements- modify-screenareadiagonal points" was used to select and modify the fiber element material properties.

\section{B.2 Analysis}

Analysis of the meshes was done on both Ideas and Abaqus. 1

After creation of the mesh in Ideas, the "case set" was created. The restraint set, the constraint set and the load set were selected and placed in a case set through "case management- create".

To solve the analysis on Ideas, the "model solution-buckling" command was chosen. The case set was selected. Next, the "solution method- solution control" was adjusted for a higher number of iterations. The reason for doing this was the default was ten iterations, and if the analysis was not complete in ten then the analysis ceased. Although the option of restarting existed in the software, the files were automatically deleted by the system disabling this feature. The "output" command was selected, allowing solution for only the first mode. Finally, the "solve-buckling" command was entered.

A typical run on Vader would take two hours during the semester and twenty minutes during the summer. Unfortunately, the MCEMV and the ECL1 machines could 
not handle the calculations and would typically crash during the run. Use of these machines was minimal, typically for file storage only and in some cases mesh generation. Loon and Turnstone, two other DEC station 4000's were not configured for running_Ideas. None of the three dimensional meshes would run on Ideas. This was due to a lack of disk space on Vader.

Abaqus input decks were created in Ideas. It was important to create a "case set" in "case management" or the boundary conditions would not get written to the input deck. It was also important to change the translator default to Abaqus from Nastran, or translation errors would occur. A minor bug existed in the writing command, the ".inp" extension would appear in the front of the file. By naming the file and adding the ".inp" in the file manager, the problem could be avoided. Writing the input deck was accomplished in "manage models- translator settings- Abaqus" which allowed the translator to write to Abaqus and "manage models- translate- Abaqus" which created the input deck.

After writing the input deck, it was easiest to FTP the file to ECL1. The Ideas input deck had some mistakes in it which were easily corrected in Ecll's editor. These had to be corrected prior to using Abaqus or the analysis would fail. The constraint section had a comma omitted in each line. Without the comma, the command put two separate numbers together and failed to form the equation relating the nodes. This comma had to be added for every constrained node. The final instructions had to be changed in order to do buckling instead of static loading. An "*END STEP" also had to be added as the last command. 
A corrected Ideas generated Abaqus input deck is included at the end of this section.

\section{B.3 Post Processing}

All Ideas analyses were post processed on Ideas using the "post processing" command. After selecting "post-processing", the data set was selected with "post processing- analysis dataset- select- current". The undeformed geometry was turned off using "post processing- undeformed geometry- no undeformed." Finally, the "post processing- line- execute" command selected. The buckling load factor was indicated in I

the upper corner of the display. A printout of the deformed mesh was generated by using "model file- picture file- write switch- on." Using the "redisplay" command, the screen was redrawn. After the screen redisplayed, the write switch was immediately turned off with model file- picture file- write switch- off." The printout was sent from the vader prompt with the command "iplot filename.pfb CASCADE", Cascade being the laser printer.

The original goal was to use Abaqus for analyses and export the completed ".fil" files back to Ideas. Unfortunately, Ideas would not recognize the files stating that they were empty. This is probably due to FTP translation problems, because the ".fil" file was generated on a unix machine and sent to a VMS machine then to an Ultrix machine or the versions of Abaqus and Ideas are incompatible.

A script was developed in order to expidite the batch jobs done on the grinder machine. The script calls Abaqus and submits jobs after the previous one is complete, 
using the UNIX command "wait." Future analyses could use this batch mode to do initial meshes for each position at the same time. Using the data from this batch, the meshes which would yield the height versus critical load for each fiber position could be analyzed in subsequent batches. This would be a minor time savings in the two dimensional work, but in the three dimensional cases would be quite helpful.

\section{B.4 Corrected Abaqus Input Deck.}

This is an example of a corrected Abaqus input deck. 
\#HEADING

SDRC I-DEAS ABAQUS FILE TRANSLATOR 18-NOV-93 10:56:47 *NODE, SYSTEM $=R$
$1,0.0000 \mathrm{E}+00,0.0000 \mathrm{E}+00,0.0000 \mathrm{E}+00$
$2,5.0000 E+00,0.0000 E+00,0.0000 E+00$
$3,1.0000 E+01,0.0000 E+00,0.0000 E+00$
$4,1.0000 \mathrm{E}+01,5.0000 \mathrm{E}+00,0.0000 \mathrm{E}+00$
$5,1.0000 \mathrm{E}+01,1.0000 \mathrm{E}+01,0.0000 \mathrm{E}+00$
$6,5.0000 \mathrm{E}+00,1.0000 \mathrm{E}+01,0.0000 \mathrm{E}+00$
$7,0.0000 \mathrm{E}+00,1.0000 \mathrm{E}+01,0.0000 \mathrm{E}+00$
$8,0.0000 \mathrm{E}+00,5.0000 \mathrm{E}+00,0.0000 \mathrm{E}+00$
9, $1.0000 \mathrm{E}+01,1.5000 \mathrm{E}+01,0.0000 \mathrm{E}+00$
$10,1.0000 E+01,2.0000 E+01,0.0000 E+00$
$11,1.0000 E+01,2.5000 E+01,0.0000 E+00$
$12,1.0000 E+01,3.0000 E+01,0.0000 E+00$
$13,1.0000 E+01,3.5000 E+01,0.0000 E+00$
$14,1.0000 E+01,4.0000 E+01,0.0000 E+00$
$15,1.0000 \mathrm{E}+01,4.5000 \mathrm{E}+01,0.0000 \mathrm{E}+00$
$16,1.0000 E+01,5.0000 E+01,0.0000 E+00$
$17,1.0000 E+01,5.5000 E+01,0.0000 E+00$
$18,1.0000 E+01,6.0000 E+01,0.0000 E+00$
$19,1.0000 E+01,6.5000 E+01,0.0000 E+00$
$20,1.0000 E+01,7.0000 E+01,0.0000 E+00$
$21,1.0000 E+01,7.5000 E+01,0.0000 E+00$
$22,1.0000 E+01,8.0000 E+01,0.0000 E+00$
$23,1.0000 E+01,8.5000 E+01,0.0000 E+00$
$24,1.0000 \mathrm{E}+01,9.0000 \mathrm{E}+01,0.0000 \mathrm{E}+00$
$25,1.0000 \mathrm{E}+01,9.5000 \mathrm{E}+01,0.0000 \mathrm{E}+00$
$26,1.0000 E+01,1.0000 E+02,0.0000 E+00$
$27,1.0000 E+01,1.0500 E+02,0.0000 E+00$
$28,1.0000 E+01,1.1000 E+02,0.0000 E+00$
$29,1.0000 E+01,1.2500 E+02,0.0000 E+00$
$30,1.0000 E+01,1.2000 E+02,0.0000 E+00$
31, $1.0000 \mathrm{E}+01,1.2500 \mathrm{E}+02,0.0000 \mathrm{E}+00$
$32,1.0000 \mathrm{E}+01,1.3000 \mathrm{E}+02,0.0000 \mathrm{E}+00$
$33,1.0000 E+01,1.3500 E+02,0.0000 E+00$
$34,1.0000 E+01,1.4000 E+02,0.0000 E+00$
$35,1.0000 \mathrm{E}+01,1.4500 \mathrm{E}+02,0.0000 \mathrm{E}+00$
$36,1.0000 E+01,1.5000 E+02,0.0000 E+00$
$37,1.0000 \mathrm{E}+01,1.5500 \mathrm{E}+02,0.0000 \mathrm{E}+00$
$38,1.0000 \mathrm{E}+01,1.6000 \mathrm{E}+02,0.0000 \mathrm{E}+00$
$39,1.0000 E+01,1.6500 E+02,0.0000 E+00$
$40,1.0000 E+01,1.7000 E+02,0.0000 E+00$
$41,1.0000 E+01,1.7500 E+02,0.0000 E+00$
$42,1.0000 E+01,1.8000 E+02,0.0000 E+00$
$43,1.0000 E+01,1.8500 E+02,0.0000 E+00$
$44,1.0000 E+01,1.9000 E+02,0.0000 E+00$
$45,1.0000 E+01,1.9500 E+02,0.0000 E+00$
$46,1.0000 E+01,2.0000 E+02,0.0000 E+00$
$47,1.0000 E+01,2.0500 E+02,0.0000 E+00$
$48,1.0000 E+01,2.2000 E+02,0.0000 E+00$
$50,5.0000 \mathrm{E}+00,2.0000 \mathrm{E}+01,0.0000 \mathrm{E}+00$
$52,5.0000 E+00,3.0000 E+01,0.0000 E+00$
$54,5.0000 E+00,4.0000 E+01,0.0000 E+00$
$56,5.0000 E+00,5.0000 E+01,0.0000 E+00$
$58,5.0000 E+00,6.0000 E+01,0.0000 E \div 00$
$60,5.0000 E+00,7.0000 E+02,0.0000 E==?$
$62,5.0000 \mathrm{E}+00,8.0000 \mathrm{E}+01,0.000 n E=2 \mathrm{n}$
$64,5.0000 E+00,9.0000 E+01,0.0000 E=$
$66,5.0000 E+00,1.0000 E+02,0.0000 \equiv-$ 


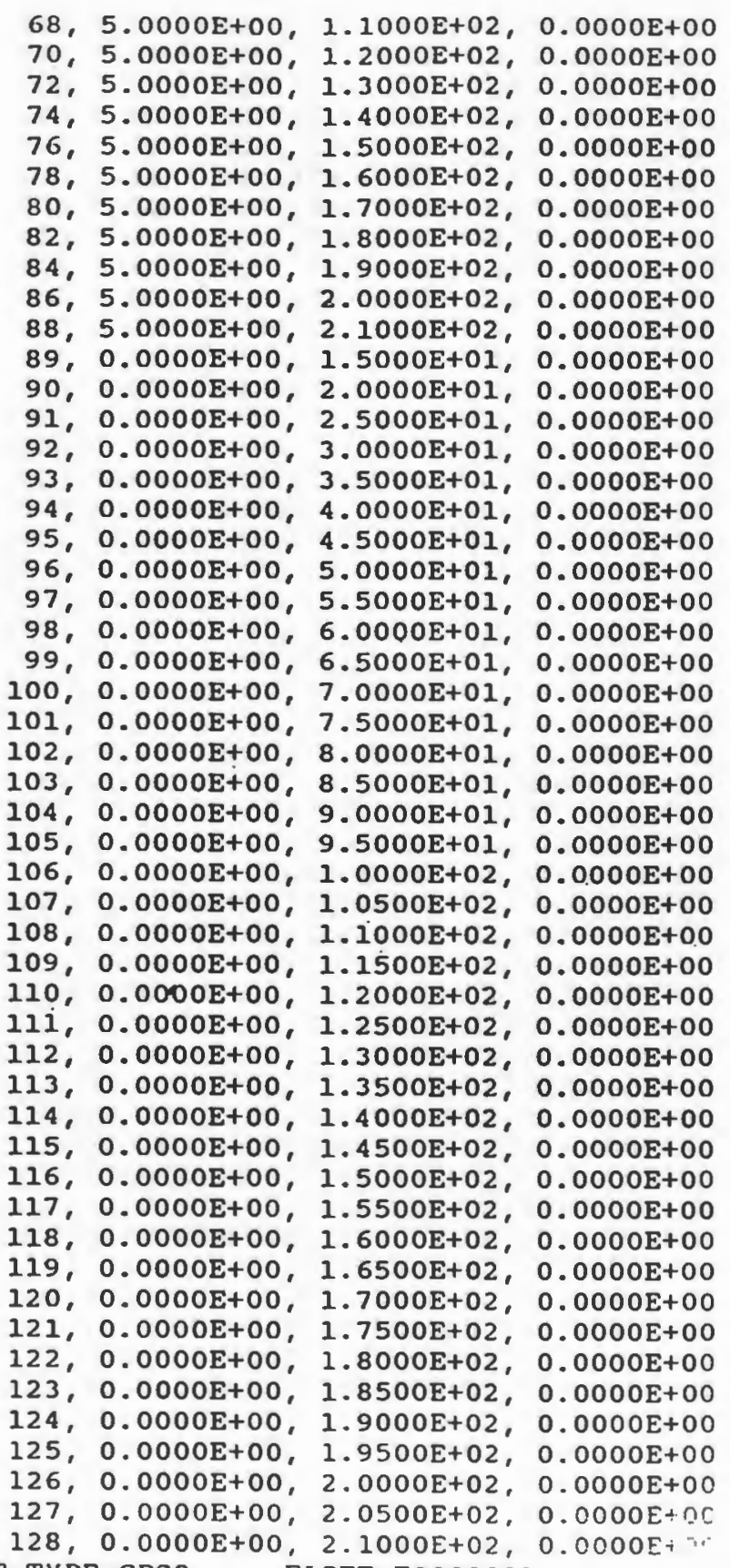
*ELEMENT , TYPE $=$ CPS 8

$\begin{array}{rrrrrrrrr}1 & 1 & 3 & 5 & 7 & 2 & 4 & 6 & 8 \\ 2 & 7 & 5 & 10 & 90 & 6 & 9 & 50 & 89 \\ 3 & 90 & 10 & 12 & 92 & 50 & 11 & 52 & 91 \\ 4 & 92 & 12 & 14 & 94 & 52 & 13 & 54 & 93 \\ 5 & 94 & 14 & 16 & 96 & 54 & 15 & 56 & 95 \\ 6 & 96 & 16 & 18 & 96 & 56 & 17 & 56 & 97 \\ 7 & 98 & 18 & 20 & 100 & 58 & 19 & 60 & 7 \\ 8 & 100 & 20 & 22 & 102 & 60 & 21 & 52 & 10\end{array}$




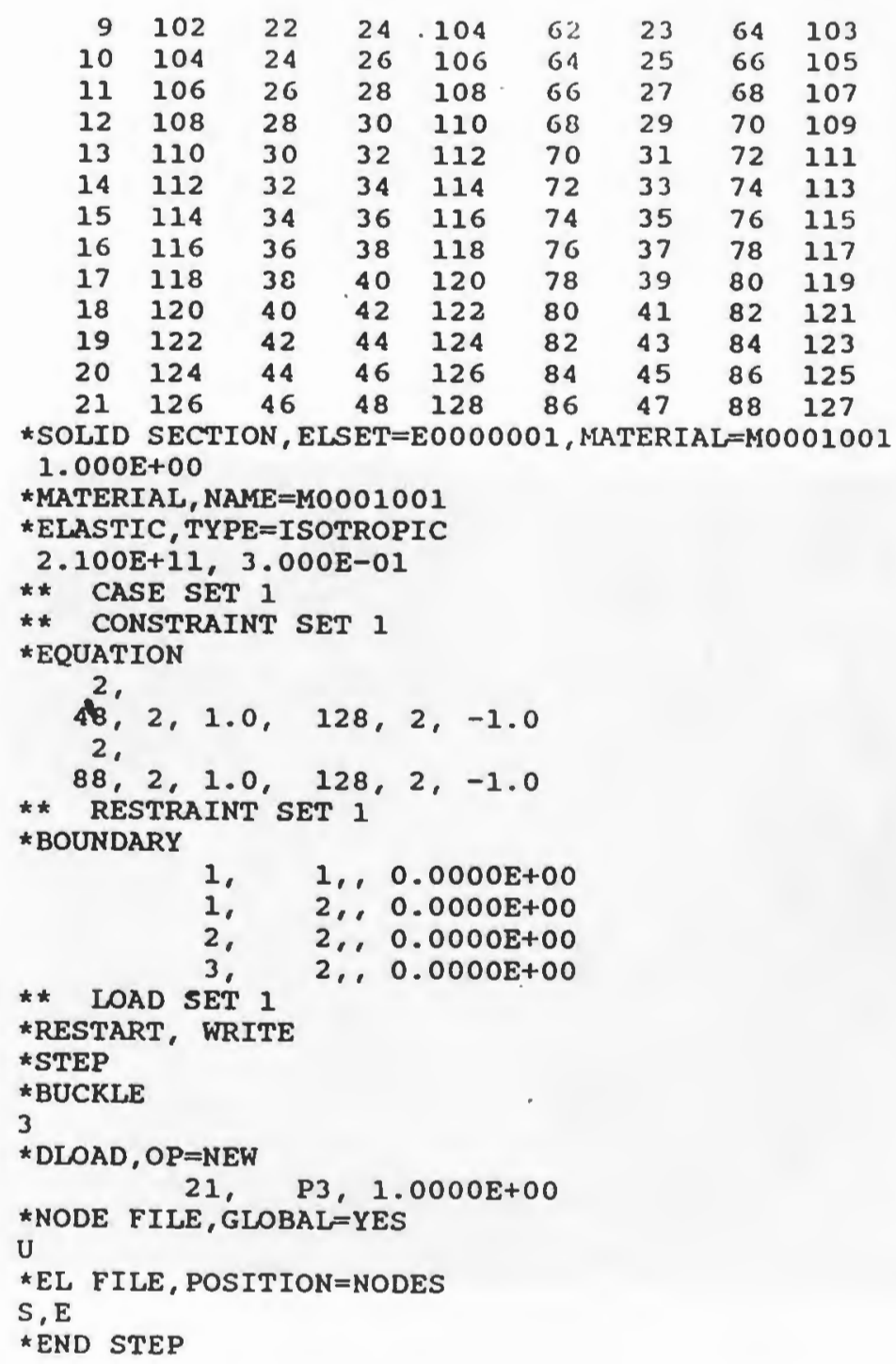




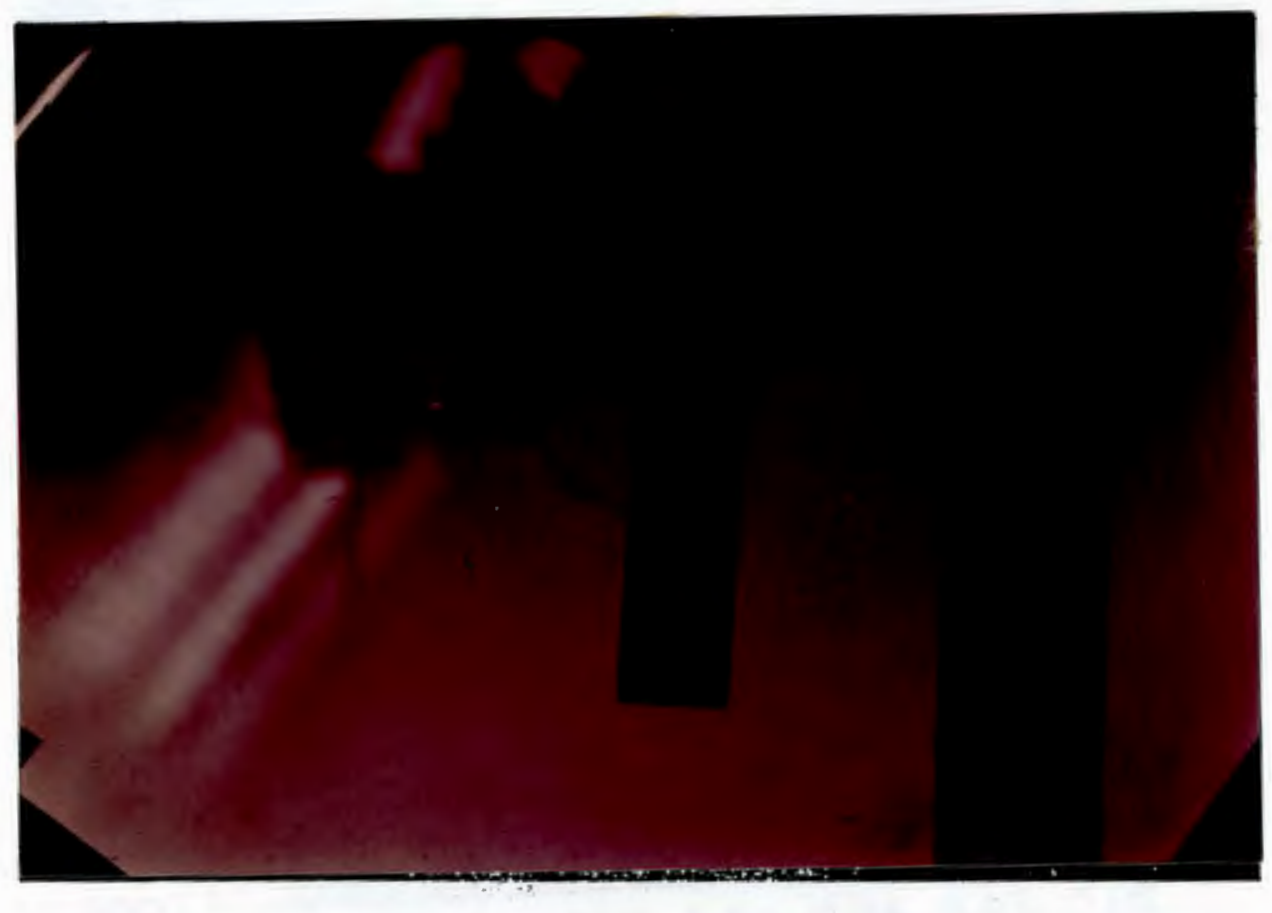

Figure 2.1 Global Buckle. 


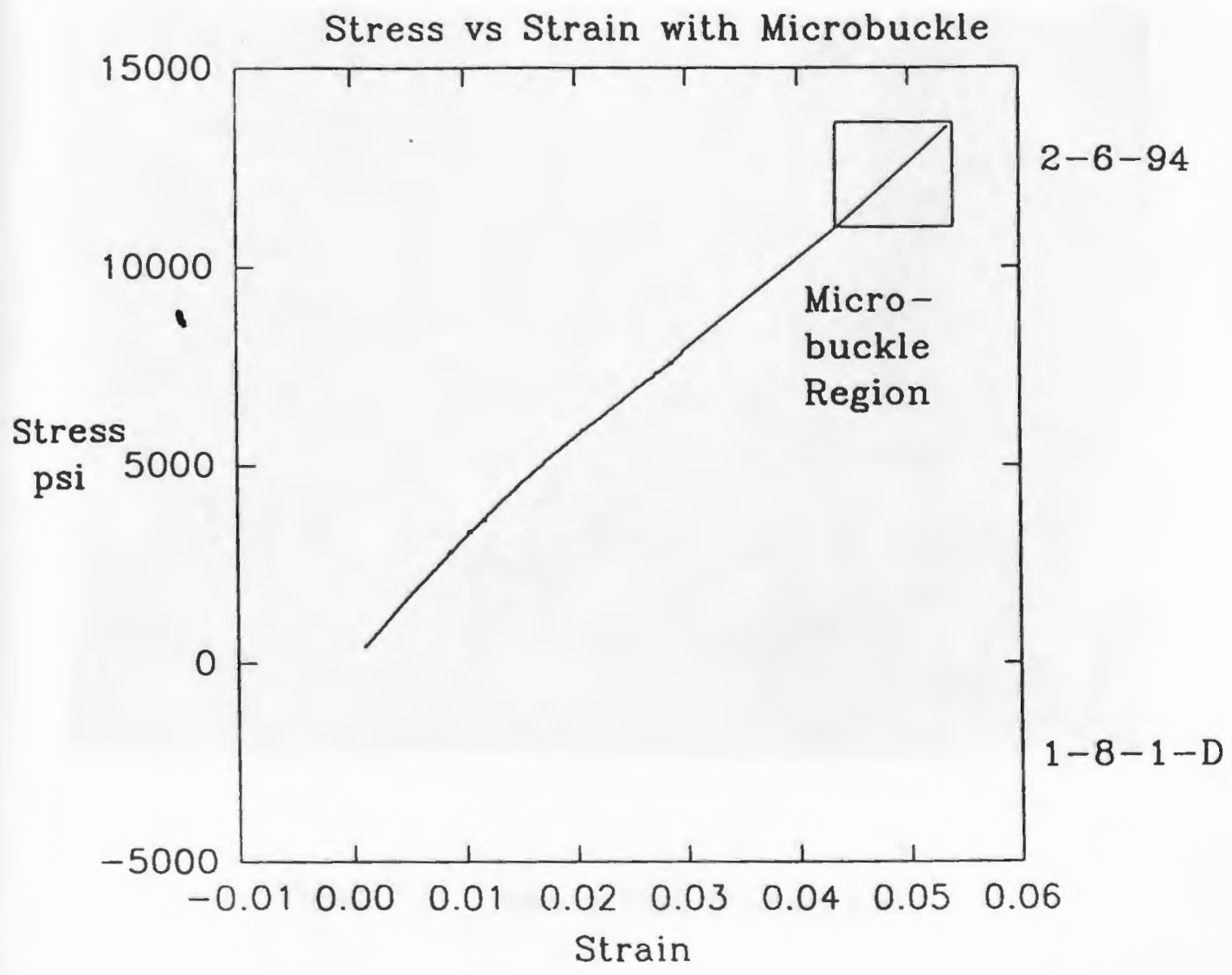

Figure 2.2 Microbuckle Stress-Strain Curve. 


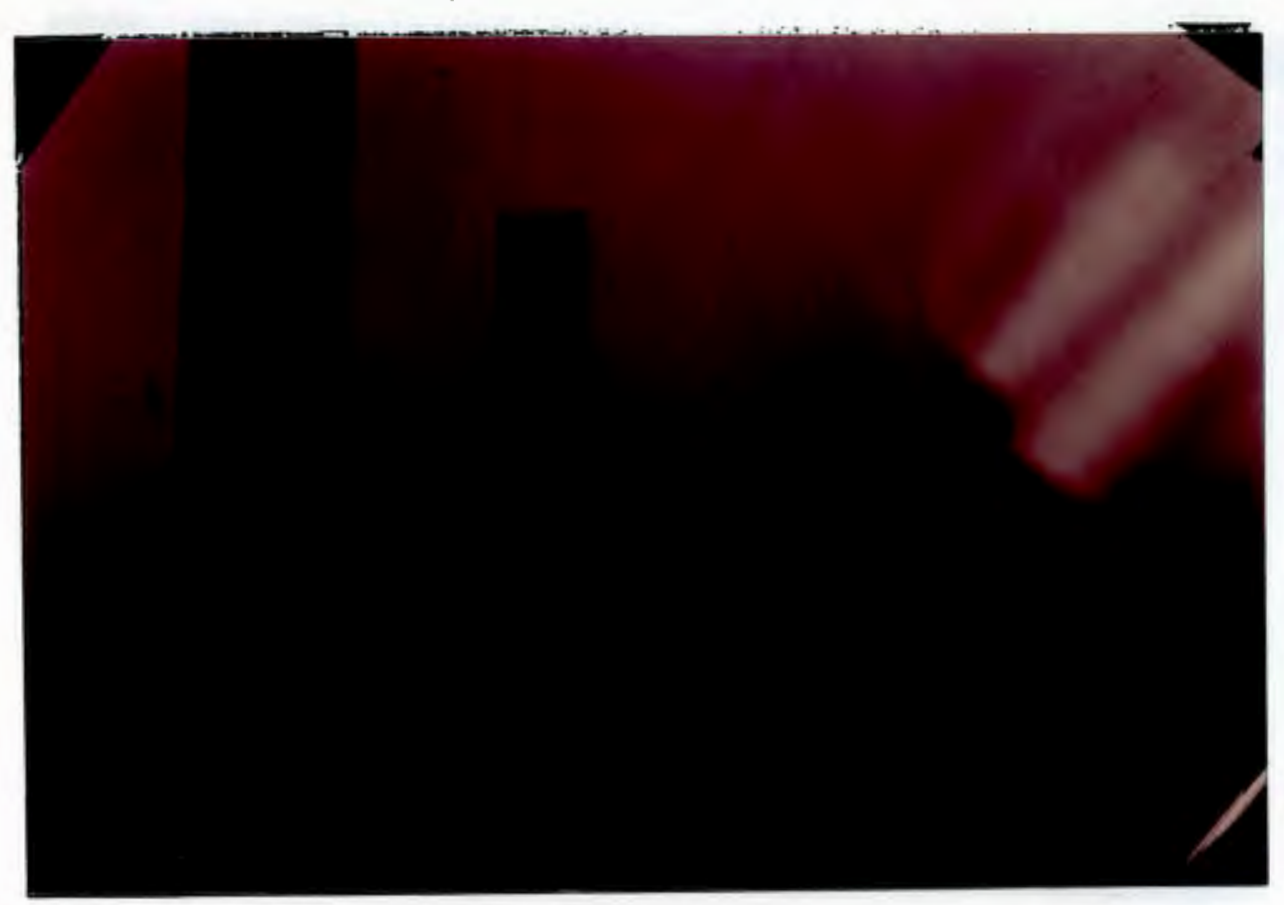

Figure 2.3 Interior Fiber Microbuckle. 


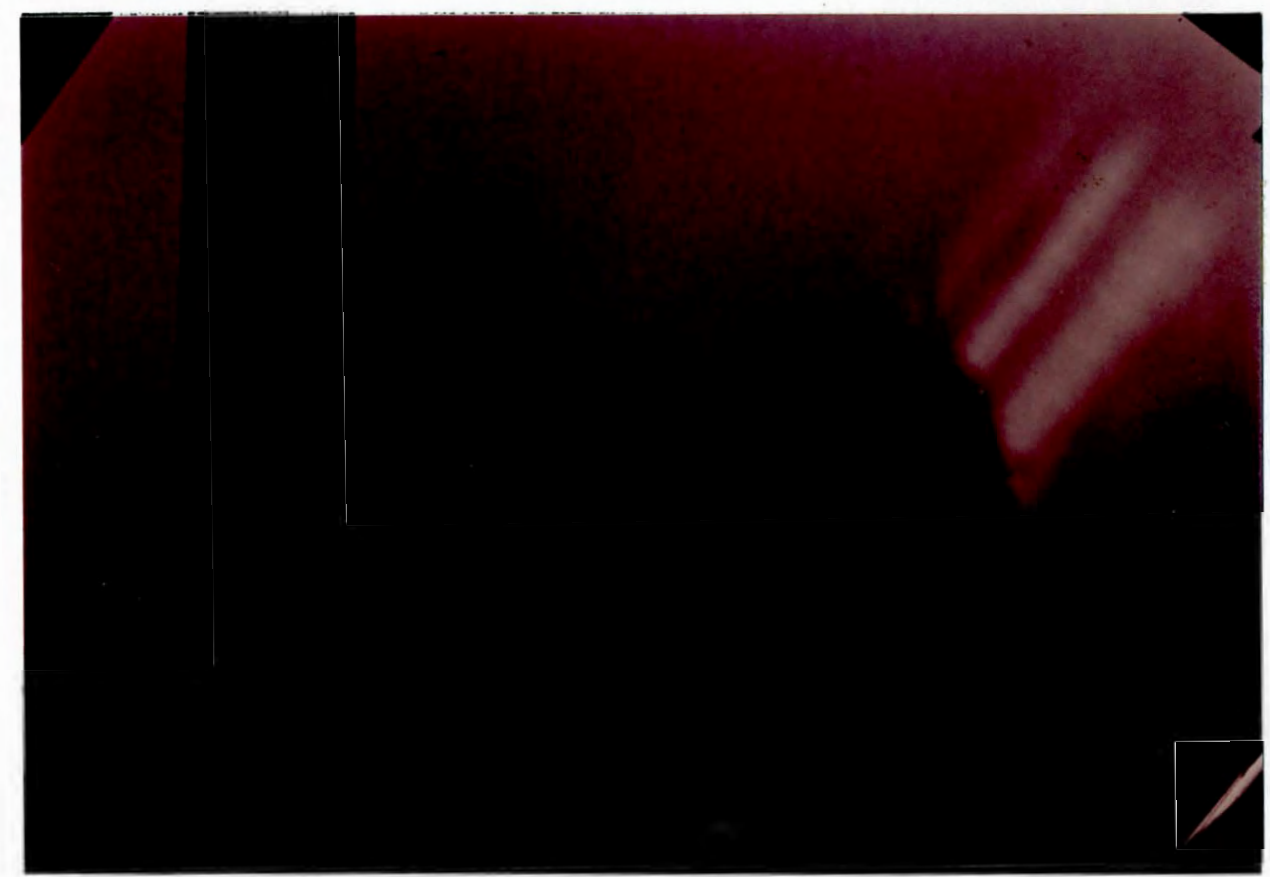

Figure 2.4 Surface Fiber Microbuckle. 


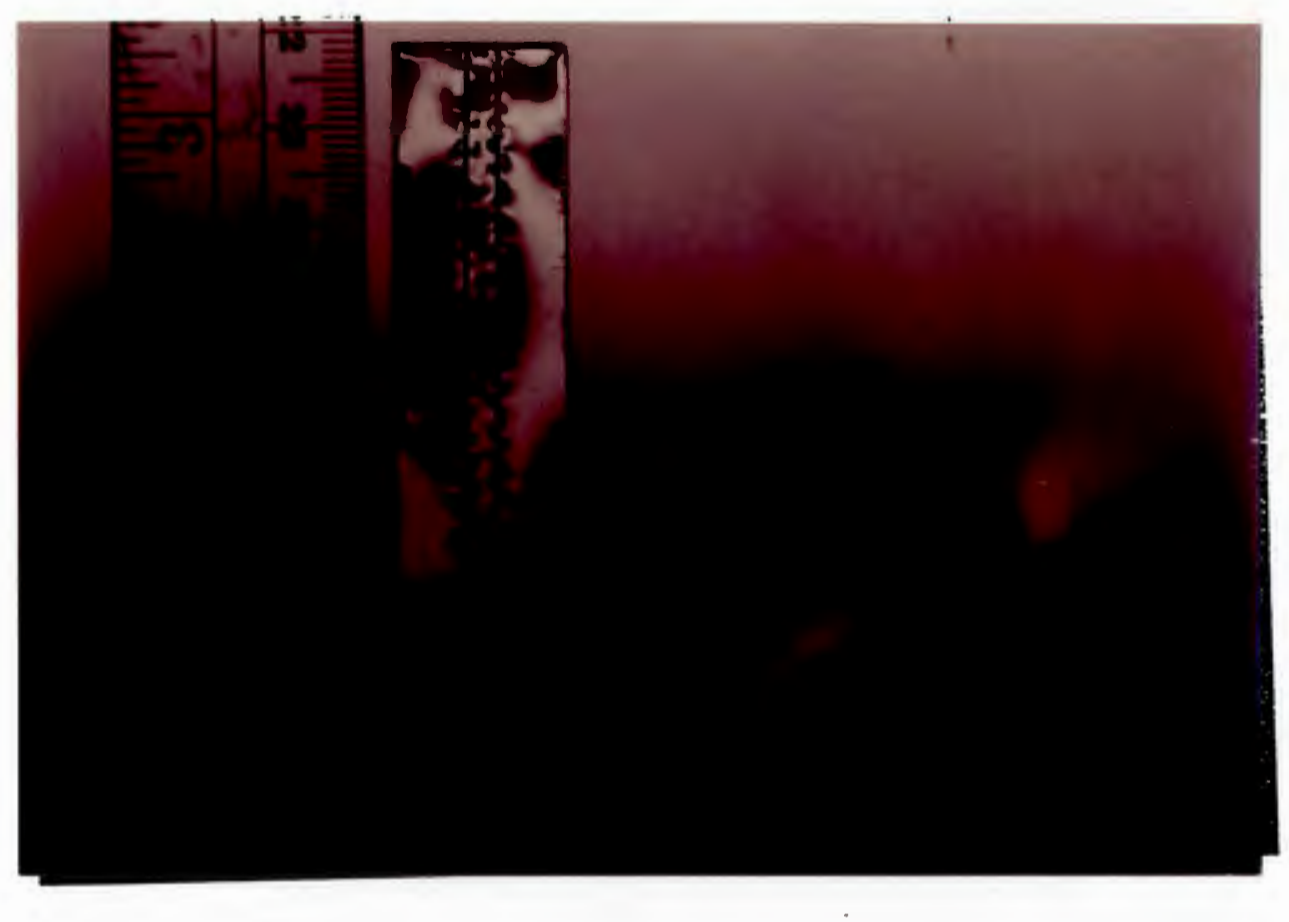

Figure 2.5 Dual Fiber Microbuckle. 


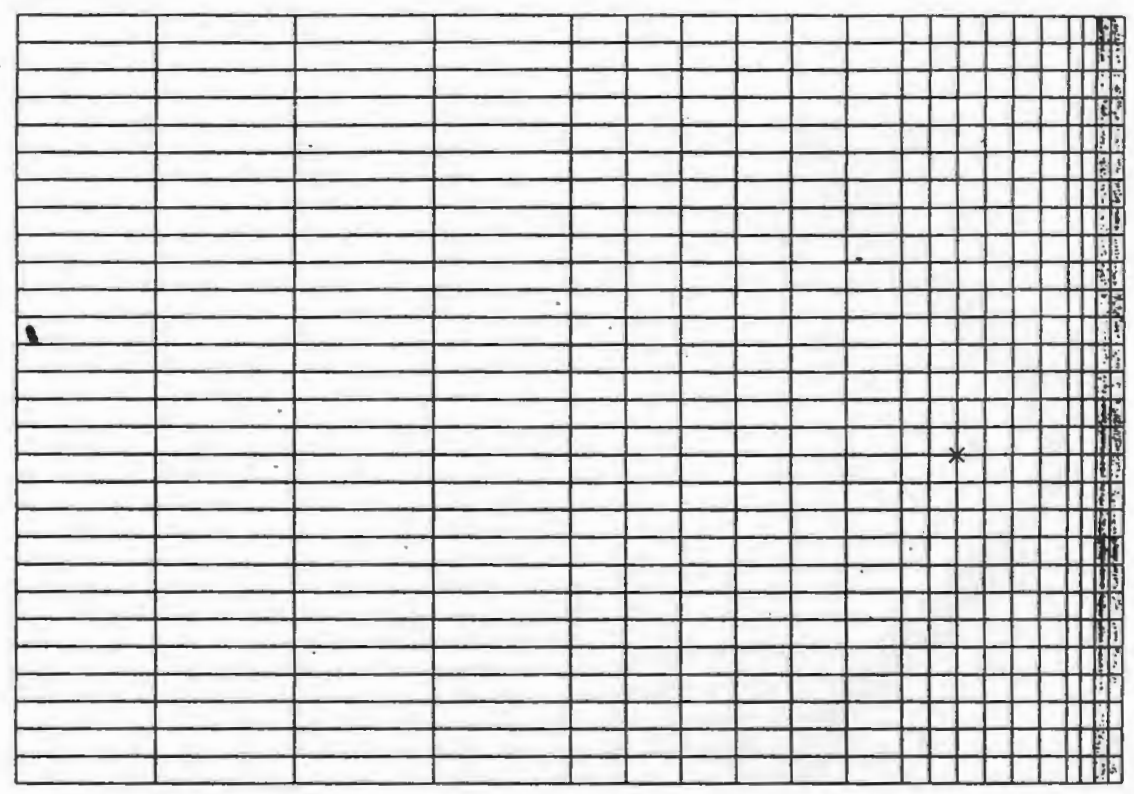

Figure 3.1 Undeformed Single Fiber Mesh. 


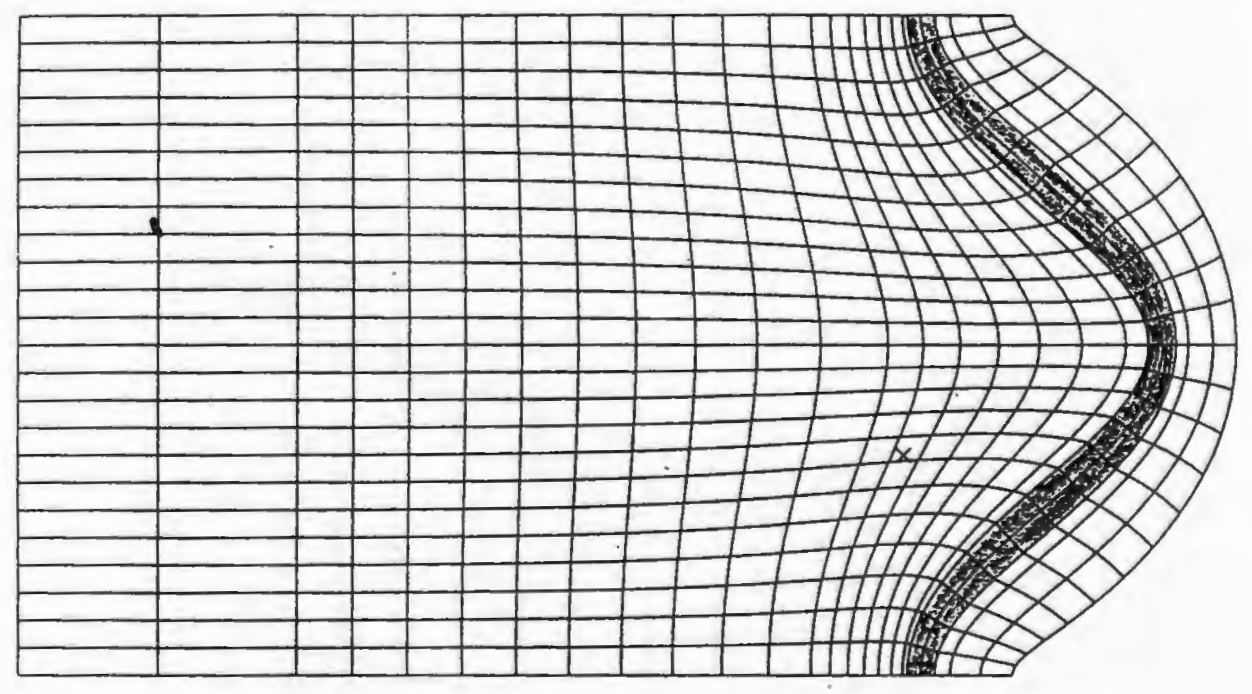

Figure 3.2A Deformed Single Fiber Mesh. 


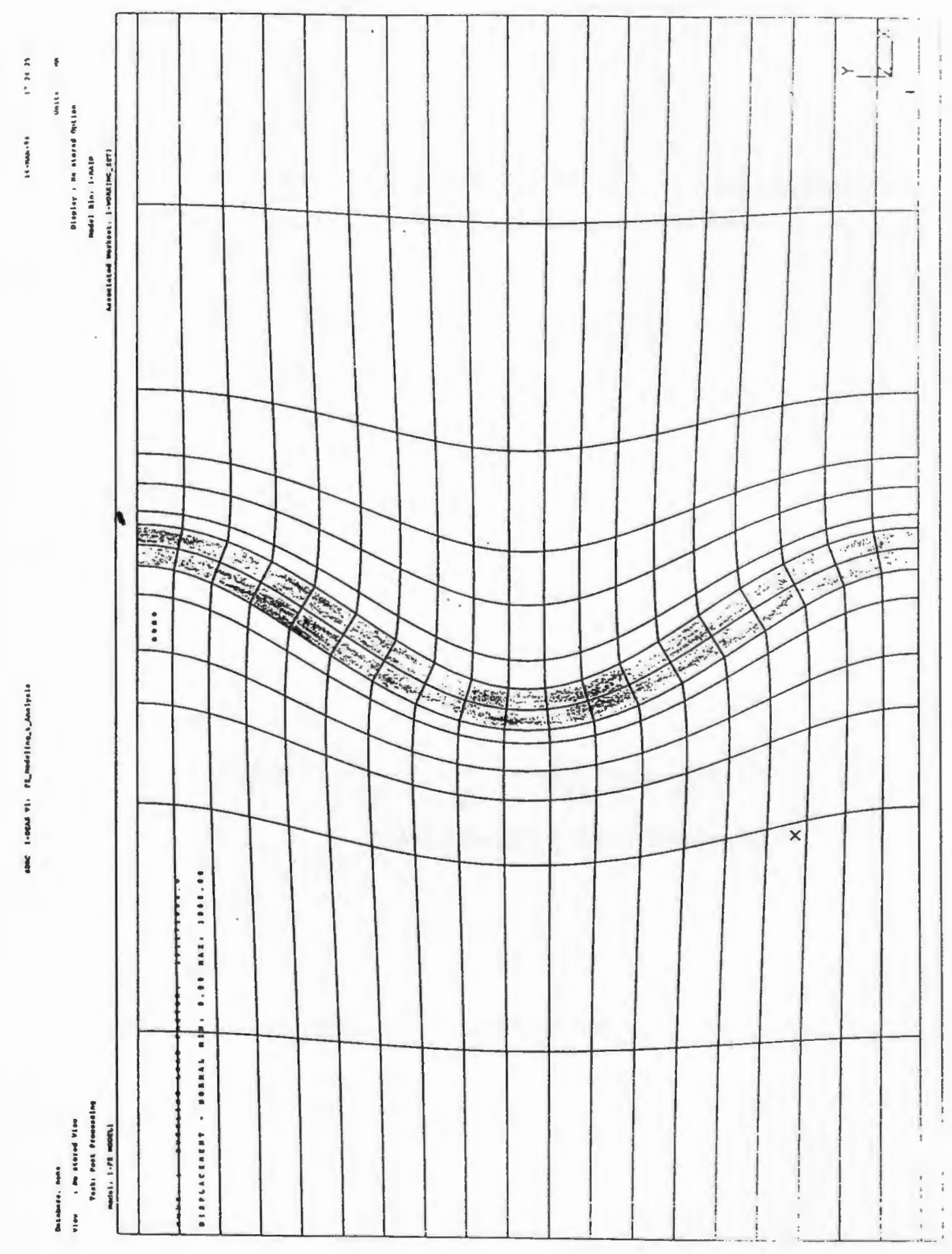

Figure 3.2B Magnified Deformed Single Fiber.Mesh. 


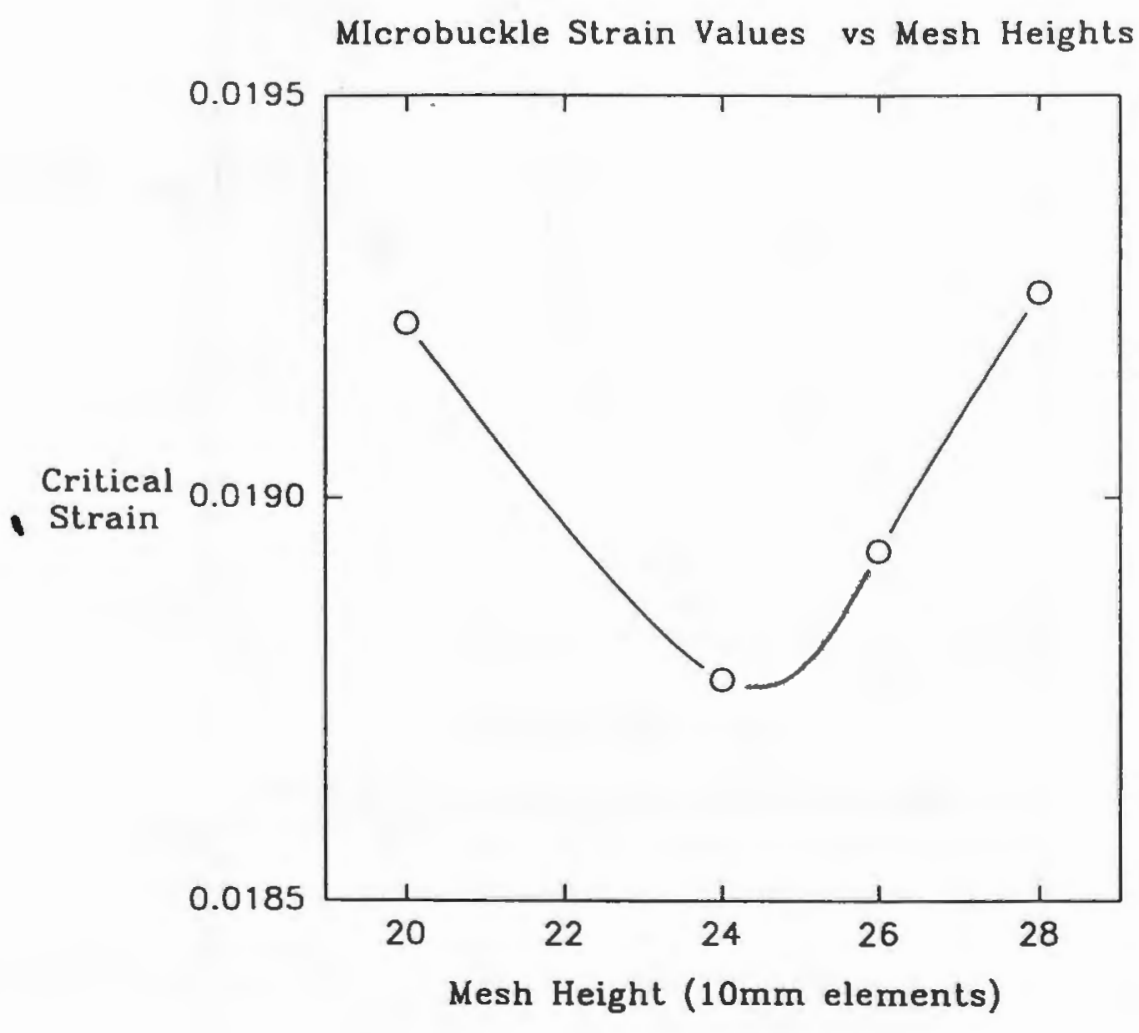

Figure 3.3 Quadratic Curve. 

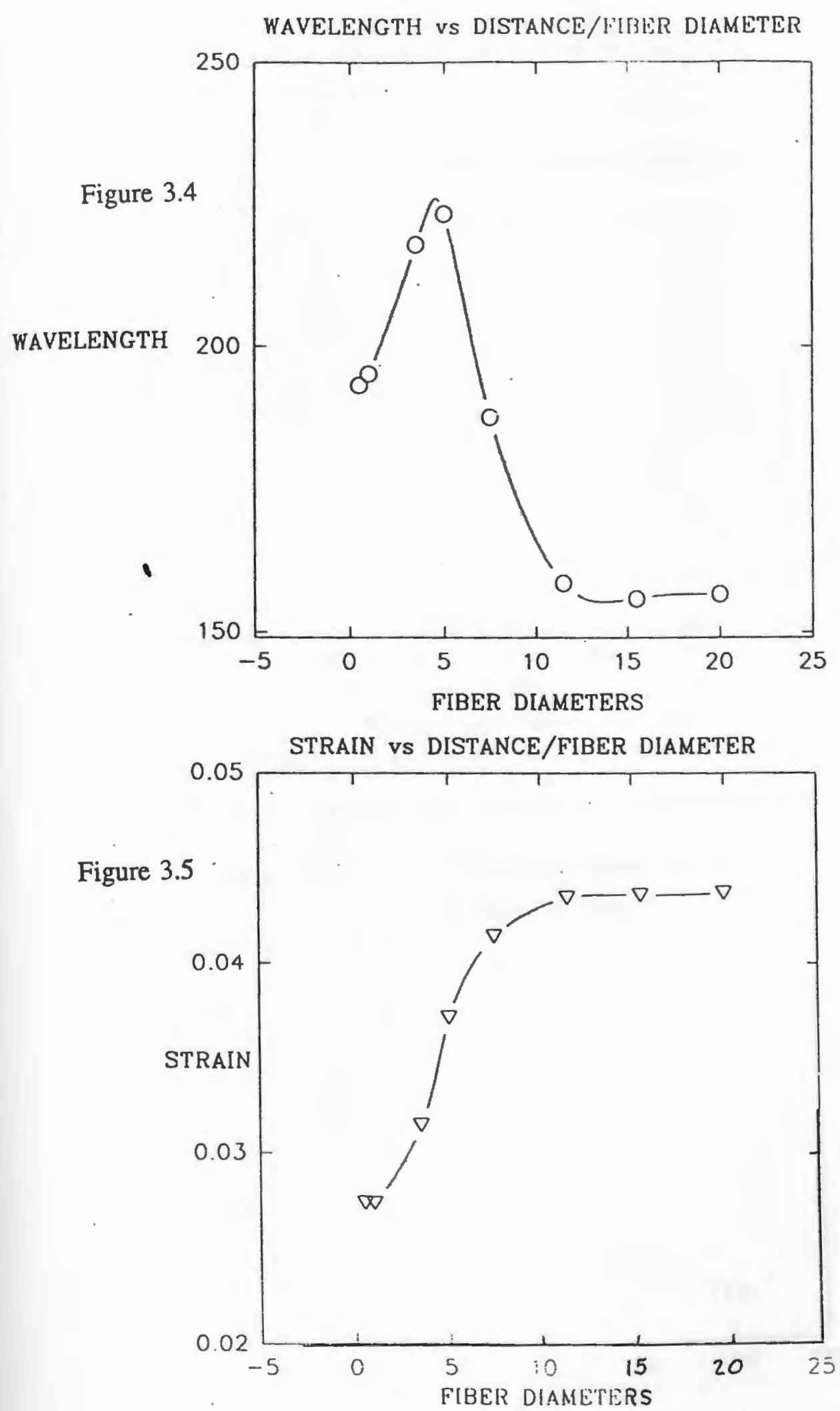
Single Fiber Infinite Support

Critical Microbuckle Strain vs Ef/Em Ratio

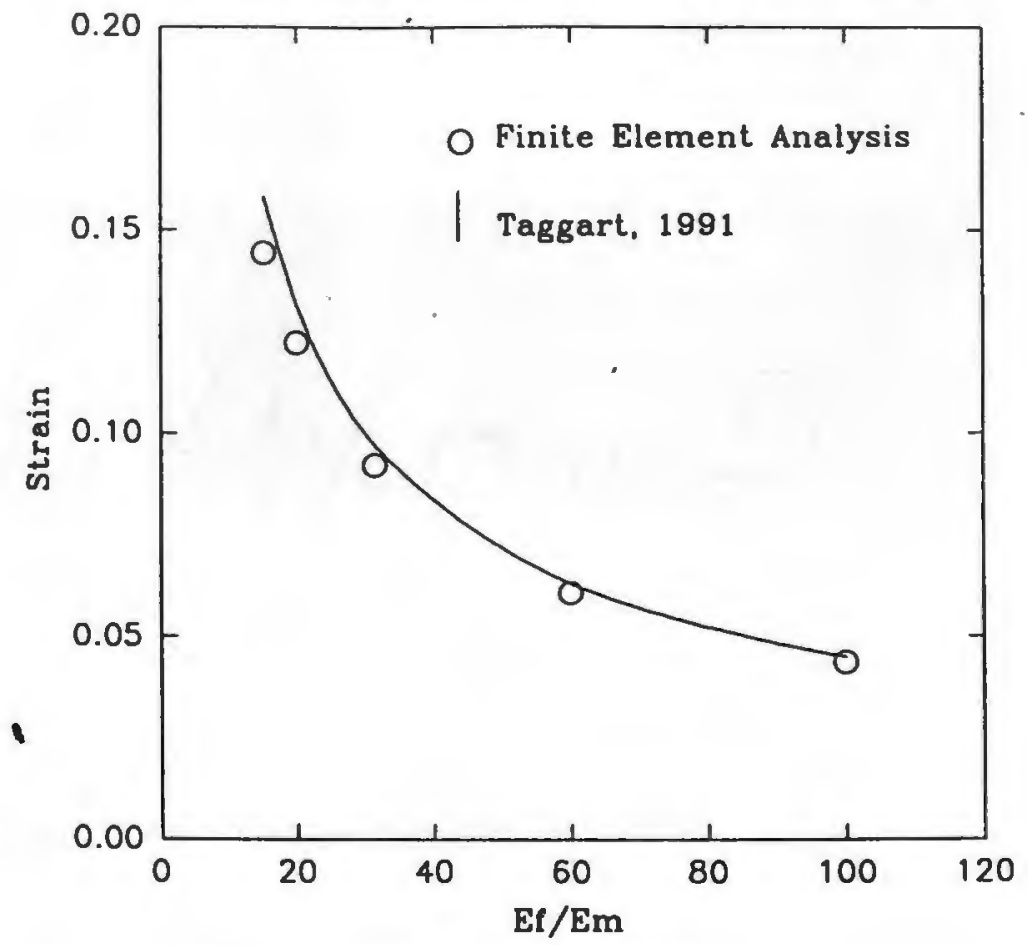

Single Fiber Suface Support

Critical Microbuckle Strain vs Ef/Em Ratio

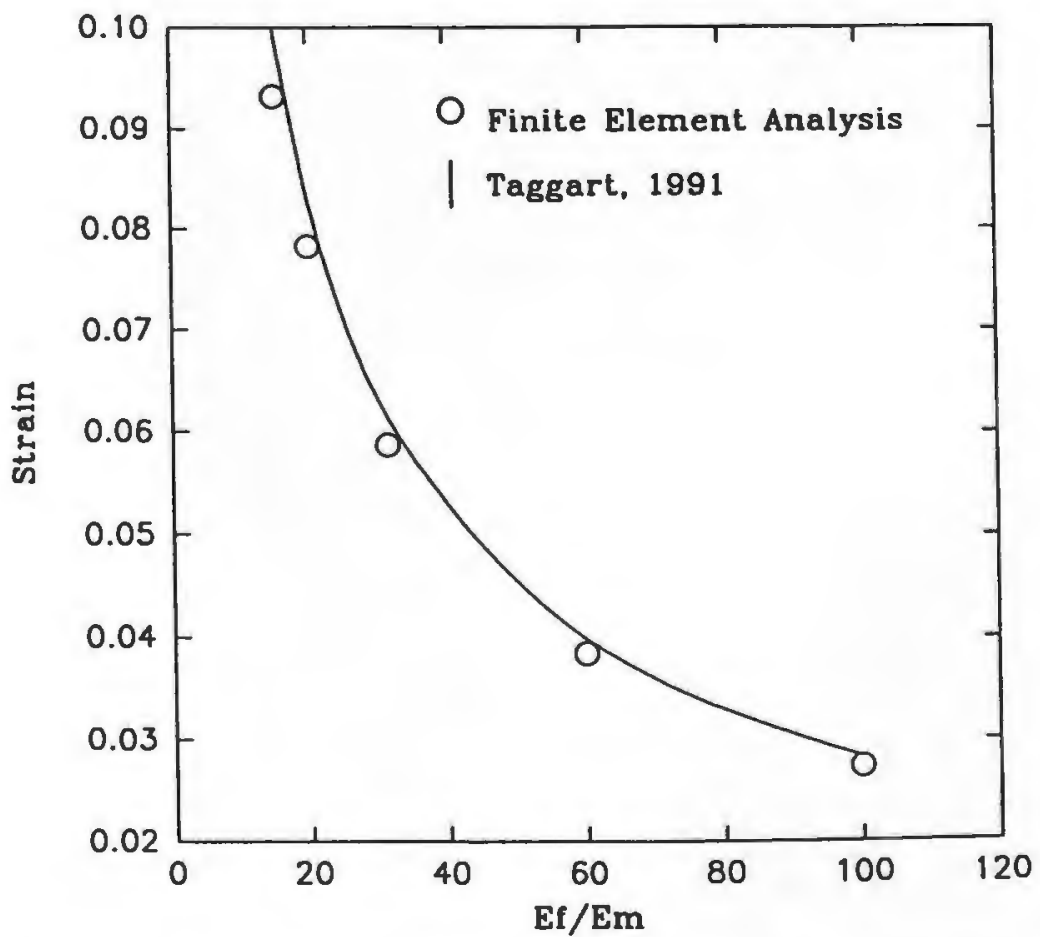

Figure 3.6 Microbuckle Strain -vs- Ef/Em Compared to Taggart. 


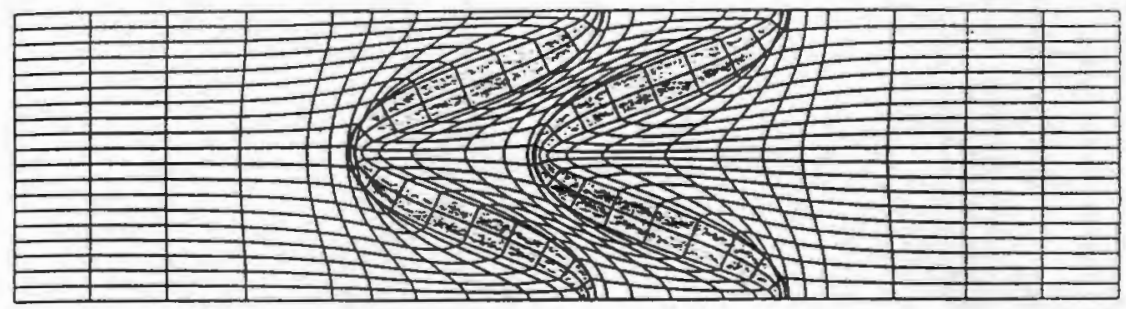

4

Figure 3.7A Dual Fiber Deformed Mesh. 


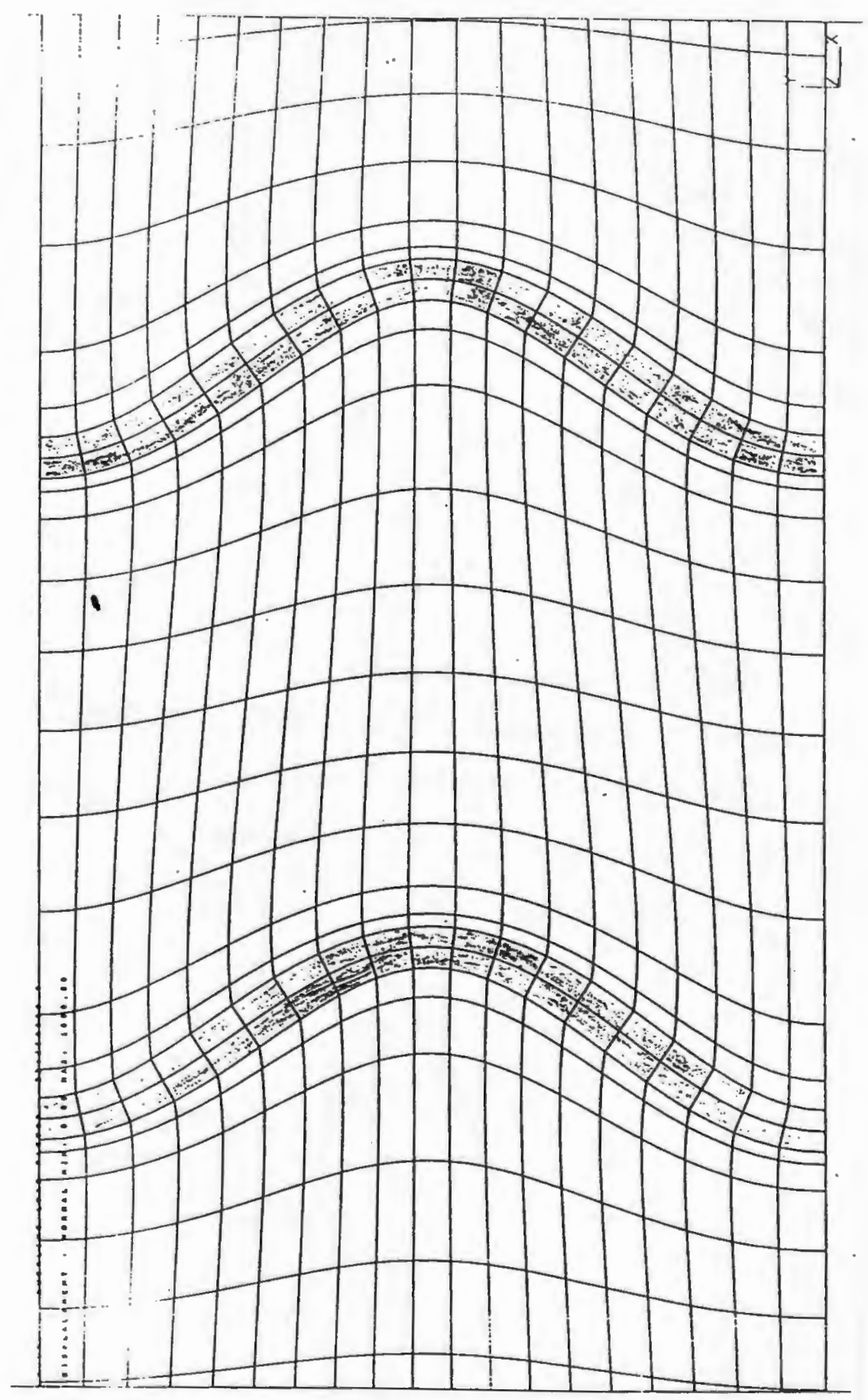

Figure 3.7B . Magnified Dual Fiber Deformed Mesh. 


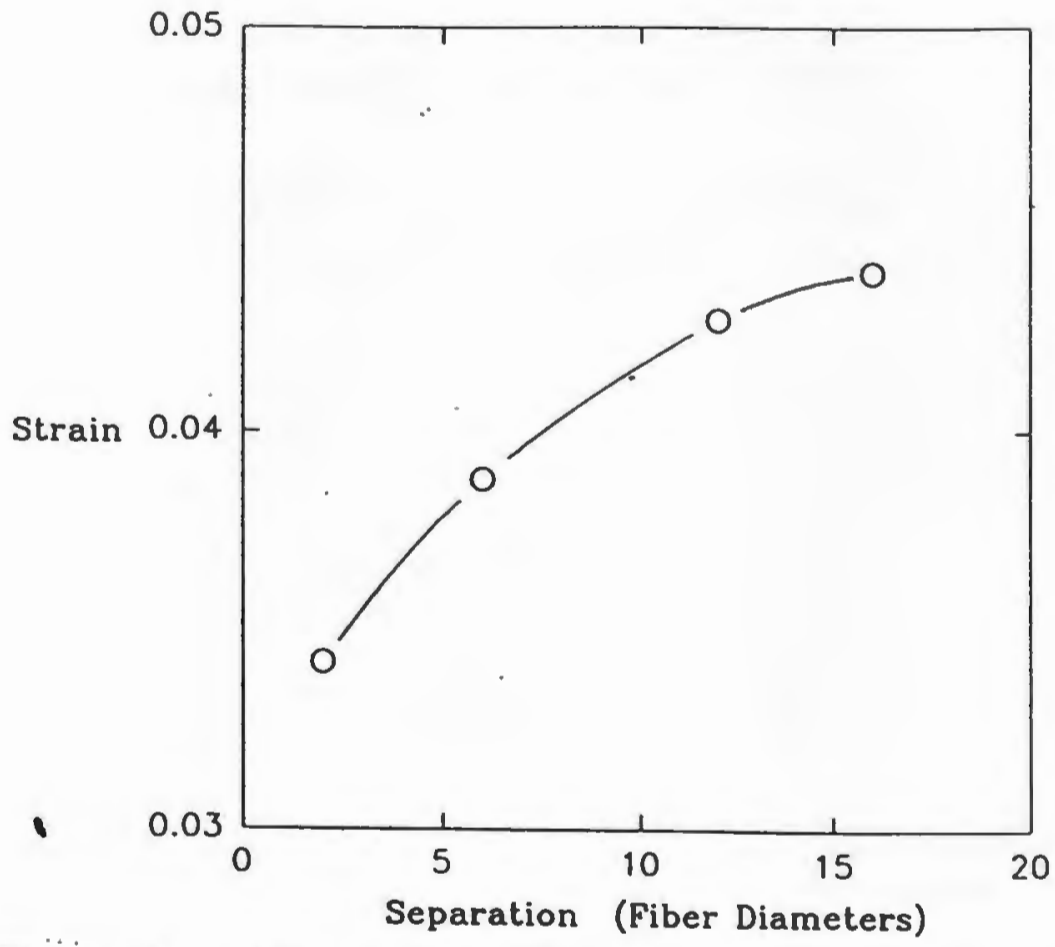

Figure 3.8 Dual Fiber Microbuckle Strain vs Position.

Dual Fiber Microbuckle wavelength vs Fiber position

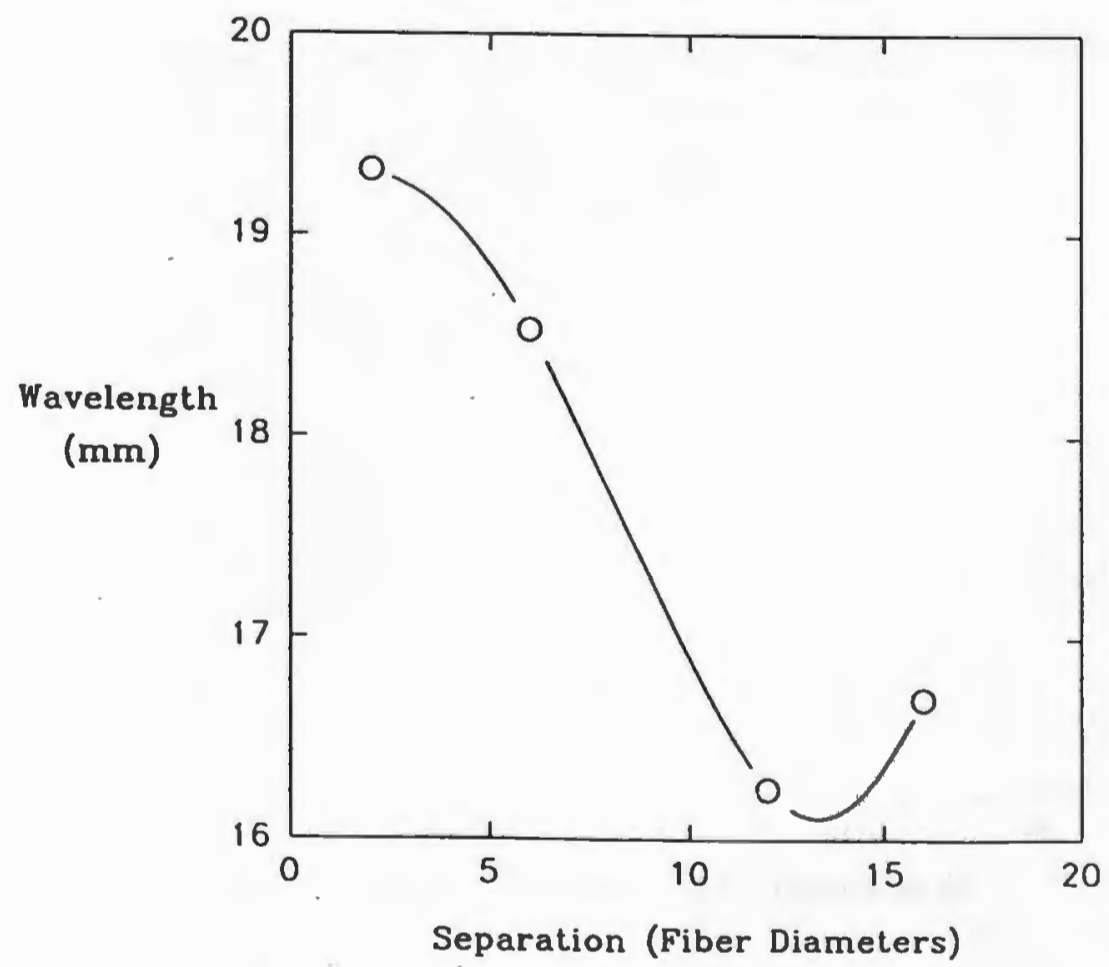

Figure 3.9 Dual Fiber Microbuckle Wavelength -vs- Separation. 
Figure 4.1 Single Fiber FEA -vs- Experiments- Strain.

Single Fiber Microbuckle Strain vs Position

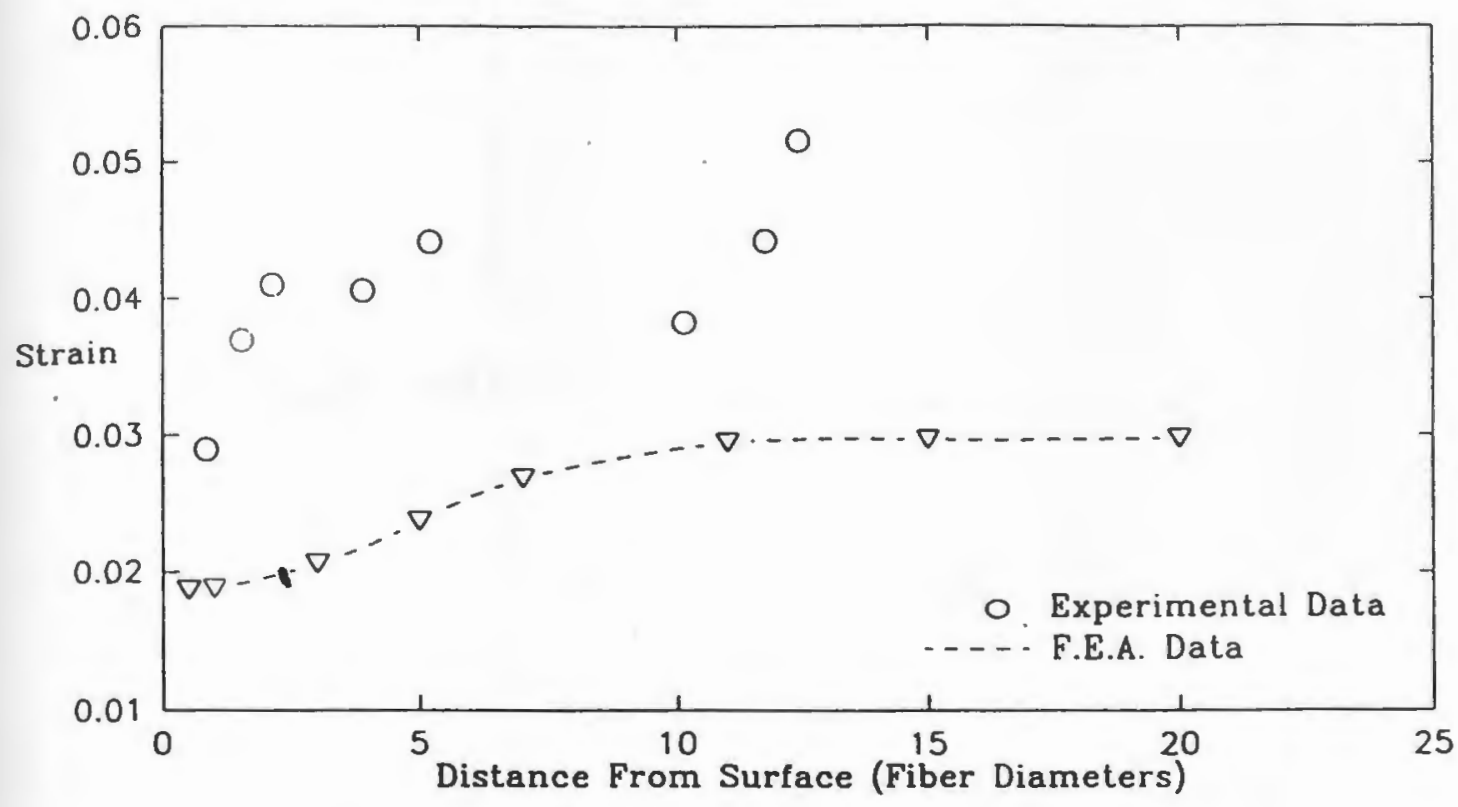

Single Fiber Normalized Microbuckle Wavelength vs Position

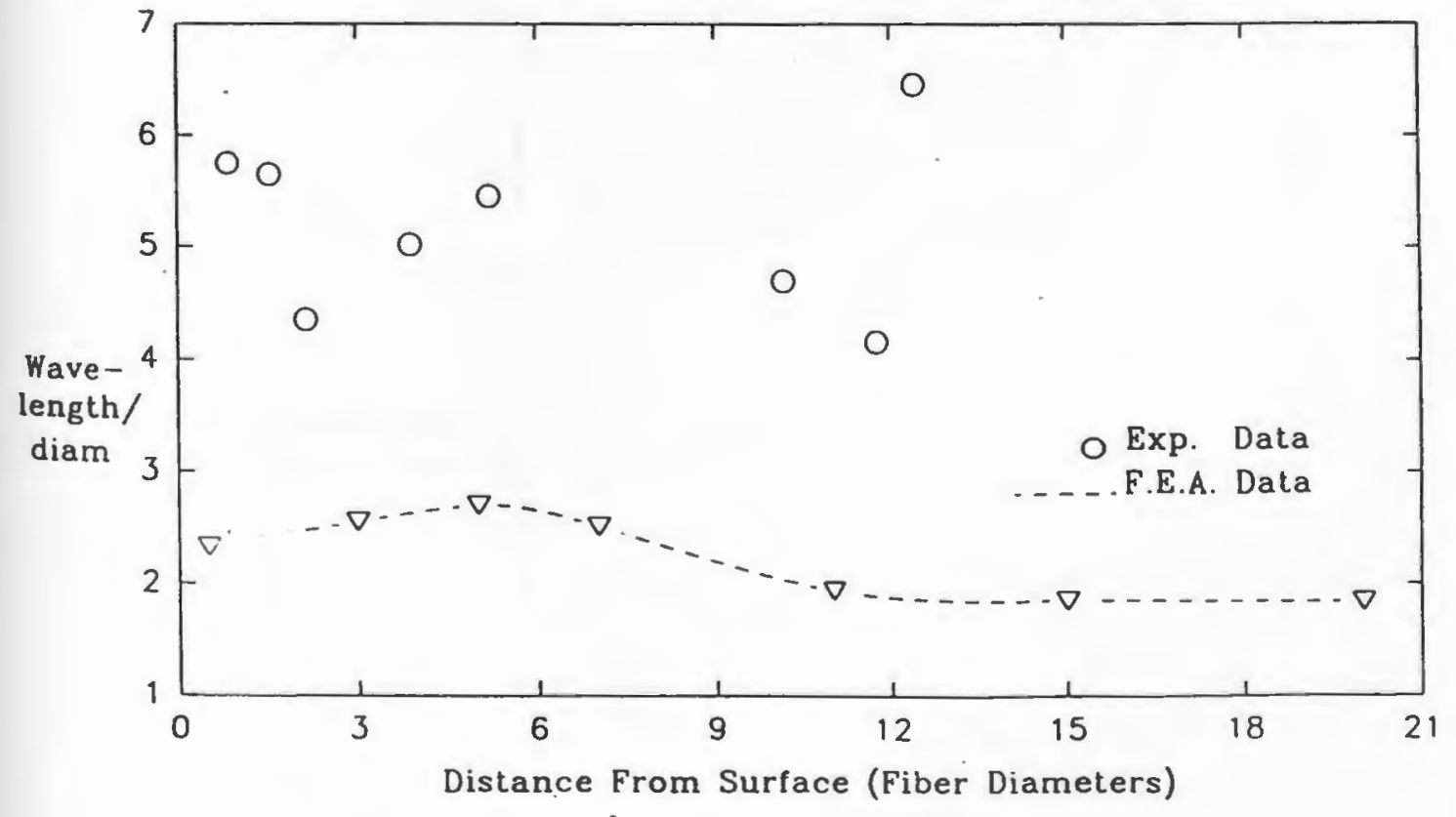

Figure 4.2 Single Fiber FEA -vs- Experiments- Wavelength. 
Figure 4.3 Dual Fiber FEA -vs- Experiments- Strain.

Dual Fiber Microbuckle Strain vs Separation

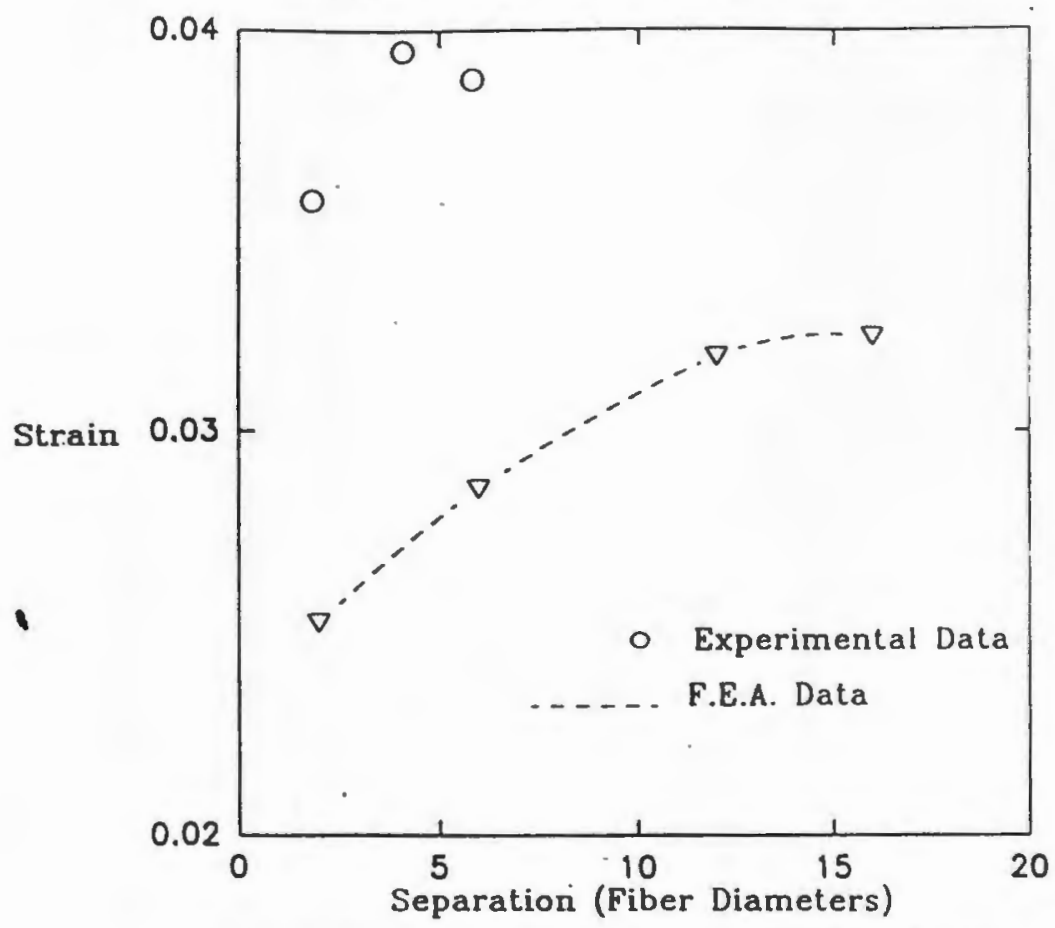

Dual Fiber Microbuckle Wavelength vs Separation

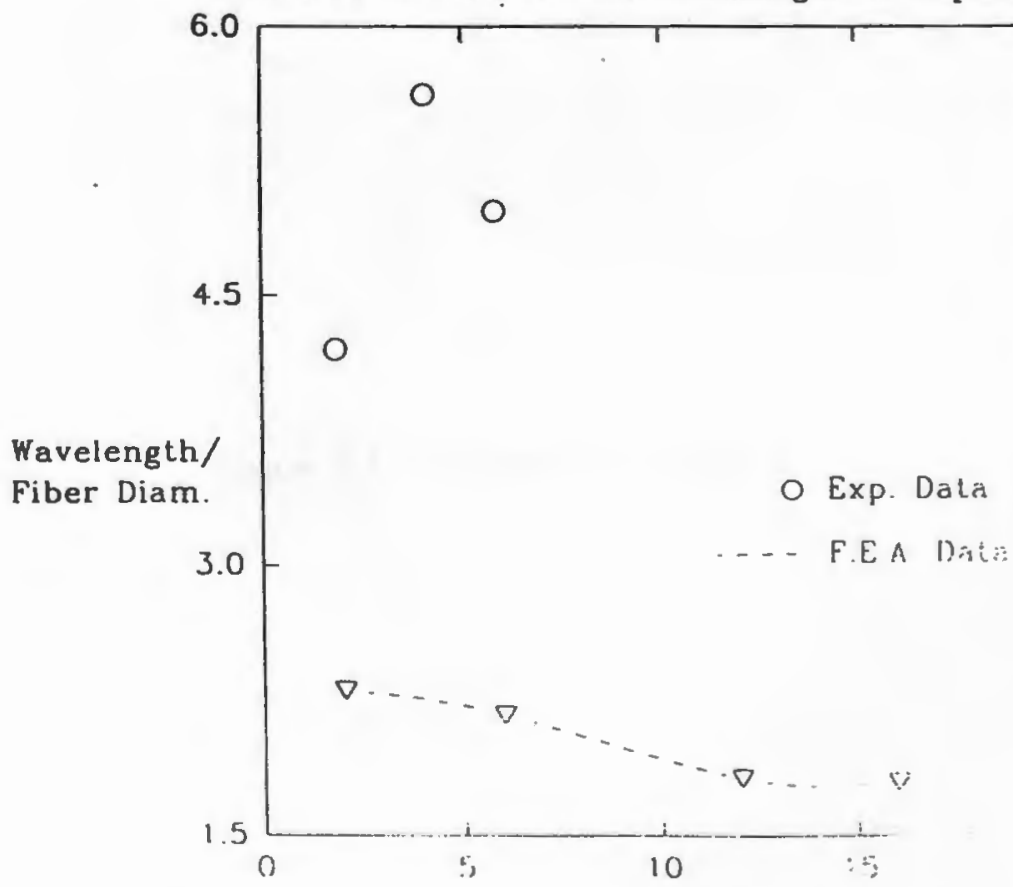

Figure 4.4 Dual Fiber FEA -vs- Experiments- Wavelength. 


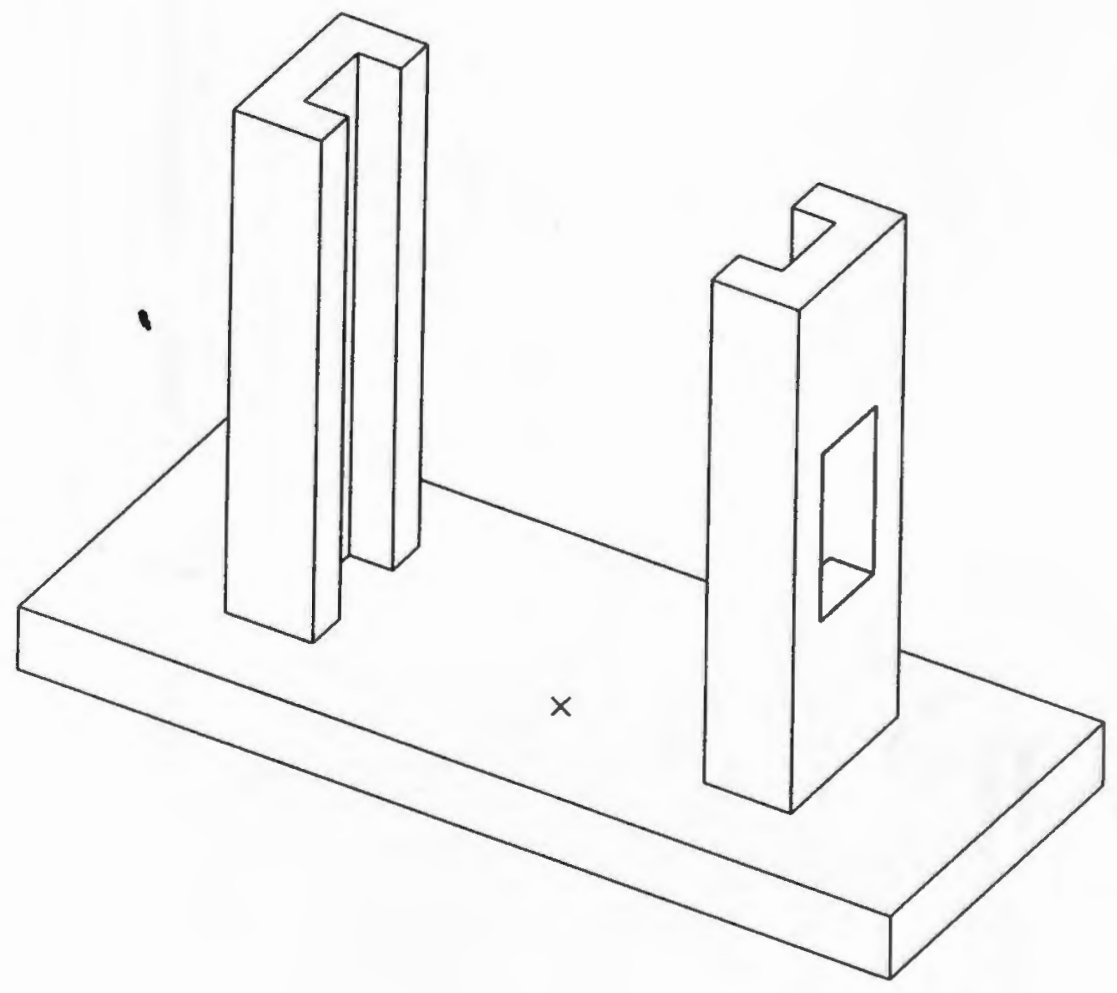

Figure 4.5 Proposed Test Fixture 


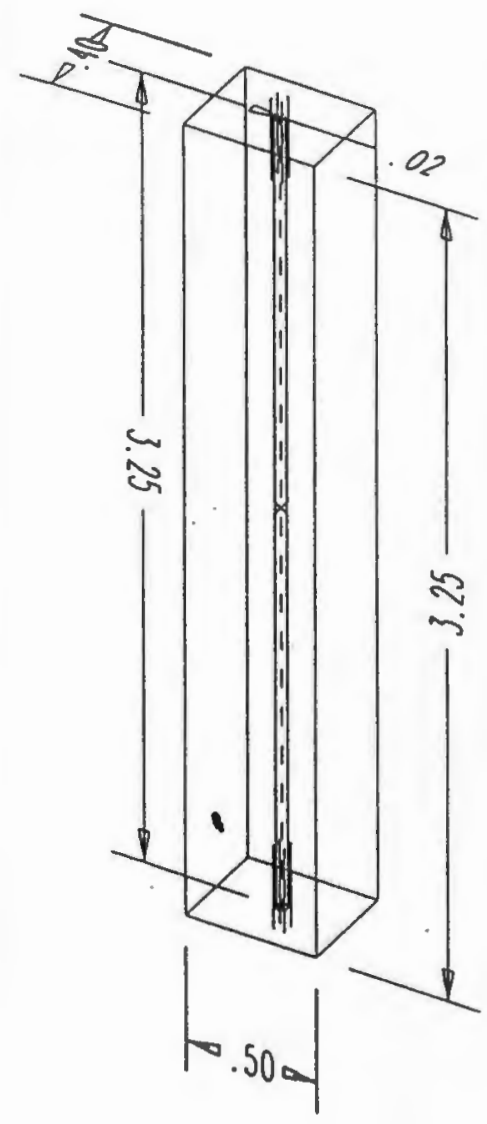

Figure A.1 Single Fiber Specimen.

Figure A.2 Dual Fiber Specimen.

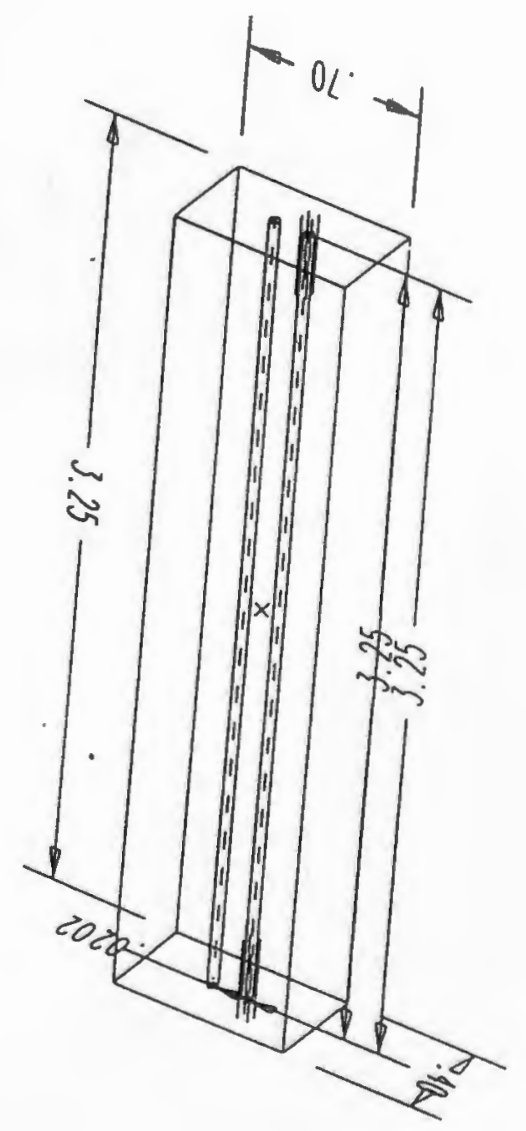




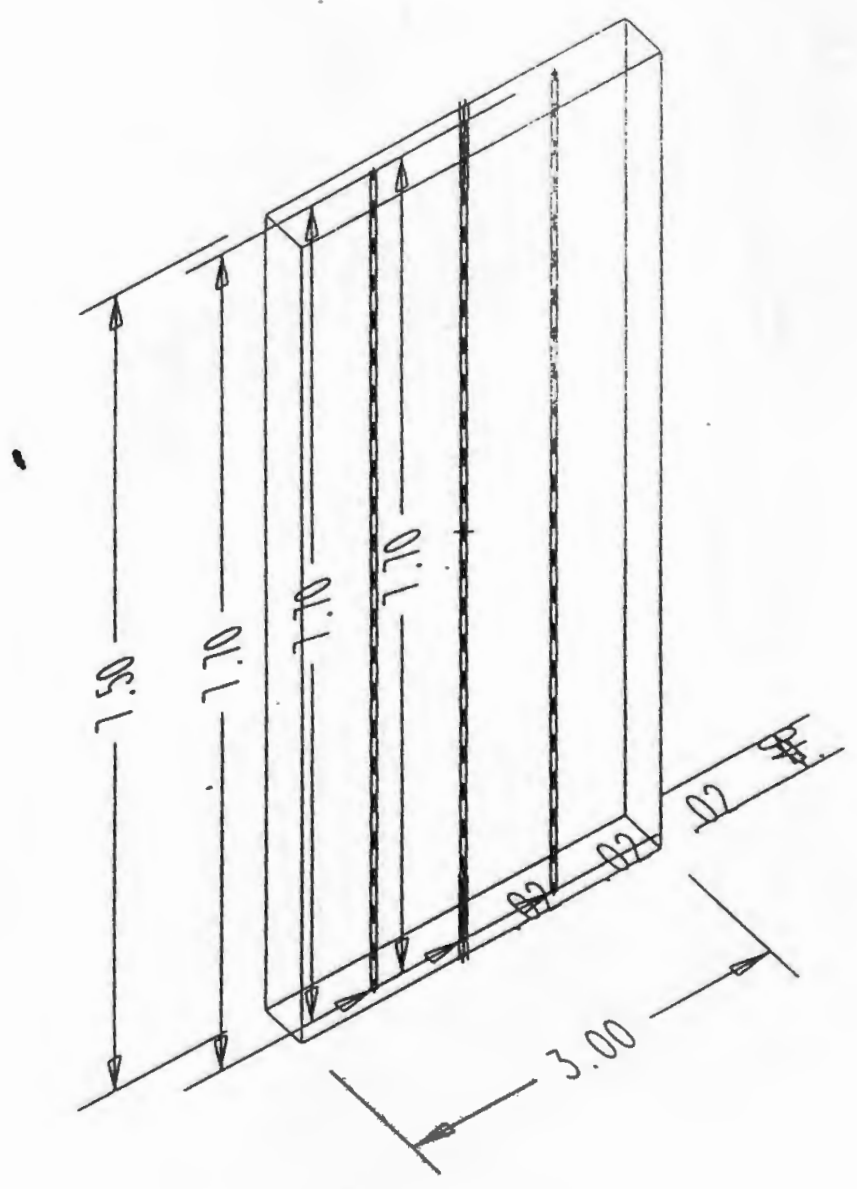

Figure A.3 Plate- Casting. 


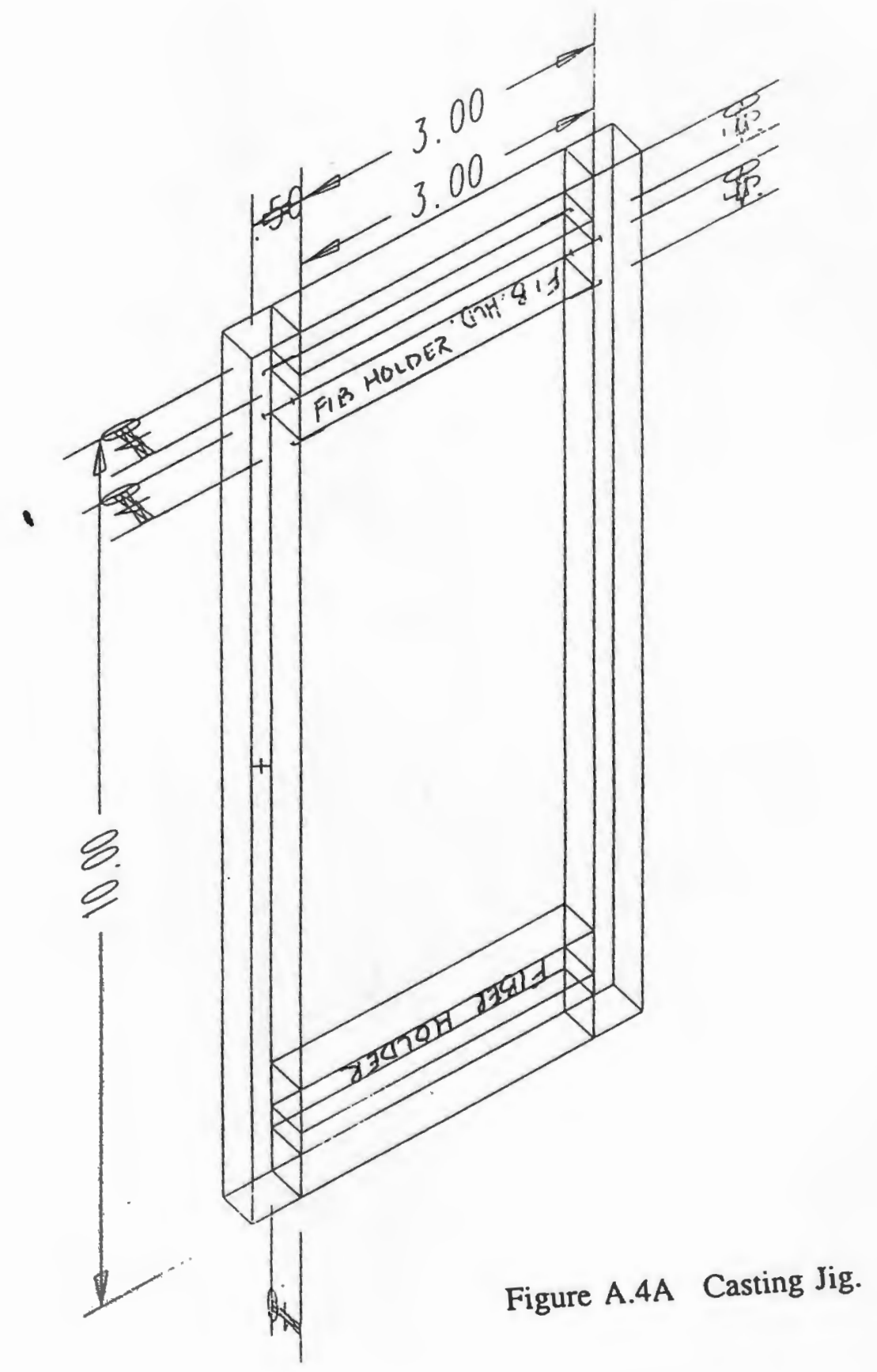




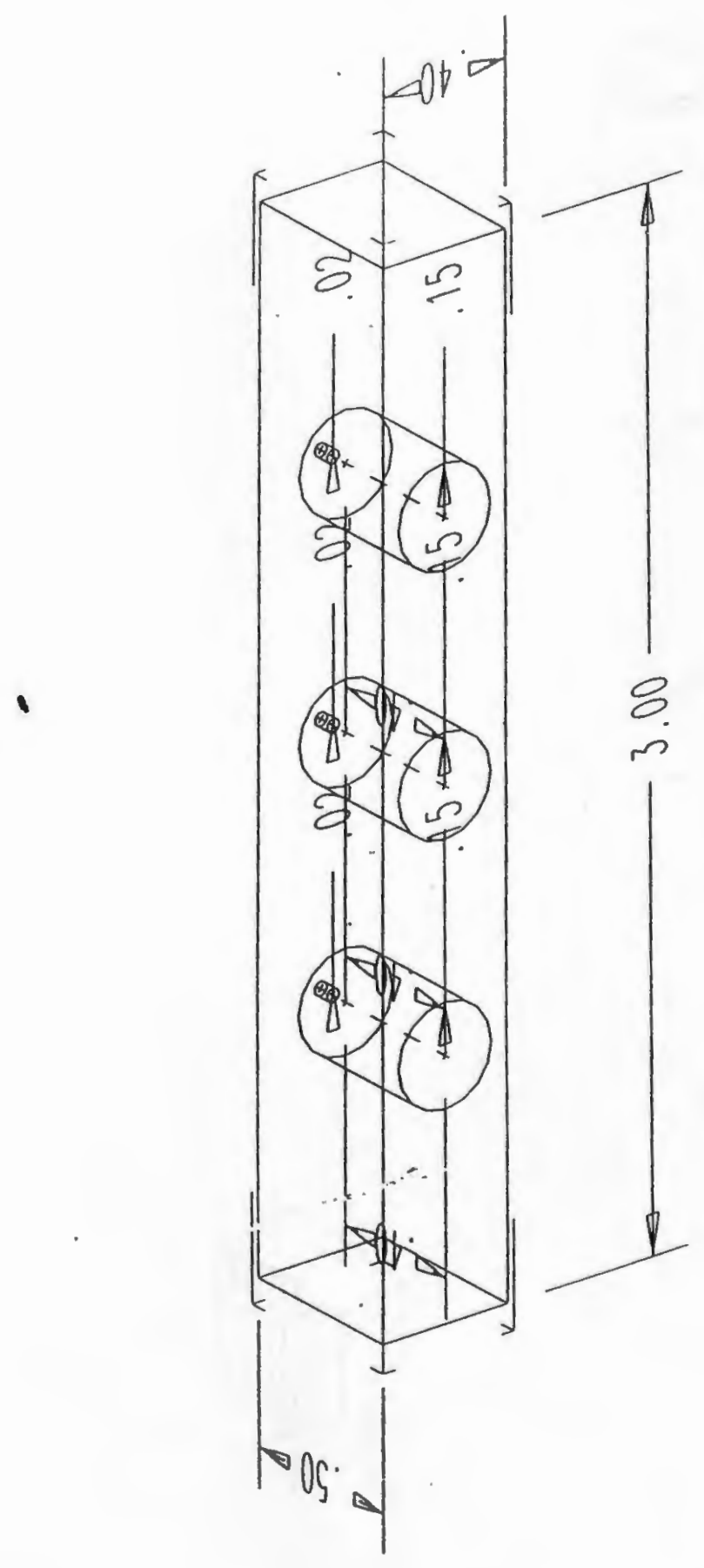

Figure A.4B Fiber Holder. 


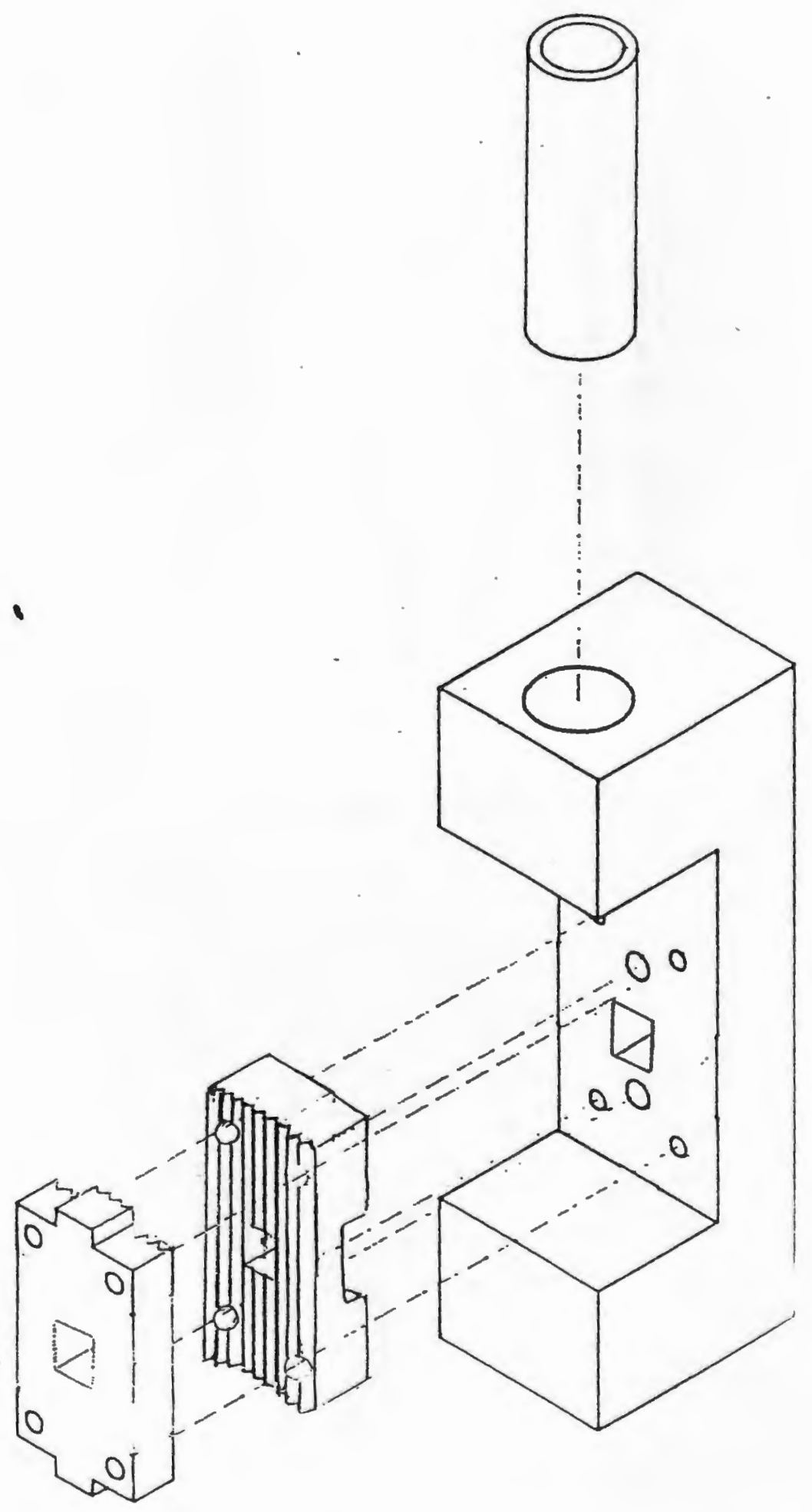

Figure A.5 Compression Fixture Courtesy Hexcei Corp. 


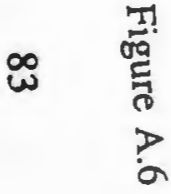

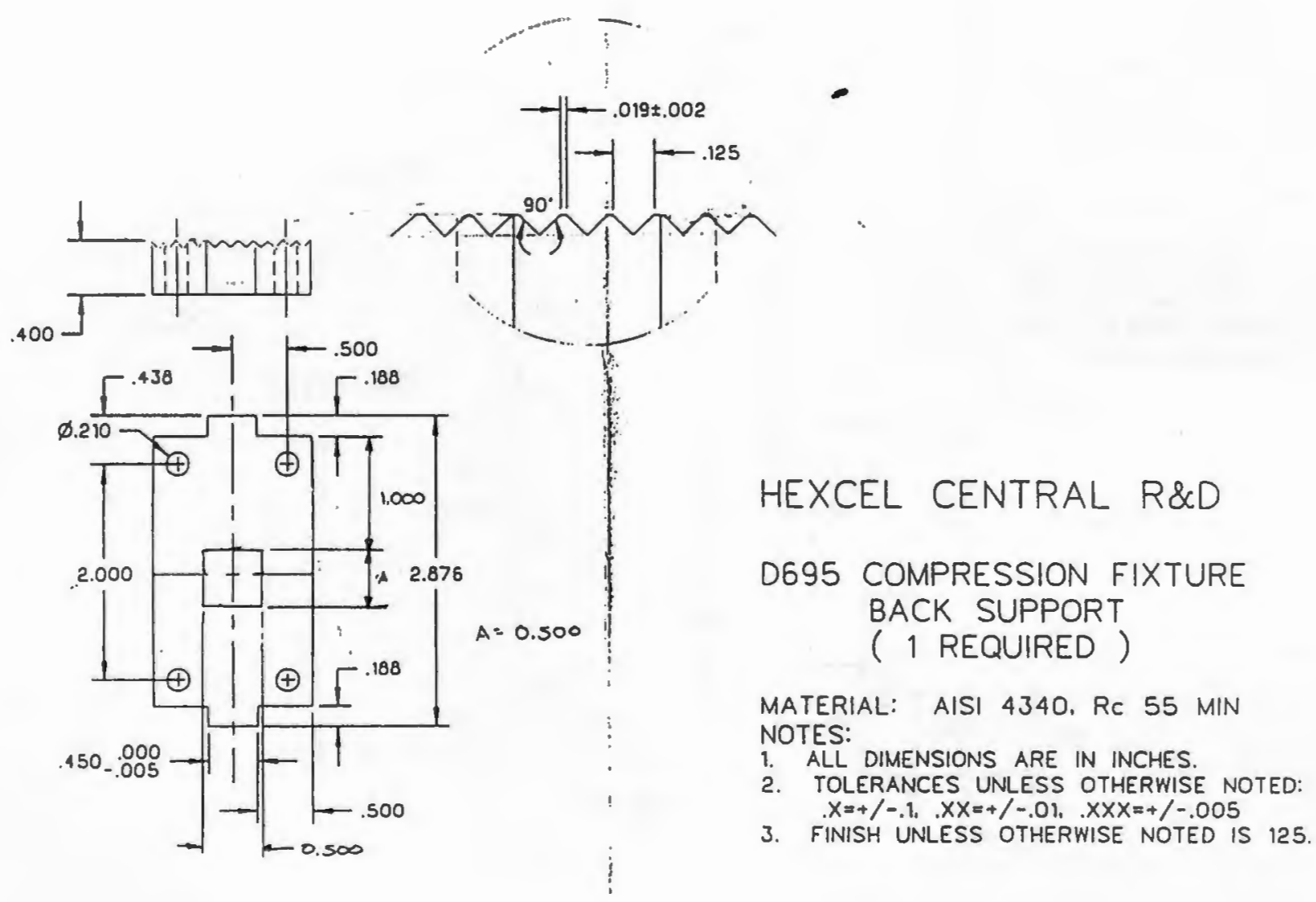



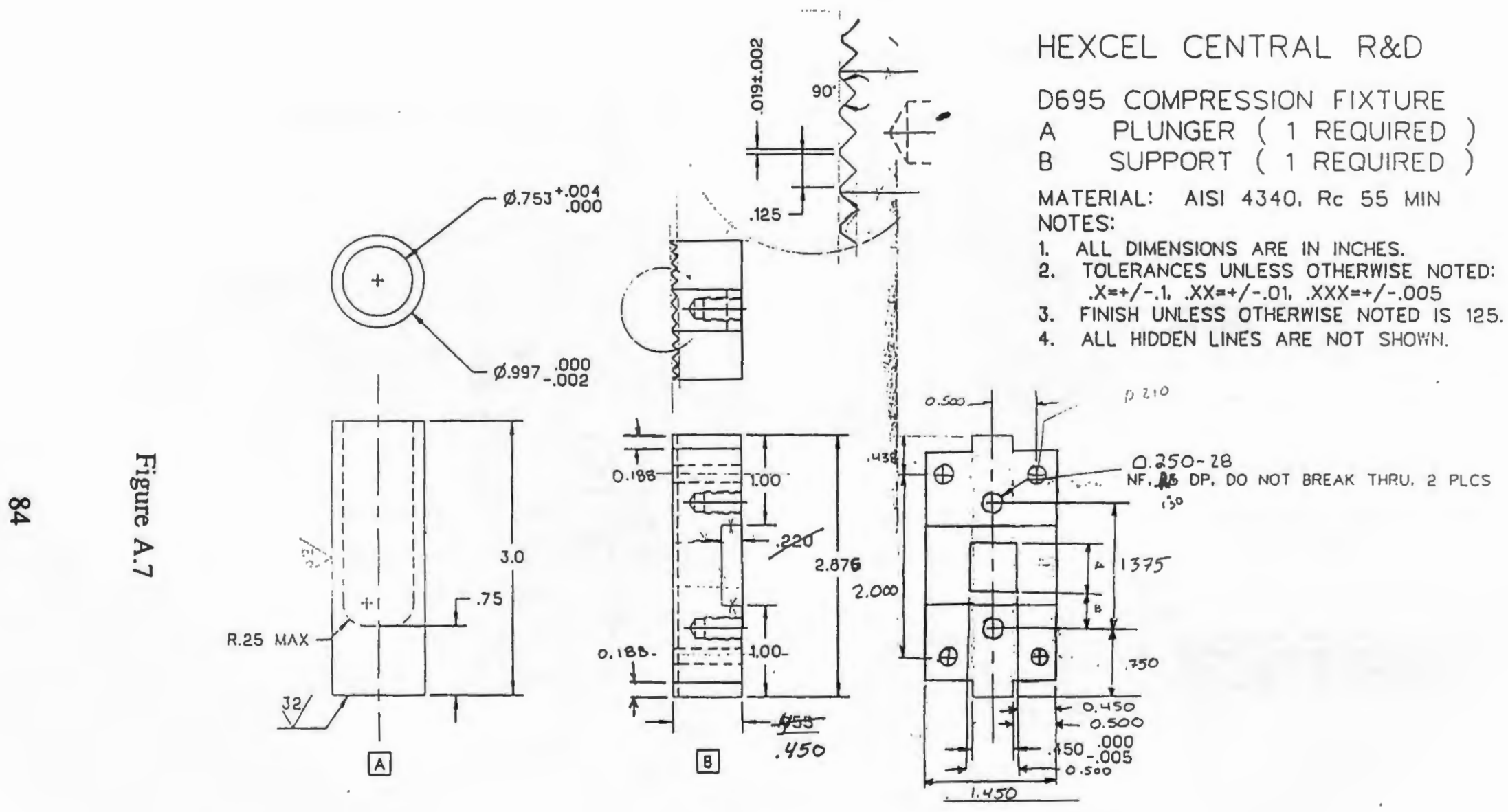

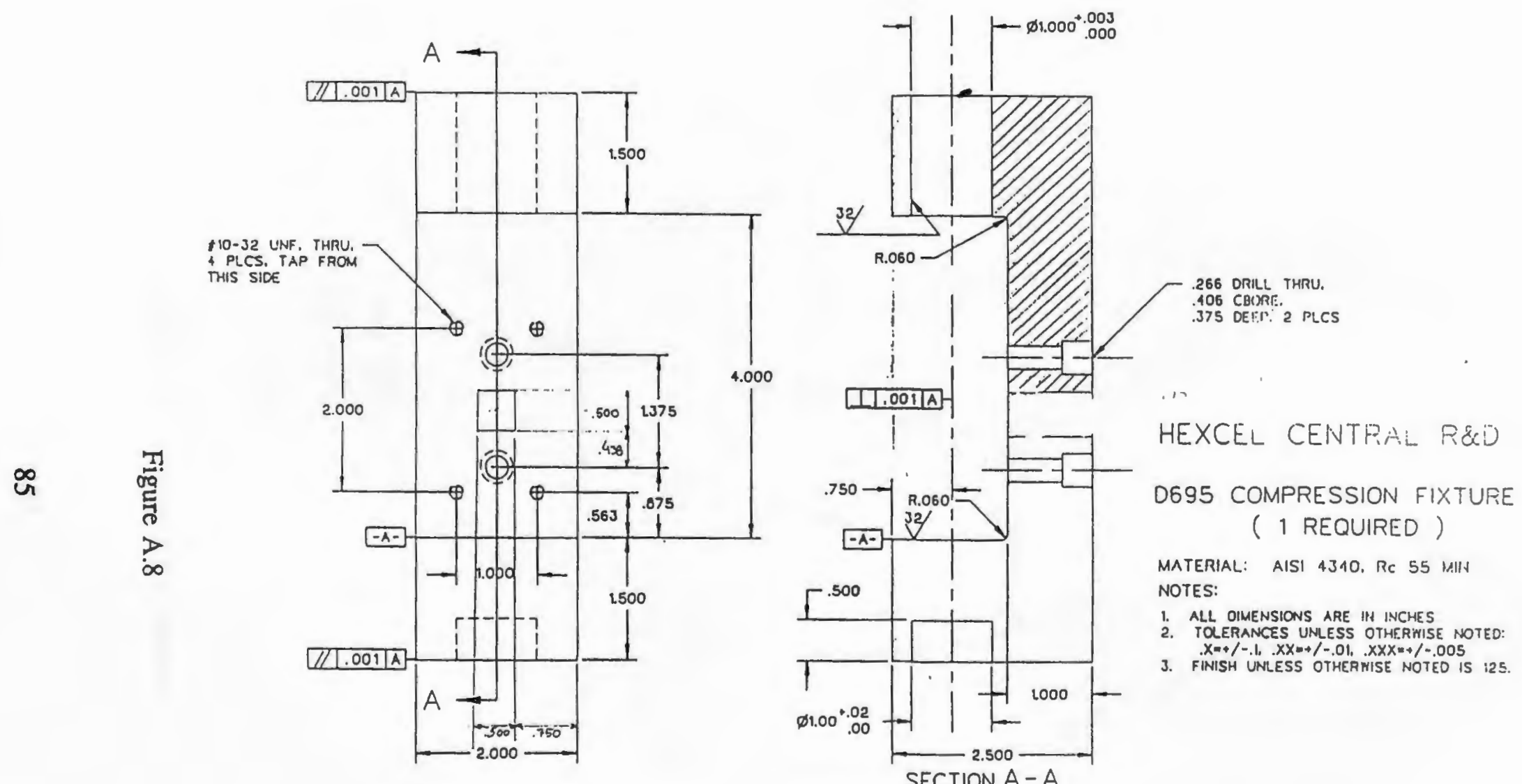

MATERIAL: AISI 4340, RC 55 HIIIN NOTES:

1. ALL OIMENSIONS ARE IN INCHES

2. TOLRANCES UNLESS OTHERWISE NOTED

3. FINISH UNLESS OTHER NISE NOTEO IS i2s. 


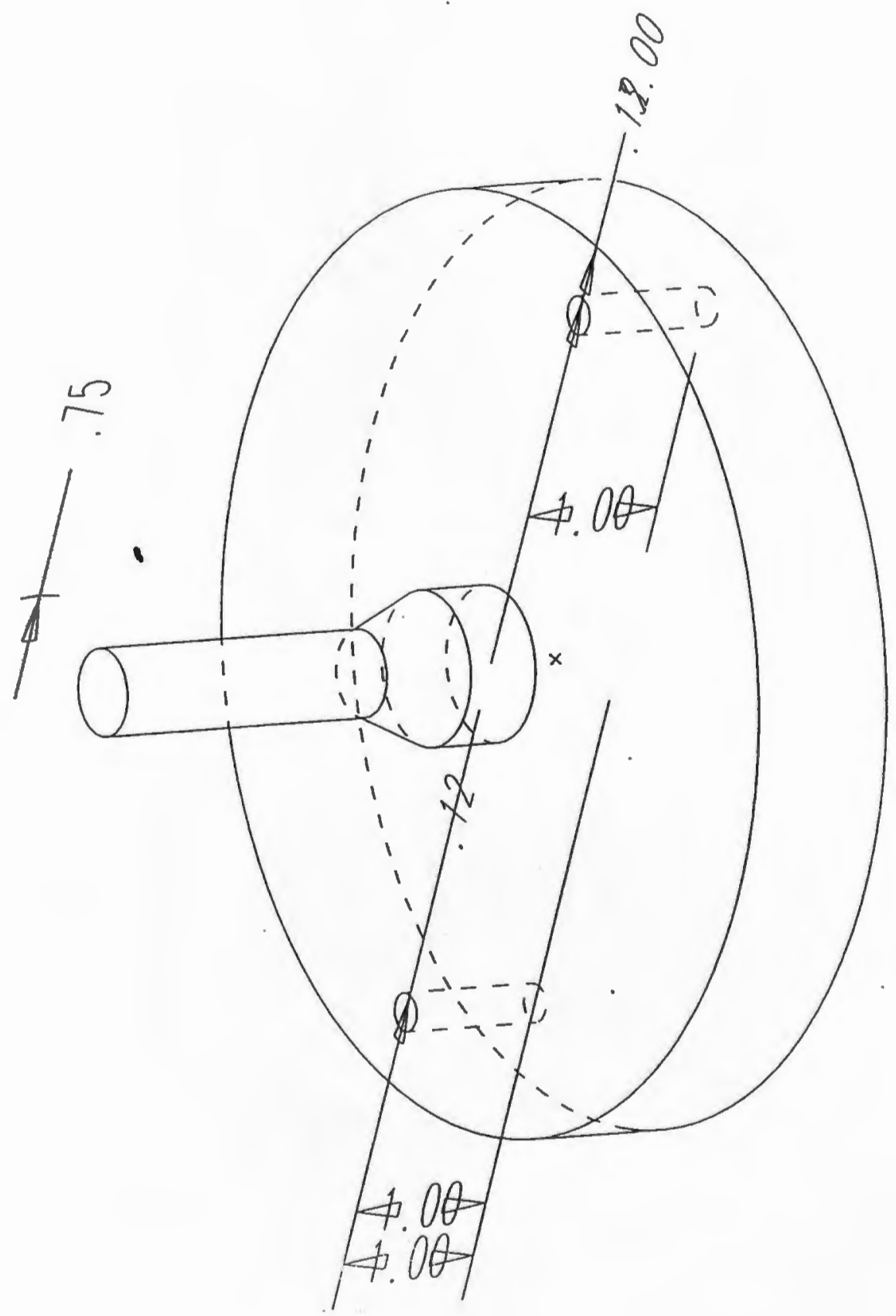

Figure A.9 Adapter for Instron. 


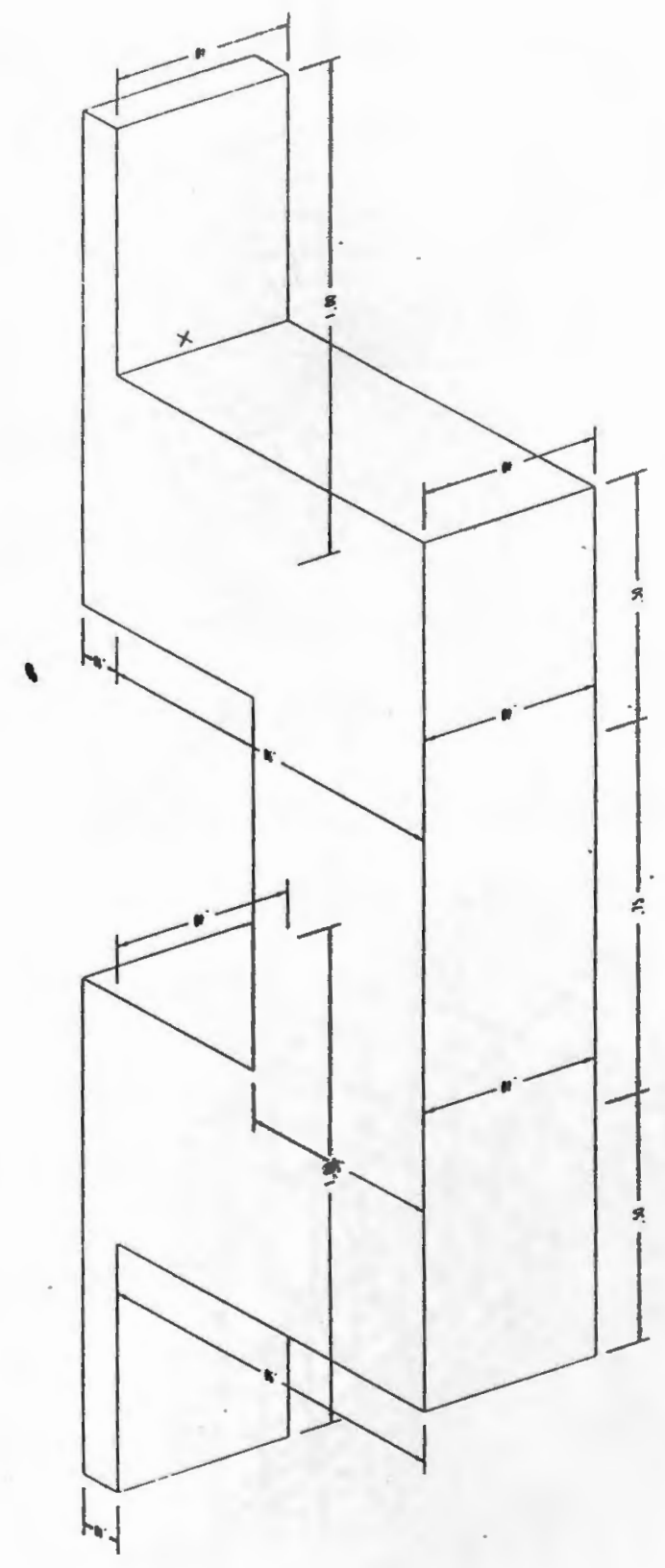

Figure A.10 Side G-ips. 


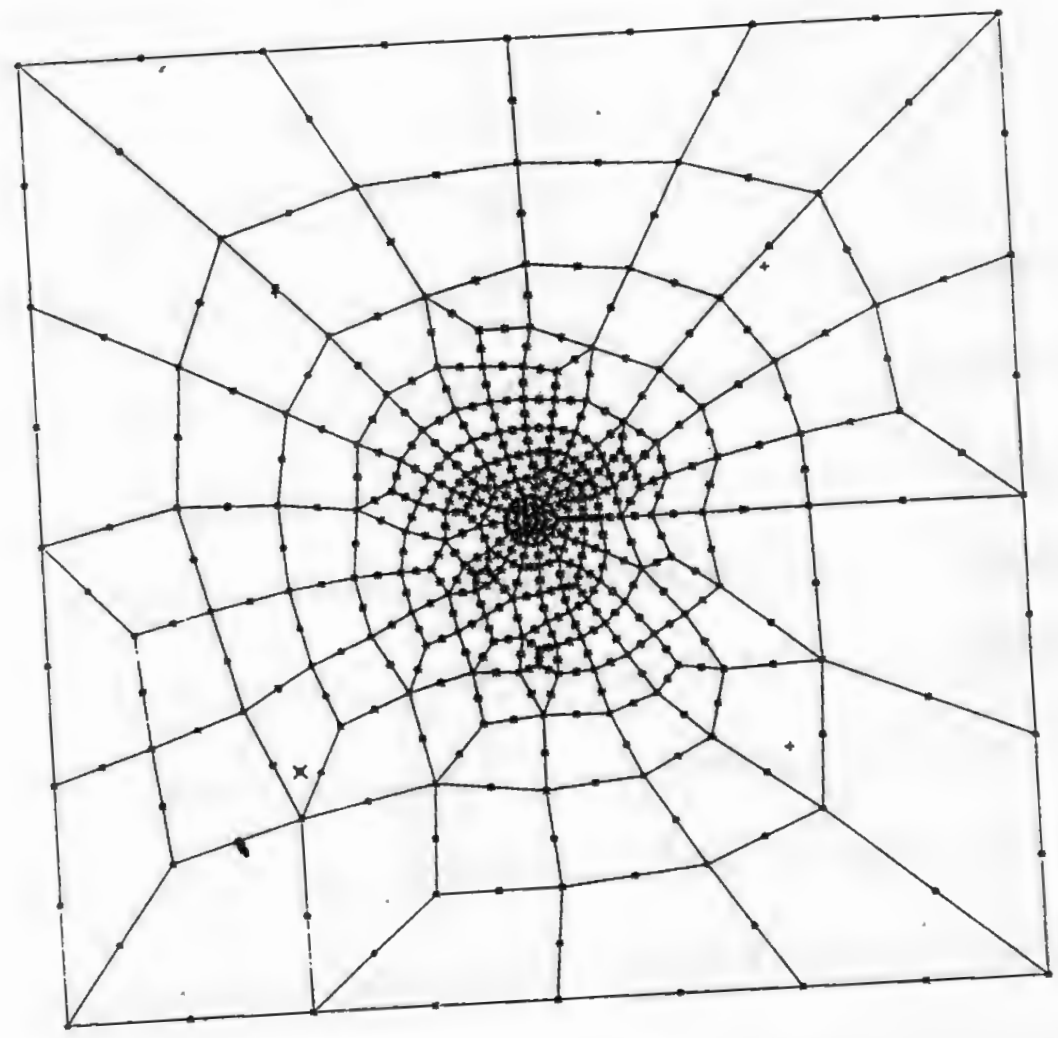

Figure B.1 Base Mesh.

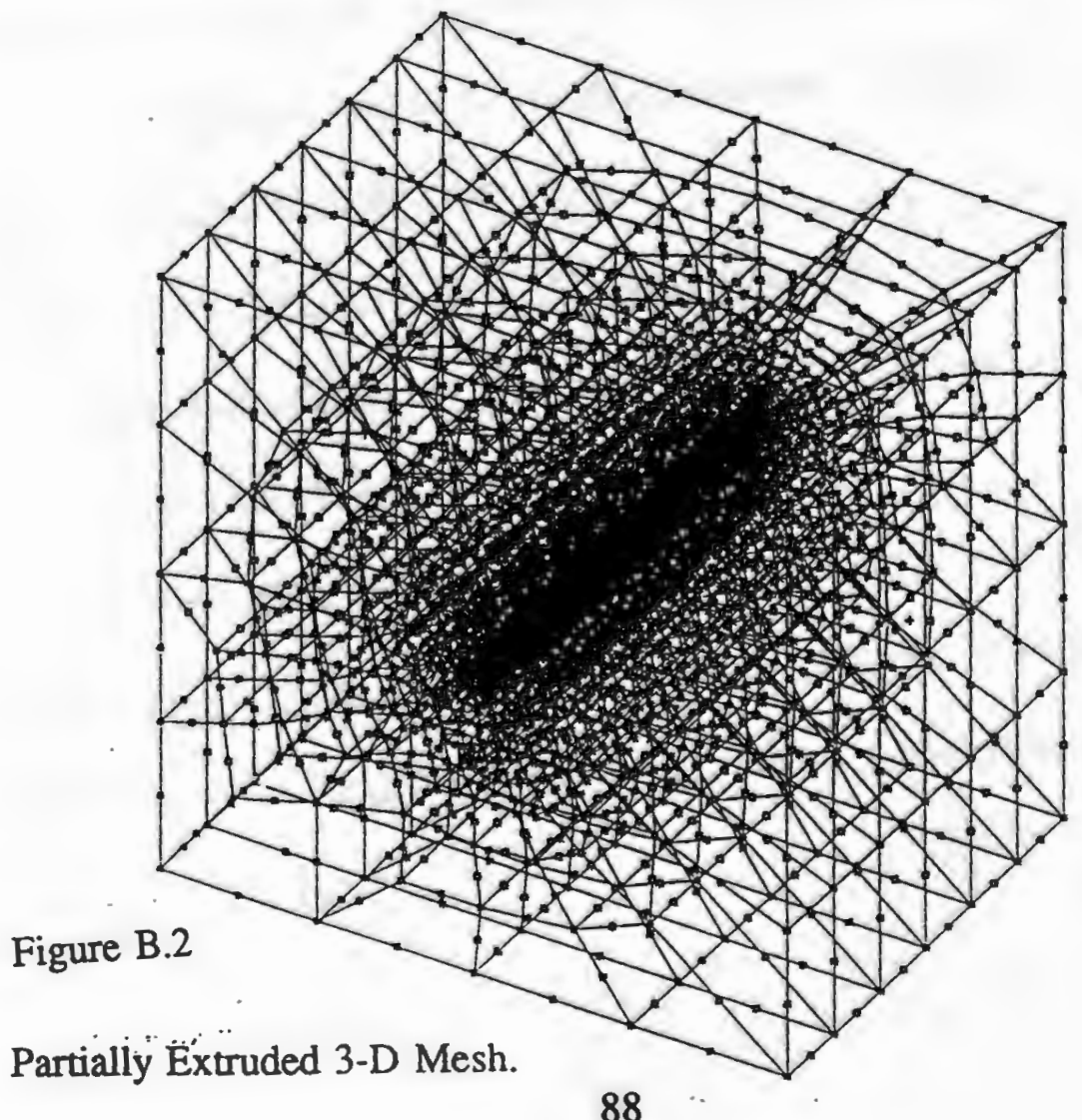




\section{Bibliography}

Agarwal, B. D. and Broutman, L. J., Analysis and Performance of Fiber Composites, Society of Plastics Engineers, 1980 pp. 1-14.

American Society for Testing Materials, D-695-80, American National Standards.

Argon, A.S., "Fracture of Composites", Treatsie on Materials Science and Technology, Vol. 1, Herman ed, Academic Press, New York, 1972.

Bascom, W.D., Boll, D.J., Jensen, R.M., Cordner, L., "Compression Behavior of Single Carbon Filaments Embedded in an Epoxy Polymer", Journal of Composite Materials, Vol. 24, February, 1990, pp. 204-219.

Broady, B. Aristech Corporation, Verbal Communication.

Budiansky, B. and Carrier, G.F., "High Shear Stresses in Stiff-Fiber Composites", Journal of Applied Mechanics, Vol. 51, December 1984, pp. 733-735.

Camponeschi, E.T., "Compression of Composite Materials: A Review", David Taylor Research Center, November 1987.

Chung, W.Y. and Testa, R.B., Journal of Composite Materials, Vol 3, 1969, pp. 58-80. Cook, R.D., Malkus, D.S., Plesha, M.E., Concepts and Applications of Finite Element Analysis, Third Ed., Wiley, 1989, New York.

Evans, A.G. and Adler, W.F., "Kinking as a mode of Structural Degradation in Carbon Fiber Composites", Acta Metallurgica, Vol. 26, 1978, pp. 725-738.

Gere, J.M., Tioshenko, S.P. Mechanics of Materials, 2nd ed., Brooks Cole, 1984, pp. 551567. 
Greszczuk, L.B. "Microbuckling Failure of Circular Fiber-Reinforced Composites", AIAA Journal, Vol. 13, No. 10 October,1975, pp. 1311-1318.

Greszczuk, L. B., "On Failure Modes of Unidirectional Composites under Compressive Loading," Proceedings of the Second USA-USSR Symposium, G.C Sih ed. March 1981. pp 231-246.

Greszczuk, L.B., "Interfiber Stress in Filamentary Composites", AIAA Journal, Vol. 9, July, 1971, pp. 1274-1280.

Hahn, H.T., Williams, J.G., "Compression Failure Mechanisms in Unidirectional 'omposites", Composite Materials: Testing and Design (Seventh Conference), ASTM STP 893, J.M. Whitney, Ed., American Society for Testing Materials, Philadelphia, 1986. pp. 115-139.

Hawthome, H.M., Teghtsoonian, E., "Axial Compression in Carbon Fibers", Journal of Materials Science, Vol. 10, 1975, pp 41-51.

Hui, C.Y. and Lagoudas, D.C., "Stress Fields of Interface Dislocations", Journal of Applied Mechanics, Vol. 57, March 1990, pp. 247-249.

Jelf, P.M. and Fleck, N.A., "Compression Failure Mechanisms in Unidirectional Composites", Journal of Composite Materials, Vol. 26, No. 18, 1992 pp. 2706.

Lager, J.R. and June, R.R., "Compressive Strength of Boron-Epoxy Composites", Journal of Composite Materials, Vol. 3, January, 1969 pp. 48-52.

Lagoudas, D.C., Tadjbakhsh, I. and Fares, N., "A New Approach to Microbuckling of Fibrous Composites", Journal of Applied Mechanics, June, 1991, pp. 1-7. 
Lagoudas, D.C. and Saleh, A.M., "Comparison Between Compressive Strength Due to Microbuckling and Kinking in Fibrous Composites", Proceedings of the International Conference of Composite Materials, July 1991, pp. 35e1-35e9.

Lagoudas, D.C. and Saleh, A.M.,"Compressive Failure due to Kinking of Fibrous Composites", Journal of Composite Materials, Vol. 27, No.1, 1993, pp. 83-106. Lanir, Y. and Fung, Y.C.B. "Fiber Composite Columns Under Compression", Journal of Composite Materials, Vol 6., July, 1972, pp. 387-401.

Measurements Group, Student Manual for Strain Gage Technology, Vishay, 1991.

Minahen, T.M. and Knauss, W.G., "A Note on Microbuckling in Unidirectional Fibrous Composites", Journal of Applied Mechanics, Vol. 56, December, 1989, pp. 983 985.

Orowan, E., " A Type of Plastic Deformation New in Metals," Nature, Vol. 149, 1949, pp. 643-644.

Piggot, M.R., Sandai, A., Chua, P.S. and Andison, D., Mechanical Interactions in the Interphasial Region of Fibre Reinforced Thermosets," Composite Interfaces, $\mathrm{H}$. Ishida and J.L. Koenig eds., Amsterdam.

Pike, T. Verbal Communication, April 1992.

Rosen, B.W., Fiber Composite Materials, American Society for Metals, pp. 37-75.

Sadowsky, M.A., and Pu, S. L., Hussain, M.A., Journal of Applied Mechanics, December, 1967, pp. 1011-1016.

Scheurch, H., AIAA Journal, Vol.4, no. 1, January, 1966, pp. 102-106.

Shukla, A. and Khanna, S.K., "Effect of Fiber Reinforcement on Dynamic Crack Growth 
in Brittle Matrix Composites," Journal of Engineering Materials and Technology, January 1993, pp. 140-145.

Sohi, M.M., Hahn,H.T., Williams, J.G., "The Effect of Resin Toughness and Modulus on Compressive Failure Modes of Quasi-Isotropic Graphite/Epoxy Laminates", NASA Technical Memorandum 87604, March, 1986.

Soutis, C., and Fleck, N.A., "Failure Prediction Technique for Compression Loaded Carbon Fiber-Epoxy Laminate with Open Holes", Journal of Composite Materials, Vol. 25, November, 1991, pp. 1476-1498.

Spicola, F., Dubois, N., Tucker, W. and Butts, J., "Compressive Strength of Fiber Reinforced Composites as a Function of Matrix Modulus of Elasticity and Component Wall Thickness", Proceedings of the Ninth International Committee on Composite Materials, July, 93 pp. 573-579.

Steif, P.S., "An exact Two Dimensional Approach tó Fiber Microbuckling", International Journal of Solids Structures, Vol. 23, No. 9, September, 1987 pp. 1235-1246.

Taggart, D. G. "Free Edge Effects in Microbuckling Failure of Unidirectional Composites", Proceedings of International Conference of Composite Materials, Vol. 8, July 1991.

Timoshenko, S.P. and Gere, J.M., Theory of Elastic Stability, 2nd edition, McGraw- Hill, New York, 1961, pp. 94-98.

Treadway, W.K. and Prewo, K.M., "Improved Performance in Monofilament Fiber Reinforced Glass Matrix Composites Through the Use of Fiber Coatings", Materials Research Society Symposium Proceedings, Vol. 170, 1990, pp. 215-274. 
Wass, A.M., Babcock, C.D., and Knauss, W.G., "A Mechanical Model for elastic Fiber Microbuckling," Journal of Applied Mechanics, March 1990, pp.138-149.

Wass, A.M., "Effect of Interface on Compressive Strength of Unidirectional Composites," Journal of Applied Mechanics, 1992, pp. 1-6.

Weaver, C.W. and Williams, J.G., "Deformation of a Carbon-Epoxy Composite Under Hydrostatic Pressure", Journal of Materials Science, Vol. 10, 1975, pp. 1323-1333. Williams, J.G. and Rhodes, M.D., "The Effect of Resin on the Impact Damage Tolerance of Graphite-Epoxy Laminates", NASA Technical Memorandum 83213, October, 1981.

Wung, E.C.J., and Chatterjee, S. N., "On the Failure Mechanisms in Laminate Compression Specimens and the Measurement of Strengths", Journal of Composite Materials, Vol. 26, No. 13, 1992, pp. 1885-1914.

Yeh, J.R. and Teply, J.L., "Compressive Response of Kevlar/Epoxy Composites", Journal of Composite Materials, Vol. 22, March 1988, PP.245-257. 